\title{
Geochemical reservoirs and timing of sulfur cycling on Mars
}

Fabrice Gaillard $^{1,2,3}$, Joseph Michalski ${ }^{4}$, Gilles Berger ${ }^{5}$, Scott M. McLennan ${ }^{6}$, Bruno Scaillet ${ }^{1,2,3}$

1. Univ dOrléans, ISTO, UMR 7327, 45071, Orléans, France

2. CNRS/INSU, ISTO, UMR 7327, 45071 Orléans, France

3. BRGM, ISTO, UMR 7327, BP 36009, 45060 Orléans, France

4. Planetary Science Institute, Tucson, 85719 Arizona, USA

5. CNRS / Université de Toulouse, IRAP, 14, avenue Edouard Belin, F-31400 Toulouse, France

6. Department of Geosciences, State University of New York at Stony Brook, Stony Brook, NY, 11794-2100, USA 


\section{Abstract-}

Sulfate-dominated sedimentary deposits are widespread on the surface of Mars, which contrasts with the rarity of carbonate deposits, and indicates surface waters with chemical features drastically different from those on Earth. While the Earth's surface chemistry and climate are intimately tied to the carbon cycle, it is the sulfur cycle that most strongly influences the Martian geosystems. The presence of sulfate minerals observed from orbit and in-situ via surface exploration within sedimentary rocks and unconsolidated regolith traces a history of post-Noachian aqueous processes mediated by sulfur. These materials likely formed in water-limited aqueous conditions compared to environments indicated by clay minerals and localized carbonates that formed in surface and subsurface settings on early Mars. Constraining the timing of sulfur delivery to the Martian exosphere, as well as volcanogenic $\mathrm{H}_{2} \mathrm{O}$ is therefore central, as it combines with volcanogenic sulfur to produce acidic fluids and ice. Here, we reassess and review the Martian geochemical reservoirs of sulfur from the innermost core, to the mantle, crust, and surficial sediments. The recognized occurrences and the mineralogical features of sedimentary sulfate deposits are synthesized and summarized. Existing models of formation of sedimentary sulfate are discussed and related to weathering processes and chemical conditions of surface waters. We also review existing models of sulfur content in the Martian mantle and analyze how volcanic activities may have transferred igneous sulfur into the exosphere and evaluate the mass transfers and speciation relationships between volcanic sulfur and sedimentary sulfates. The sedimentary clay-sulfate succession can be reconciled with a continuous volcanic eruption rate throughout the Noachian-Hesperian, but a process occurring around the mid-Noachian must have profoundly changed the composition of volcanic degassing. A hypothetical increase in the oxidation state or in water content of Martian lavas or a decrease in atmospheric pressure is necessary to account for by such a change in composition of volcanic gases. This would allow the pre mid-Noachian volcanic gases to be dominated by water and carbon-species but late Noachian and Hesperian volcanic gases to be sulfur-rich and characterized by high $\mathrm{SO}_{2}$ content. Interruption of early dynamo and impact ejection of the atmosphere may have decreased the 
atmospheric pressure during the early Noachian whereas it remains unclear how the redox state or water content of lavas could have changed. Nevertheless, volcanic emission of $\mathrm{SO}_{2}$ rich gases since the late Noachian can explain many features of Martian sulfate-rich regolith, including the mass of sulfate and the particular chemical features (i.e. acidity) of surface waters accompanying these deposits. How $\mathrm{SO}_{2}$ impacted on Mars's climate, with possible short time scale global warming and long time scale cooling effects, remains controversial. However, the ancient wet and warm era on Mars seems incompatible with elevated atmospheric sulfur dioxide because conditions favorable to volcanic $\mathrm{SO}_{2}$ degassing were most likely not in place at this time. 


\section{Introduction}

A striking feature of the surface of Mars revealed by in-situ and remote sensing instruments is the overwhelming abundance of sulfur (Clark et al., 1979; Foley et al., 2008; Brückner et al., 2008; King and McLennan, 2010), predominantly in its oxidized mineralogical form -sulfate- that covers terrains dated from the late Noachian and Hesperian epochs (Gendrin et al, 2005). Sulfate minerals are most likely predominantly of sedimentary origin, although hydrothermal occurrences may also exist. The surface waters that produced such deposits were most likely acidic (Fairen et al., 2004; Chevrier et al., 2007) and ultimately related to sporadic events possibly triggered by intermittent volcanic eruptions in a thin atmosphere. The emerging picture for Mars is that of a planet whose surface geochemistry and possibly its climate was dominated by the sulfur chemical cycle (e.g., Settle, 1979; Clark and Baird, 1979; Wanke and Dreibus, 1994; King et al., 2004; Halevy et al., 2007; McLennan and Grotzinger, 2008; Johnson et al., 2008; King and McLennan, 2010; McLennan, 2012). This picture contrasts with Earth for which the carbon cycle is believed to control the dynamics of chemical and climate processes in the near-surface environment (e.g., Berner, 1995). Yet, on Mars, the period conducive to widespread sulfate deposits was preceded by a period marked by sedimentary processes depositing clay minerals and possibly carbonates, although the overall importance of carbonate minerals remains to be defined (Ehlmann et al., 2008; Michalski and Niles, 2010). Such a sequence of mineralogical eras undoubtedly reflects a sequence of surface geochemical eras (Jakosky and Phillips, 2001; Poulet et al., 2007; Bibring et al., 2006), that in turn reflects complex and evolving exchanges between the various Martian reservoirs: mantle-crust-atmosphere-hydrosphere.

The purpose of this paper is to summarize the most recent advances about Martian sulfur, from source to sink. We also attempt to step beyond a conventional review paper by suggesting links and hypotheses that allow several observations to be connected. Accordingly, we also propose a sequence of events relating igneous Mars to surficial Mars. Finally, we draw comparisons and highlight several differences between the surface chemistry of Mars and that of Earth. 
Because we are concerned with the fate of a single element, sulfur, through the various Martian reservoirs, from the innermost core to the outermost sediments, various processes need to be considered, from early accretion, core formation and mantle differentiation, mantle melting and basalt eruption, to volcanic degassing and atmospheric processes, and finally to sedimentary processes. We believe this approach is justified because of the ubiquitous role of sulfur in surficial Martian processes and because sulfur in itself is a very complex chemical element, with many different redox states (-II, $0,+\mathrm{I},+\mathrm{II},+\mathrm{IV},+\mathrm{VI})$. Depending on its redox state, sulfur would potentially have very different chemical behaviours as a function of redox conditions (Gaillard and Scaillet, 2009). Also noteworthy is that the behaviour of sulfur is influenced by other chemical elements or chemical parameters, which unavoidably requires us to deviate in places from the sulfur-only perspective.

Accordingly, the paper is organized with an observation to model perspective. We first present and discuss sedimentary Mars, essentially based on numerous recent observations. This part of the paper characterizes the inventory of sedimentary sulfate deposits and evaluates of the processes that may have generated these deposits. We then discuss models of the deep martian interior and igneous Mars, including an examination of volcanic degassing of sulfur. The last sections discuss the exchanges of sulfur between the different reservoirs and how these exchanges may have varied through time and how they may have affected martian climate.

\section{Inventory and nature of sulfate deposits on Mars}

\section{a. Overview}

The earliest surface exploration by the Viking spacecraft revealed high sulfur contents that were interpreted as evidence for sulfate minerals in a widely homogenized layer of regolith (Clark et al., 1977; 1993). This interpretation was supported by analyses of surface chemistry by the Mars 
Pathfinder and Soujourner Rover, which also detected relatively high levels of sulfur in regolith and on rock surfaces (Rieder et al., 1997). Since that time, sulfur and sulfate minerals have been detected in a number of geological settings on Mars using both orbital remote sensing and in-situ analyses (Figure 1 - global map) (Table 1 - list of detections) (Gendrin et al., 2005; Langevin et al., 2005; Clark et al., 2005; Bibring et al., 2006; Murchie et al., 2009a). Deposits can be categorized into one of 5 groups: a) Hesperian layered sulfates (Squyres and Knoll, 2005; Clark et al., 2005; McLennan et al., 2005), b) Interior Layered Deposits (ILDs), c) polar deposits, d) intracrater sediments, and e) as part of the global dust and regolith (Wang et al., 2006; Lane et al., 2008). Recent results suggest that a sixth type of deposit has been detected: sulfates as secondary vein minerals within silicate bedrock on the rim of Endurance Crater (Squyres et al., 2012). Taken together, these observations clearly illustrate that sulfur and sulfate minerals constitute a significant fraction of Mars' aqueous geologic record, from pole to equator, and have played a major role in Mars' sedimentary rock cycle (King and McLennan, 2010; McLennan, 2012).

Below, we discuss the various deposits of sulfates in more detail. First, we provide summary of progress in detection and mapping of sulfates on Mars from orbital data. Then, we describe some interesting trends in mineral associations between sulfates and other minerals. Lastly, we discuss the geology of the various types of sulfate deposits, organized by deposit type.

\section{b. Orbital detection of sulfates}

Two instruments have provided unambiguous evidence for sulfate minerals on Mars from orbit. The first discoveries where reported using data from the Obervatoire pour la Minéralogie, l'Eau, les Glaces, et l'Activité (OMEGA) (Gendrin et al., 2005; Langevin et al., 2005) onboard the Mars Express spacecraft. OMEGA has now mapped a large fraction of the Martian surface at the scale of 100s of meters/pixel (eg. Figure $2-4$ panel figure) and revealed numerous sulfate deposits on the surface (Bibring et al., 2006; Poulet et al., 2007; Carter et al., 2011). Targeted observations with the Compact Reconnaissance Imaging Spectrometer for Mars (CRISM) on the Mars Reconnaissance 
Orbiter spacecraft have revealed additional sulfate deposits (Figure 3 - CRISM figure), and shown the detections at higher spectral and spatial resolution ( 18 m/pixel) (Murchie et al., 2009a). Both spectrometers operate in the visible-near infrared $(\sim 0.5-4 \mu \mathrm{m})$ region and are therefore sensitive to spectroscopic absorptions that arise from S-O vibrational overtones and combination bands, vibrations associated with bound or adsorbed water, and electronic transitions associated with Fe, if present in the sulfate structure (Lane and Christensen, 1998; Cloutis et al., 2006 and references therein).

From a mineralogical perspective, two major categories of sulfates have been detected from infrared remote sensing: monohydrated and polyhydrated sulfates (MHS or PHS, respectively). Specific sulfates such as kieserite, gypsum, jarosite, alunite, szomolnokite, and ferricopiapite have been detected from orbit with varying levels of confidence, but in many cases, it is not possible to distinguish specific minerals beyond PHS or MHS. Mg- and Fe-bearing sulfates are more common than Ca-bearing sulfates (e.g. Figure 3).

The abundances of sulfate minerals are difficult to interpret from infrared remote sensing data because the interpretation depends not only on the actual abundance, but also the texture of the surface, grain size of particulates, crystallinity, and hydration state. Furthermore, thin rock coatings could potentially mask minerals present as bulk components of a substrate (e.g. Kraft et al., 2003). A simple baseline for sulfate abundances on Mars comes from observations of the Martian soils and dust. Surface chemical measurements suggest that $6-7 \% \mathrm{SO}_{3}$ is typically present within the globally homogenized dusty soil, which may translate to $~ 5-10 \%$ sulfate minerals (McSween et al., 2010). These values are also consistent with global mapping of $S$ concentrations in the upper few tens of centimetres of the Martian surface by the Mars Odyssey gamma-ray spectrometer experiment (King and McLennan, 2010). OMEGA and CRISM observations of the global dust/soil do not show the presence of sulfates, therefore, this abundance is the minimum detection limit for fine-grained sulfates on Mars from orbital data.

In cases where sulfate is clearly detected, the data can be compared to mathematical mixtures that take into account fundamental spectral properties and estimates of grain size (e.g. Poulet and 
Erard, 2004). For example, dunes in the north polar region of Mars can be modeled with a mixture of $\sim 35 \%$ gypsum and 65\% siliciclastic material (Fishbaugh et al., 2007). In other cases, rocks that are known to be sulfate-bearing from in-situ analyses may contain little or no spectral evidence for sulfates from orbit (Figure 2). Yet, similar rocks in the same region clearly show evidence for sulfates (Figure 3 CRISM example). Such differences in detectability may be an example of the influence of rock texture and weathering style or surface exposure age on the spectral character of the deposits.

Mineral abundances have also been modeled using orbital thermal infrared remote sensing data from the Thermal Emission Spectrometer (TES) and thermal infrared data from the Mini-TES instruments aboard the Mars Exploration Rovers. These analyses suggest that $20-40 \%$ sulfates are present in layered rocks at Meridiani Planum (Glotch et al., 2006), and 15\% sulfates in similar rocks in Aram Chaos (Glotch and Christensen, 2005). Chemical analyses of rocks at Meridiani Planum also point to abundances of $\sim 20-30 \%$ sulfates (Clark et al., 2005). Taken together, all available data suggest that many "sulfate-rich" rocks on Mars may contain roughly 1/3 sulfate minerals by volume. A range is likely to exist, but it is unlikely that that the orbital detections of sulfates could correspond to sulfates that occur only as trace components.

\section{c. Mineral associations}

An important consideration for interpreting the geological significance of sulfate minerals on Mars is the associations among the various minerals. In this sense, the most obvious association seems to be the co-occurrence of sulfate minerals with hematite. Coarsely crystalline gray hematite was originally detected in Meridiani Planum with TES data (Christensen et al., 2000), and it is now clear from surface observations that the hematite occurs as "blueberries," or mm-scale spherules (Squyres et al., 2004, 2005), that have eroded out of sulfate-rich bedrock and are now found as a lag deposit on the surface. The thermal infrared observations of these spherules suggest that they contain c-axis-oriented hematite, always oriented away from the surface of the spherule (Glotch et al., 2006b). 
This observation likely supports an interpretation of the hematite spherules as diagenetic concretions within the sulfates (McLennan et al., 2005; Sefton-Nash and Catling, 2008).

Further work with TES and OMEGA data has shown that hematite is found in association with sulfates in many locations, including chaos terrains and within the ILDs (Christensen et al., 2001; Bibring et al., 2007; Weitz et al., 2008; Mangold et al., 2008; Le Deit et al., 2008). The nature of this association was investigated experimentally by Tosca et al. (2008), who demonstrated that low temperature oxidation of ferrous and ferric sulfates, in the presence of high ionic strength brines, leads ultimately to the precipitation of ferric oxides. These critical observations suggest that diagenetic hematite formation may be a critical component of sulfate formation on Mars (e.g. Roach et al., 2010; McLennan, 2012).

Other mineral associations are observed. In layered terrains on the plains around Valles Marineris, jarosite appears to occur along with hydrated amorphous silica (Milliken et al., 2008). This observation might point to a similar origin as the sulfate within Meridiani Planum deposits, which occurs within siliciclastic rocks that likely contain a component of amorphous silica (Clark et al., 2005; Glotch et al., 2006a). Clay minerals are not commonly associated with sulfates from the orbital remote sensing perspective. However, in a few cases, interlayered sulfates and phyllosilicates are observed. In Columbus Crater, aluminous clays and sulfates are interlayered in crater-floor sediments (Wray et al., 2010). In the Mawrth Vallis channel, Fe/Mg-bearing clays occur stratigraphically above sulfates in certain cases (Wray et al., 2010). Also in the Mawrth Vallis area, aluminous clays occur in deposits that seem to be stratigraphically equivalent with jarosite-bearing deposits (Farrand et al., 2009). The base of the mound within Gale Crater (Mount Sharp) may contain interlayered sulfates and clays, which await exploration by the Curiosity Rover (Milliken et al., 2010).

d. Geology. 
Layered sulfates of probable Early Hesperian age are found throughout the western Arabia Terra region, in the greater Sinus Meridiani area (Poulet et al., 2008a; Griffes et al., 2007; Wiseman et al., 2010). Also in this category are certain instances of layered crater fill, such as the sulfates found within Gale Crater (Milliken et al., 2010; Thomson et al., 2011). Exploration of such deposits by the Opportunity Rover shows that, in the Meridiani area, the rocks are layered at the decimeter scale, and laminated down to millimeter scale in places (Grotzinger et al., 2005, 2006). Sulfur contents were consistently measured in the range of $20-30 \% \mathrm{SO}_{3}$, and chemical correlations suggest that $\mathrm{Mg}$-sulfates are the most abundant group of minerals (Clark et al., 2005). However, jarosite was also directly detected from Mossbauer spectroscopy (Morris et al, 2006). The low amount of energy required to grind into the rocks with the Rock Abrasion Tool (RAT) aboard Opportunity indicates that most of the rocks are relatively soft (specific grind energies mostly less than $2 \mathrm{~J} \mathrm{~mm}^{-3}$ ), as might be expected for evaporites (Herkenhoff et al., 2008). Microscale imaging of the rock textures shows that they are composed of fine-grained material. Sand-sized particles are observed, and required for the formation of eolian cross bedding seen in the section (Grotzinger et al., 2005, 2006), however the sand grains themselves may in turn be composed of finer-grained materials, such as recycled sulfate-cemented muds (Grotzinger et al., 2005; McLennan et al., 2005; also see Niles and Michalski, 2009). Secondary porosity in the form of crystal molds and other vugs observed in parts of the section point to an extended and complex history involving diagenetic fluids (McLennan et al., 2005; McLennan and Grotzinger, 2008).

\section{Interior Layered Deposits (ILDs)}

The ILDs are found throughout the Valles Marineris trough system, as well as within other chasmata (Chapman and Tanaka, 2001). The deposits consist of massive mounds of layered materials that can reach kilometers in height, rivaling the elevation of the canyon rims in places. They lie unconformably on canyon floor deposits (Quantin et al., 2004), drape onto the canyon walls, and do not exhibit massive extensional faults that would have been formed during tectonic formation of the 
troughs (Okubo et al., 2008). Therefore, the deposits are interpreted to have formed after the final phase of formation of the Valles Marineris, which likely occurred in the late Noachian. The ILDs are challenging to accurately date due to their irregular geometry, but crater counting suggests a lower bound on their ages of Late Hesperian, and in rare cases, perhaps Early Amazonian (Quantin et al., 2004). They are therefore of similar age to the Hesperian layered deposits and may have a similar origin.

Spectral imaging shows that the ILDs, where they are well exposed, contain evidence for sulfates (Figure 4), hematite, and locally, silica and phyllosilicates (Gendrin et al., 2005; Bishop et al., 2009; Mangold et al., 2008; Le Deit et al., 2008 ; Murchie et al., 2009b ; Flahaut et al., 2010a; Roach et al., 2010a ; Feuten et al., 2011; Weitz et al., 2011). In the central Valles Marineris, crude compositional stratigraphy is observed where monohydrated sulfates overlie polyhydrated sulfates (Mangold et al., 2008).

\section{Polar sulfates}

Gypsum deposits occur in the massive north polar dune field, Olympia Undae (Langevin et al, 2005; Fishbaugh et al., 2007) (Figure 5 -polar). The dunes are Amazonian in age and are thought to have been derived from erosion of the Basal Unit beneath the north polar cap (Fishbaugh et al., 2007). However, there is no evidence to date for sulfates within the Basal Unit itself. One possibility is that the sulfate formed within the dunes, after the clastic material was derived from the Basal Unit by erosion. Another possibility is that the gypsum is more easily detectable in the sand-sized materials within the dunes than in the competent layers of the basal unit. Yet another possibility is that the sulfates occur within the basal unit, but in lower concentration and that they have been concentrated within the dunes due to their density.

Sulfates have also been detected within sedimentary deposits surrounding other parts of the north polar cap (Masse et al., 2010; 2012). These sulfates have a more subtle spectroscopic signature than those within the Olympia Undae dunefield. Their weaker spectral features could correspond to 
lower absolute abundances, lower crystallinity, or different physical form (e.g. grain size, surface texture) compared to those in the dune sands. The deposits containing these sulfates are interpreted as sediments that weathered out of the polar cap, or as glacial sediments (Masse et al., 2010; 2012) and have formed in association with ice.

\section{Intracrater deposits}

Intracrater sulfate deposits are relatively rare, but have been detected within craters in the Terra Sirenum region of Mars. Here, deposits within the floors of Columbus and Cross Craters contain poly- and monohydrated sulfates that are interbedded with aluminous phyllosilicates and associated with alunite, jarosite, Fe-oxides, and Fe/Mg-phyllosilicates (Wray et al., 2011). Alteration minerals occur within a ring in the interior of Columbus Crater, and within layered deposits exposed by erosion and impact degradation of the floor deposits. Such deposits are interpreted to have formed due to groundwater upwelling that may have fed a deep lake, or a transient, spring-fed environment (Wray et al., 2011).

\section{Sulfates within the soil and dust}

Sulfur occurs with the Martian soil at all landing sites visited thus far at an average level of $\sim 6.8 \% \mathrm{SO}_{3}$ (King and McLennan, 2010). The mineralogy of this sulfur is not well known, although recent results have shed some light. Results from the Wet Chemistry Laboratory (WCL) aboard the Phoenix Lander have demonstrated the presence of soluble sulfates within high latitude soils (Knounaves et al., 2010). At this site, the most likely salts are epsomite and gypsum. This is in contrast to some soils at the Gusev Crater site, which also contain significant levels of Fe-sulfates (Wang et al., 2006). At the Paso Robles site in Gusev Crater, the Spirit Rover exposed soils from the shallow subsurface with its wheels. Chemical and spectroscopic constraints on the bright soils suggest the presence of hydrated Fe-sulfate similar to ferricopiapite (Lane et al., 2008). 


\section{e. Summary of observed sulfate deposits}

Sulfate deposits are observed or inferred to exist within the global regolith, as well as in discret geological deposits from pole to equator on Mars. Evidence to date suggests that the deposits can generally be considered siliciclastic materials, in some cases unconsolidated and in other cases, as somewhat competent sedimentary rock. By what geologic processes did these deposits form? Is there a common thread or have various deposits formed from disconnected processes at different times? It is almost certain that the ultimate source for sulfur in these deposits is volcanogenic. But, what were the aqueous conditions under which the minerals precipitated? How much water was involved and from what sources? We address these questions in the following section.

\section{Mineralization of sulfur at Mars surface.}

\section{a. Chemical constraints}

There is a growing consensus that sulfates formed mostly during the late Noachian to Hesperian, succeeding the era of phyllosilicates in the early-middle Noachian. Since the Hesperian, there is little evidence for formation of water-related minerals, clays or sulfates. Transformation of iron sulfates to iron oxides may be an ongoing, albeit very slow process (Tosca et al., 2008; McLennan, 2012). Alteration of mafic minerals on the Earth, Mars or elsewhere is the chemical response of desequilibrated water-rock systems, influenced, sometimes inhibited, by kinetic constraints. Silicate minerals, from the chemical point of view, are oxide mixtures having alkaline properties, mainly because of their alkali and alkaline-earth content. As an example, the pH value buffered by pure $\mathrm{CaO}$ is 12.7 at $25^{\circ} \mathrm{C}$, near 12 for $\mathrm{MgO}$ and much more for $\mathrm{Na}_{2} \mathrm{O}$ and $\mathrm{K}_{2} \mathrm{O}$. So substantial mineralogical transformations are generated by acid agents that can lead to huge deviations from equilibrium, and the amount of alteration phases can be compared, possibly correlated, to the amount of protons added to the system. Because the production of protons, and accompanying acidic fluids, always associates 
with concomitant anions for the obvious constraint of charge balance, this anion can be implied in the secondary phases formed by the conjugate base of the acid and the conjugate acid of the oxide. The occurrence of sulfate in the Martian soils at Meridiani Planum or elsewhere, argues for the idea that the source of protons that drove the alteration is associated with the sulfur cycle.

\section{b. The Burns Formation example}

The presence of sulfur-rich sedimentary rocks at Meridiani Planum, termed the Burns formation, was a major discovery by the Mars Exploration Rover (MER) mission. The sediment contains up to 60\% secondary minerals (amorphous silica, $\mathrm{Mg}$ - and Ca-sulfates, jarosite, hematite and possibly chlorides). The presence of jarosite has been cited as prime evidence for low $\mathrm{pH}$ conditions since it is known to be stable at $\mathrm{pH}<4$.

The interpretation of the MER team is that sulfate-bearing sedimentary grains were derived from a weathered basaltic source and cemented by later sulfate-dominated secondary minerals (Squyres et al., 2004; Grotzinger et al., 2005, 2006; McLennan et al., 2005; Metz et al., 2009) with a variety of diagenetic features, including secondary porosity, multiple generations of cements and hematitic concretions. In this model, sulfates form through a variety of evaporative and later diagenetic processes.

A number of alternative scenarios have also been proposed to explain the morphology and chemistry of the Burns formation sediments. Hynek et al. (2002) and McCollom and Hynek (2005) proposed that the Burns formation represented pyroclastic ash flows and air fall whereas Knauth et al. (2005) suggested that the layered deposits formed through debris flow following an impact. McCollom and Hynek (2005) interpreted the chemical composition of the Burns sediments as a mixture between a pristine basalt and a pure hydrated sulfur compound (with a composition within the $\mathrm{SO}_{2}-\mathrm{O}_{2}-\mathrm{H}_{2} \mathrm{O}$ ternary system), which is in contrast to the eolian-groundwater model that calls for a mixture of altered basalt and sulfate minerals. These two interpretations are presented in a ternary 
diagram in Fig.6 where the trend formed by Meridiani sediments suggests a mixture between an aluminosilicate component and a $\mathrm{Mg}, \mathrm{Fe}, \mathrm{Ca}$ sulfate component. The aluminosilicate component does not match the exact composition of a martian basalt but rather appears consistent with an altered basalt. More recently, Niles and Michalski (2009) proposed another scenario in which the deposition at Meridiani Planum of massive ice/dust layered deposits during periods of high obliquity was accompanied by a cryo-concentration of volatile-bearing brines in ice that contained outgassed sulfurbearing species. In this model, alteration of fine-grained silicates by acidic brines in the ice produces vast quantities of alteration products with limited chemical mobility. In their model, the eolian textures formed from reworking of the sublimation lag during and after removal of ice. The diagenetic textures were generated by water released during dehydration of sulfate minerals that were originally highly hydrated. Such a model has some advantages in that it can explain the formation of layered sulfates in vast mounds that lack obvious provenance, such as the ILDs (Michalski and Niles, 2012).

Some of the relevant geochemical issues were discussed by Tosca et al. $(2005,2008)$ for the chemistry of evaporating brines. On the other hand, Tréguier et al. (2008) and Berger et al. (2009) focused on the source of sulfur and its reaction with a pristine basalt in an in-situ alteration scenario. They argued that $\mathrm{SO}_{3}$, a strong acid gas resulting from the oxidation of volcanic $\mathrm{SO}_{2}$ in a dry atmosphere, may have produced a strong and pristine acid solution at the ground through interaction with water produced by ice melting. Based on the statistical analysis (PCA) of the Meridiani chemical compositions and weathering scenario tested by numerical modeling they reproduced the chemical and mineralogical data available for the Burns Formation sediments (Fig. 7), provided that the generated brine leaves the system after a short reaction time and evaporates elsewhere. The oxidation of $\mathrm{SO}_{2}$ can result from several atmospheric reactions and can be driven back to the surface by acid rains as reported by Schiffman et al. (2006) for the Earth, or can occur at the surface directly assuming a high penetration of the UV radiation through a thin and dry atmosphere. However, as pointed out by Zolotov and Mirenko (2007), the generation of sulfuric acid through oxidation of $\mathrm{SO}_{2}$ and $\mathrm{H}_{2} \mathrm{~S}$ is limited by the concentration of photochemically-produced atmospheric oxidants and these 
authors proposed impact-generated acid rainfalls as an alternative origin of $\mathrm{SO}_{3}$. But sulfur brought by impactors would nevertheless require an oxidation step to produce $\mathrm{SO}_{3}$. In both scenarios, volcanic SO2 or impact-generated sulfur can produce pristine acidic water covering the whole surface. In contrast, hydrothermal systems imply acid-base reactions occurring at depth and the resulting fluid reaching the surface is a brine being evolved and partially neutralized. The latter could account for the evaporitic processes suggested by the MER team while the surficial acid weathering scenario can account for the "Meridiani Trend" as described by McCollom and Hynek (2005), i.e. chemical mixing between a pristine basalt and a pure sulfur component, as suggested in Berger et al. (2009) or Niles and Michalski (2009).

The acidic features of the Meridiani sediments were also discussed by Hurowitz et al. (2010). They suggested the oxidation of aqueous ferrous iron as an alternative process to generate acidic solutions at a local scale. However, this process also requires protons to get $\mathrm{Fe}^{++}$in solution in a previous stage. For exemple, Figure 8 illustrates the effect of several acid sources on $\mathrm{FeO}$ (the ferrous component in mineral). The amount of released ferrous iron depends on the solubility of the conjugate anion salts (chloride, sulfate, carbonate) and the proportion of the complexed forms such as $\mathrm{Fe}(\mathrm{OH})^{+}, \mathrm{FeCl}_{2}$, etc... A general equation could be: $\mathrm{FeO}+\mathrm{H}_{2} \mathrm{O}+\mathrm{HX} \Leftrightarrow \mathrm{aFe}^{++}$aq $+\mathrm{bFeX}_{\text {aq }}^{-}+\mathrm{cFeX}_{2}$ aq $+\mathrm{dFeX}_{2 \text { solid. }}$. The calculations show that a substantial mobilization of $\mathrm{Fe}^{++}$requires substantial addition of protons with a highly soluble conjugate anion. $\mathrm{H}_{2} \mathrm{SO}_{3}$ appears as the most efficient extracting agent.

Finally, the diversity of the proposed scenarios suggests that, despite the quantitative information collected by Opportunity, the origin of sulfur and the chemical constraints on water-gasrock interaction remains an important issue for understanding sulfate-bearing sediments at the Martian surface. For example, recently published experimental observations (Dehouck et al., 2012) indicate that alteration of sulfide-bearing basalts may produce mineral assemblies containing sulfate minerals that mimic those identified on Mars. In section 4 and 5, we present several pieces of evidence that volcanic gases can provide most of the sedimentary sulfate and can furthermore trigger the succession of different periods with contrasted surface chemistry. 


\section{c. $\mathrm{SO}_{2}$ versus $\mathrm{CO}_{2}$ in the sediments/soil records with time}

The formation of sulfate minerals during late Noachian and Hesperian suggests an alteration process driven by volcanic $\mathrm{SO}_{2}$. Even in early Noachian terrains where phyllosilicates rather than sulfates are detected, the source of protons for the alteration process, whether $\mathrm{SO}_{3} / \mathrm{SO}_{2}$ and/or $\mathrm{CO}_{2}$ is an open question. Carbon-based acids having lower dissociation constants (i.e., weak acids), typically have reaction by-products dominated by clays (Berger et al., 2009). The lack of widespread observations of carbonate minerals in the altered Martian sediments (this point is extensively discussed in the accompanying Niles's paper, this issue) could be explained by the presence of another more acidic compound that precludes the precipitation of $\mathrm{Ca}, \mathrm{Mg}, \mathrm{Fe}$ carbonates. Significant, concentrations of $\mathrm{SO}_{2}$ in the atmosphere is a reasonable assumption, given the importance of sulfur during the Hesperian era. However, in the context of clay minerals, constraining the in-situ $\mathrm{pH}$ (and carbonate precipitation feasibility) is not trivial. Clays, such as smectite, have exchangeable cations in the interlayer positions of their structure, which confer to these minerals a large sorption capacity and make the clays an ion exchanger and $\mathrm{pH}$ buffer. Even in the case of low cationic exchange capacities (CEC), i.e. kaolinite, illite, or chlorites, the small particle size confers a huge specific surface area to the material and enhances the consequences of surface chemistry. However, although the acid-base properties of aluminosilicate surfaces and CEC of smectite material are now well known (see for example Tertre et al., 2006), other textural parameters and the accurate estimation of the reacting mineral surface make the prediction of reaction paths and rates difficult.

Another parameter is the differential progression of an $\mathrm{SO}_{3}$ and $\mathrm{CO}_{2}$ front within soils and sediments when these two gases are present simultaneously in the lower atmosphere. When $\mathrm{SO}_{3}$ is not concentrated in the lower atmosphere, it will rapidly be consumed in the superficial layer of the soil, given the high silicate alteration rate at low $\mathrm{pH}$, and will probably not influence the chemistry of the deep sediments. By contrast, $\mathrm{CO}_{2}$ is a less acidic gas $(\mathrm{pH}>4)$ and the solubility of its conjugate salt (carbonate) is highly $\mathrm{pH}$ sensitive. $\mathrm{CO}_{2}$ will not produce carbonate in the $\mathrm{SO}_{3}$ influenced zone and can subsequently diffuse deeper in the sediments, a process made easier given that rock alteration is slow 
in the middly acidic pH-range. This simple analysis, illustrated in Fig. 9, leads to the suggestion that carbonate deposits may exist at depth in the regolith on Mars and, accordingly, could constitute a significant sink for $\mathrm{CO}_{2}$.

The prediction of carbonate precipitation from atmospheric $\mathrm{CO}_{2}$ should also take into account the water:rock ratio. In the case of a high run-off (low residence time of water within the martian regolith) and/or under near neutral conditions (slow dissolution kinetics) and/or presence of another acid gas (high carbonate solubility at low $\mathrm{pH}$ ) carbonate precipitation is not expected. An example is shown in Fabre et al. (2011) for the "Snow Ball Earth" aftermath during the Precambrian time where even $10 \%$ atmospheric $\mathrm{CO}_{2}$ may not have led to continental carbonates.

In conclusion, the mineral evolution of the Martian soil/sediments over the geological time can be interpreted as resulting from a global atmospheric change from Noachian to Hesperian, with a decrease of the $\mathrm{CO}_{2} / \mathrm{SO}_{2}$ ratio. 


\section{Geochemical reservoirs of the interior of Mars}

Chondrites, from which terrestrial planets most likely accreted, contain several weight percent of sulfur as sulfide (S content ranging from 2 to $10 \mathrm{wt} \%$ for all varieties of chondrites, see Chabot et al., 2004; Gaillard and Scaillet, 2009; Ebel, 2010). Geochemical observations, however, indicate a general depletion in volatile elements of planetary bodies with respect to chondrites (Righter et al., 2006). This depletion is generally related to the intense early solar activity and/or incomplete condensation during the earliest period of planetary accretion. In some cases, some form of planetary devolatilisation may have accompanied high temperature processes during the accretion process (e.g., giant impacts or volcanic degassing of planetary embryos) and therefore contributed to additional depletion in strongly volatile elements $(\mathrm{C}-\mathrm{O}-\mathrm{H}-\mathrm{S})$, but quantitative constraints on such processes are strongly model dependent. Existing geochemical models point towards sulfur content lower than 5 wt\% for bulk Mars (Wanke and Dreibus, 1994), whereas similar models for the Earth indicate less than 0.5 wt\% sulfur (Dreibus and Palme, 1996). The emerging but still poorly constrained conventional wisdom is therefore that Mars must be enriched in sulfur in comparison to the Earth (Dreibus and Wanke, 1985; Stewart et al., 2007). Below, we review partitioning of sulfur between Femetal, molten silicate, and fluid in order to assess both sulfur reservoirs and fluxes between core, mantle, basalt and evaluate net sulfur transfers by volcanic degassing into the atmosphere.

\section{a. Core-Mantle}

We discuss here existing studies on the behavior of sulfur during core-mantle equilibration in a magma ocean scenario. The conventional wisdom here is that sulfur contents of the core and mantle of Mars were inherited from a single (or last) equilibration step between metal and silicate at high P-T 
conditions (Righter and Chabot, 2011). Such equilibration is classically addressed by models based on partitioning experiments performed under controlled thermodynamic conditions. Most assessments of partitioning of sulfur between silicate and metal and its application to core-mantle equilibration on planetary bodies are based on the assumption that molten FeS is a good analogue of Fe-metal containing little sulfur. Many influential experiments have indeed studied the partitioning of sulfur between molten silicate and nearly stochiometric FeS (Fei et al., 1995; Li and Age, 1996; Li and Agee, 2001; Holzheid and Grove, 2002) leading to the implicit analogy between chalcophile and siderophile tendencies. This useful simplification, however, ignores the strongly non-ideal thermodynamic behaviour of the Fe-S system, which implies that the energetics of sulfur in molten Fe metal with low S-content cannot simply be extrapolated from that of molten FeS (through a dilution factor, eg. Holzheid and Grove, 2002). The available experimental data bearing on S-partitioning between molten silicate and liquid, S-poor, Fe metal are scarce (Ohtani et al., 1997; Kilburn and Wood, 1997; Rose-Weston et al., 2009; Agee and Li, 2001). These data are reported in Figure 10. The simplest thermodynamic treatment that best approximates the partitioning of sulfur between Fe metal and molten silicate can be formulated as (e.g., Gaillard and Scaillet, 2009):

$\mathrm{S}^{\text {metal }}+\mathrm{O}^{2 \text { - silicate }}=\mathrm{S}^{2 \text { - silicate }}+1 / 2 \mathrm{O}_{2}$

This equilibrium is the sum of the reaction of sulfur equilibrium between silicate melt and gas phases which reads as (O’Neill and Mavrogenes, 2002):

$\mathrm{S}^{2 \text { - silicate }}+1 / 2 \mathrm{O}_{2}{ }^{\text {gas }}=1 / 2 \mathrm{~S}_{2}{ }^{\text {gas }}+\mathrm{O}^{2-\text { melt }}$

and the dissolution reaction of sulfur gas within molten Fe metal (Wang et al., 1991):

$1 / 2 \mathrm{~S}_{2}{ }^{\text {gas }}=\mathrm{S}^{\text {metal }}$

Combining reactions (2) and (3), and using appropriate equilibrium constants, we can write (Gaillard and Scaillet, 2009):

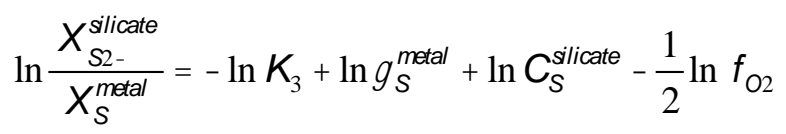


Following the notation of O'Neill and Mavrogenes (2002) the fraction of sulfur in the molten silicate $X_{S 2}^{\text {silicate }}$ is expressed in wt ppm whereas the fraction of sulfur in the molten Fe-metal $X_{S}^{\text {metal }}$ is given in atomic fraction. The sulfur capacity $\left(\mathrm{C}_{\mathrm{s}}^{\text {silicate }}\right)$ is a concept introduced by metallurgists (Fincham and Richardson, 1954), defining the ability of silicate melts to dissolve sulfur (by reaction 2) and its variability with melt composition. $\mathrm{C}_{\mathrm{s}}^{\text {silicate }}$ has been defined as (Fincham and Richardson, 1954):

$$
\ln C_{S}^{\text {silicate }}=\ln X_{S 2-}^{\text {silicate }}+\frac{1}{2} \ln f_{O 2}-\frac{1}{2} \ln f_{S 2}
$$

It is well established that the chemical parameter that exerts a prime control on sulfur solubility in silicate melts is their ferrous iron content $(\mathrm{FeO})$. Ferrous iron-rich melts tend to dissolve more sulfur than those poor in $\mathrm{FeO}$. The sulfur capacity, $\mathrm{C}_{\mathrm{s}}^{\text {silicate }}$ for mafic and ultramafic melts has been extensively studied by O'Neill and Mavrogenes (2002) at $1400^{\circ} \mathrm{C}$. Ln $\mathrm{K}_{3}$ is the equilibrium constant of reaction (3) whilst ( $\operatorname{gama}_{S}^{\text {metal }}$ ) ${ }_{S}^{\text {metal }}$ is the activity coefficient of sulfur in the molten metal which, according to the interstitial model of Wang et al. (1991), incorporates the effect of temperature. At low $S$ contents (i.e. $X_{S}^{\text {metal }}<0.1$ ), the activity coefficient of $S$ in Fe metal is in the range 1-0.7 decreasing down to 0.3 at $X_{s}^{\text {metal }}=0.35$.

Equation (4) appears in the form of a partition coefficient between metal and silicate, a widely used concept in geochemistry to define the pressure and temperature dependence of partitioning properties. However the partition coefficient is here influenced by a large number of additional parameters that are also interdependent: (i) the strongly non-ideal behaviour of $\mathrm{S}$ in Fe-metal that makes (gama $\left.{ }_{S}^{\text {metal }}\right)_{S}^{\text {metal }}$ strongly dependent on the bulk S content; (ii) the dependence of eq.(4) on $f \mathrm{O}_{2}$; (iii) the dependence of $\mathrm{C}_{\mathrm{s}}$ on $\mathrm{FeO}^{\text {melt }}$; (4) the dependence of $\mathrm{FeO}^{\text {melt }}$ on $f \mathrm{O}_{2}$ at $\mathrm{Fe}$-metal saturation. In several studies, the $\mathrm{fO}_{2}$ dependence of sulfur partitioning between molten silicate and metal has been ignored because of the implicit assumption that liquid FeS and liquids in the S-poor region of the Fe-FeS binary are energetically broadly similar (Holzheid and Grove, 2002; Rose-Weston et al., 
2009). In fact, metal-silicate S-partitioning data (Figure 10), display a considerable scatter that is poorly related to variations in pressure and temperature. Figure 10 also shows that increasing temperature and pressure makes sulfur slightly more siderophile, but this effect remains small, even debatable if error bars are considered.

In contrast, when plotted as a function of oxygen fugacity (determined by the equilibrium $\mathrm{Fe}+1 / 2$ $\mathrm{O}_{2}=\mathrm{FeO}$ ), the data define a single clear trend indicating that sulfur becomes more siderophile as conditions become increasingly oxidizing. The fundamental reason of such a trend is that sulfur dissolves in silicate melts as $\mathrm{S}^{2-}$ whereas it is in the $\mathrm{S}^{0}$ form in the molten Fe-metal. Redox conditions for core-mantle equilibration for Mars may be oxidizing (IW-1.5 for a Martian mantle with 18-20 $\mathrm{wt} \% \mathrm{FeO}$ ) relative to those for Earth (IW-2.2 for a Earth's mantle with $8 \mathrm{wt} \% \mathrm{FeO}$ ) (see Righter et al., 1996). Although no experimental data exist at $\mathrm{fO}_{2}$ relevant to Mars core-mantle equilibration, equation (4) predicts that sulfur should be less siderophile, as indicated by the dashed lines in Figure 10.

Figure 11 shows the expected relationship between sulfur in the mantle and sulfur in the core using equation (4) at $2100^{\circ} \mathrm{C}-14 \mathrm{GPa}$. For Mars, these P-T conditions of core-mantle equilibration are after Righter and Chabot (2011) (see also Debaille et al. (2009)). The strongly non-linear relationship is due to the non-ideal behaviour of sulfur in molten iron. If we adopt a sulfur content in the Martian core to be in the range of 14-18 wt\%, as suggested by cosmochemical constraints (Dreibus and Wanke, 1985; Wanke and Dreibus, 1994: averaging 14.2\%) or as inferred from inversion of recent geodetic data (Rivoldini et al., 2011; estimated at 16 $\pm 2 \%$ ), the sulfur content in the Martian mantle is calculated to be 2000-2200 ppm. This corresponds to 10 - 20 times more sulfur than in the Earth's mantle (assuming S-content in the Earth's mantle at 120-250 ppm after Dreibus and Palme, 1996 ; McDonough and Sun, 1995 ; Allègre et al., 2001). It is interesting to note that $15 \mathrm{wt} \%$ sulfur in the Martian core corresponds to the eutectic composition at the pressure of the core-mantle boundary (23 GPa) (as defined by Fei et al., 1997; see also Morard et al., 2008). As this eutectic has a very low temperature $(1400 \mathrm{~K})$, we could expect that a Martian core with $15 \mathrm{wt} \%$ sulfur is presently liquid 
(Stewart et al., 2007). This would also corroborate gravity constraints that imply an entirely fluid Martian core (Marty et al., 2009).

There are however several reasons to question existing estimates of the sulfur content in the Martian core. Cosmochemical inferences are strongly model-dependent, especially for volatile and siderophile elements, and it is difficult to assess uncertainties. A major factor in suggesting a sulfur rich core is the depletion of chalcophile elements in martian meteorites, suggesting they were stripped into a S-rich core (Righter and Humayun, 2012). However, sulfide fractionation from S-rich Martian basalts may also lead to depletion in chalcophile elements and interpretation of element depletions in terms of core-mantle differentiation may be non-unique as increasingly recognized for the Earth (Righter et al., 2007). Geodetic constraints are less model-dependent, but the assessment of the Martian core sulfur content by Rivoldini et al. (2011) assumes ideal mixing for volume properties of sulfur in iron molten core. Recent experimental data collected at 4 GPa (Nishida et al., 2008) on liquid Fe-S mixtures show that the density of molten iron is weakly affected by the addition of up to 20 at $\%$ sulfur, which indicates strongly non-ideal volume of mixing. Thermodynamic analyses of the effect of increasing pressure on the liquidus of the Fe-rich side of the Fe-FeS system (Buono and Walker, 2011) indicate that pressure would tend to make mixing properties more ideal (e.g. Gibbs free energy of mixing between $\mathrm{Fe}$ and $\mathrm{FeS}$ ), but it is actually difficult to retrieve information about the partial molar volume of S from such thermodynamic treatment. If the volume mixing properties of Nishida et al (2008) still hold at higher pressure (see discussion in Buono and Walker, 2011), it is expected that density would be relatively insensitive to sulfur content in the core of Mars, making the Rivoldini et al. (2011) assessment provisional (maximum S-content). In contrast, if non-ideal volume of mixing of the Fe-S system vanishes at pressures higher than $4 \mathrm{GPa}$ (i.e. $10 \mathrm{GPa}$ ), the core of Mars is expected to be S-rich and probably still fully molten (Stewart et al., 2007; Rivoldini et al. 2011).

Gaillard and Scaillet (2009) preferred to ignore the high sulfur content of Mars suggested by cosmochemical considerations and instead assumed that the bulk sulfur content of terrestrial bodies are similar. If we consider that Mars has a sulfur content similar to bulk Earth, metal-silicate 
partitioning calculations shown in Figure 11 would then indicate likely sulfur contents of 700-900 ppm for the Martian mantle and 1-3 wt\% for its core. We can therefore conclude that the sulfur content of the Martian mantle must be in the range of 700-2000 ppm. It is worth noting that, even if large uncertainties for the sulfur content of the core persist, the uncertainties for the sulfur content of the Martian mantle are comparatively much smaller, because of the flattening of the metal-silicate partitioning for high sulfur content. All in all, the $S$ content of the Martian mantle remains well above the sulfur content on the Earth's mantle (Table 2).

\section{b. Mantle melting, basalts and the crust}

Adopting a sulfur content in the mantle of Mars in the range 700-2000 ppm permits a massbalance calculation for the maximum content of sulfur in basalts formed upon mantle melting. Assuming 10-20\% of partial melting and considering that sulfur is perfectly incompatible during melting, then between 3,500-18,000 ppm sulfur can be expected in primary mantle Martian basalts (0.35 to $1.8 \mathrm{wt} \% \mathrm{~S})$. However, the sulfur content in basaltic liquids produced by mantle melting is limited by the saturation in sulfide (FeS). The sulfur content of basalt formed upon mantle melting at sulfide saturation therefore provides the maximum sulfur content that basalts can convey upon ascent to the surface.

The equilibrium between sulfide and basaltic melts can be written as:

$$
\mathrm{FeS}^{\text {sulfide }}+1 / 2 \mathrm{O}_{2}=\mathrm{FeO}^{\text {basalt }}+1 / 2 \mathrm{~S}_{2}
$$

O’Neill and Mavrogenes (2002) reformulated the above equilibrium and combined it with eq. (5) so that the sulfur content of basalt at sulfide saturation can be formulated independently of both $\mathrm{f}_{\mathrm{O} 2}$ and $\mathrm{f}_{\mathrm{S} 2}$ :

$\operatorname{Ln}\left(\mathrm{X}_{\mathrm{S} 2-}\right)^{\mathrm{ppm}-\text { basalt }}=\Delta \mathrm{G}^{\circ}{ }_{(6)} /[\mathrm{RT}]+\ln \mathrm{Cs}-\ln \mathrm{a}_{\mathrm{FeO}}$ 
The sulfur capacity $\mathrm{Cs}$ is the same as in eq. (5), $\mathrm{a}_{\mathrm{FeO}}$ stands for the activity of ferrous iron in silicate melts (Gaillard et al., 2003a) and $\Delta \mathrm{G}^{\circ}{ }_{(6)}$ is the Gibbs free energy of equilibrium for eq. (6).

Such a concept (i.e., that the sulfur content at sulfide saturation does not depend on $\mathrm{fO}_{2}$ ) remains valid provided that one considers only ferrous iron in eq. (7) and not total iron as obtained using standard analytical procedures. Accordingly, eq. (7) is strictly $\mathrm{fO}_{2}$ independent only when conditions are sufficiently reducing $(<F M Q)$ to neglect the presence of ferric iron in the melt, which is indeed likely for Martian basalts. Keeping this restriction in mind, the sulfur content of Martian basalts at sulfide saturation is therefore a function of pressure and temperature, but also a function of melt composition, particularly its iron content.

Gaillard and Scaillet (2009) used equation (7) to show that Martian basalts can contain up to 4000-7000 ppm sulfur upon mantle melting under the P-T conditions inferred from multiple saturation experiments (Monders et al., 2007; Musselwhite et al., 2006). Experiments done by Righter et al. (2009), confirm these calculations, suggesting sulfur contents at the low end of the Gaillard and Scaillet (2009) calculated range (Figure 13). These studies illustrate how the sulfur content of basaltic compositions increases as a function of total iron content (reported as FeO). Shergottite-like basaltic compositions have $\mathrm{FeO}$ in the range $16-20 \mathrm{wt} \%$, which compares favorably to an estimate of the $\mathrm{FeO}$ content for the overall Martian crust of $18.2 \%$ (Taylor and McLennan, 2009). According to the experiments of Righter et al. (2009) (1-8,000 bar and $1200-1500^{\circ} \mathrm{C}$; that are shown in Figure 13 by the empty red circles), such iron-rich melts can dissolve up to 3000-5000 ppm sulfur at sulfide saturation. Considering the likely P-T conditions of mantle melting on Mars, as inferred by Monders et al. (2007) and Musselwhite et al. (2006), Righter et al (2009) concluded that primary martian basalts must contain 3000-4000 ppm dissolved S. Under similar conditions, Earth's mantle-derived basalts can dissolve about 1000-1500 ppm, which was the value adopted by Johnson et al. (2008) as the sulfur content in Martian basalts. The latter value would imply that Martian basalts are undersaturated in FeS during mantle melting, a view which conflicts with simple mass balance arguments. Indeed, given the Martian mantle sulfur concentration inferred above (700-2000 ppm S), 
and assuming that $10-20 \%$ of mantle partial melting is needed to produce Martian basalts, Martian basalts with $4000 \mathrm{ppm} \mathrm{S}$ would not exhaust the mantle in sulfur.

The Martian crust is dominated by basaltic compositions and Taylor and McLennan (2009) concluded that a large fraction of the crust ( 70-90\%) was "primary" and thus formed or was strongly influenced by magma ocean processes (Elkins-Tanton et al., 2005). The sulfur content of the Martian crust can therefore be estimated via the concept of sulfur content at sulfide saturation. We therefore conclude that the Martian crust has a bulk sulfur content of 3500-4000 ppm. This should nevertheless be regarded as a maximum S-content.

\section{Volcanic degassing, redox state and water content of Martian basalts}

Upon magma ascent, the decrease in pressure acts against FeS saturation, whereas cooling should promote FeS stability (Mavrogenes and O’Neill, 1999; Holzheid and Grove, 2002). For fast rising magmas, such as hot martian basalts, cooling must be limited during ascent. We therefore make the simplifying assumption that all sulfur dissolved in the basalt formed at mantle conditions is entirely conveyed to the surface.

\section{a. Degassing trends in the $C-H-S-O$ system}

Based on the above considerations, we adopt the average sulfur content of primary Martian basalts as $3500 \mathrm{ppm}$, which is admittedly a conservative estimate, and further assume that this amount of sulfur is conveyed by the melt throughout the Martian crust. This simplification may also apply to $\sim 80 \%$ of the primary basaltic Martian crust likely formed as a result of magma ocean processes (e.g., Elkins-Tanton et al., 2005; Taylor and McLennan, 2009). The amount of sulfur eventually released into the atmosphere during magma degassing is complex and depends on a variety of parameters that we discuss below. Degassing of a magma ocean has been addressed in Gaillard and Scaillet (2009) and shown to be unimportant for $\mathrm{S}$-species and instead dominated by $\mathrm{CO}$ and $\mathrm{H}_{2}$ species. We 
concentrate hereafter on extrusive post-magma ocean magmatism, as defined by Craddock and Greeley (2009), which is dated from the middle Noachian to late Amazonian. Our approach differs from Righter et al. (2009) who considered that most degassed shergottites have between 1500-2000 ppm S and subtracted this number from the sulfur content of primary mantle basalts (3500-4000 ppm) to obtain averaged degassed sulfur. Here, following Gaillard and Scaillet (2009), we simulate equilibrium degassing of primary shergottitic basalts. During degassing variable amount of sulfur is lost into the atmosphere, in equilibrium with different gas species, whose relative abundances depend on pressure, oxygen fugacity, water content, as observed on Earth (Gaillard et al., 2011).

Since volatile solubilities are primarily pressure dependent (e.g., Behrens and Gaillard, 2006), the pressure at which degassing occurs is of prime importance. We can, for example, distinguish intrusive magmas, which degas at depth, from extrusive ones that release gases directly into the atmosphere. More degassing is expected for the extrusive regime than for the intrusive one, but variations in atmospheric pressure, which possibly occurred throughout Mars' history, must have also greatly influenced the nature and amount of volatiles expelled by sub-aerial volcanic eruptions. We could also consider the influence of the eruptive dynamics as addressed by Wilson and Head (1994). If explosive basaltic eruptions have been facilitated on Mars compared to the Earth due to low atmospheric pressure and lower gravity (Wilson and Head, 1994), we may expect that the gas composition of subaerial emissions is inherited from melt-gas equilibria occurring at pressures different (higher) than the atmospheric pressure. Overall, it is probable that Martian eruptive dynamics are not so critical if volatile contents in Martian basalts are small (see below). Plinian or strombolian basaltic eruptions, as occurring in subduction settings on Earth, are associated with preeruptive volatile contents generally exceeding $3 \mathrm{wt} \% \mathrm{H}_{2} \mathrm{O}$ and more than $1 \mathrm{wt} \% \mathrm{CO}_{2}$ (e.g., Aiuppa et al., 2010). Evidence for such elevated concentration levels, typical of arc-volcanoes on Earth, have been so far lacking for Martian basalts.

Table 3, which provides calculations of the amount of volcanic volatiles emitted in ppm-wt of magma erupted (for a sulfur content of the primary basalt of $3500 \mathrm{ppm}$ ), illustrates the effect of the 
pressure of degassing (500 bar for intrusive magma emplacement; 1, 0.1, 0.01 bar for atmospheric degassing under an atmosphere of variable density). Calculations are performed here in the C-O-H-S system and the mass fraction of the following species are shown: $\mathrm{CO}_{2}, \mathrm{CO}, \mathrm{H}_{2} \mathrm{O}, \mathrm{H}_{2}, \mathrm{SO}_{2}, \mathrm{~S}_{2}, \mathrm{H}_{2} \mathrm{~S}$. It is noteworthy that, in all cases, calculated $\mathrm{CH}_{4}$ concentrations are negligible at the pressuretemperature of volcanic degassing even under strongly reduced conditions (Gaillard and Scaillet, 2009). It appears that degassing occurring at elevated pressure (500 bar, intrusive magma) emits only C-species. Subaerial degassing occurring at variable pressures, from 1 to 0.01 bar, shows major differences. At 1 bar, little sulfur is emitted in comparison to degassing at 0.01 bar. This means that sulfur mostly remains in the lava in the case of eruption in an atmosphere of 1 bar, whereas if the same lava flows in an atmosphere at 0.01 bar, most of its sulfur will outgas. We emphasize here that such calculations are not aimed at equilibrating the composition of volcanic gases with that of the surrounding atmosphere. The atmosphere is not chemically participating in the process of volcanic degassing but it is physically controlling the final pressure of melt-gas equilibration. Equilibration of the melt with the composition of the atmosphere is impossible as the rate of redox equilibration and diffusion of volatiles into a cooling lava is far too slow (Berhens and Gaillard, 2006; Pommier et al., 2010).

Table 2 also shows some chemical effects, which are also important and may interfere with the effect of degassing pressure. The most studied chemical parameter is oxygen fugacity. Under reducing conditions, similar to IW, sulfur is only moderately volatile, and it tends to remain in the basaltic melt even at low pressure. Under oxidizing conditions, similar to FMQ, within the oxygen fugacity range indicated by Martian meteorites (Herd et al., 2002; Herd et al., 2005), sulfur is more volatile and more sulfur can be degassed to the atmosphere (Gaillard and Scaillet, 2009). The positive effect of oxygen fugacity on the efficiency of sulfur degassing at atmospheric pressure is shown in Figure 13, which also illustrates the role of water: for low pre-eruptive water contents, sulfur degasses weakly whereas water-rich melts (by martian standards) efficiently lose much of their sulfur (Gaillard and Scaillet, 2009). As for the previous set of calculations, the starting S content is fixed at $3500 \mathrm{ppm}$. The impacts 
of changes in $\mathrm{fO}_{2}$ or water content on the amount sulfur outgassed are both positive and comparable in magnitude. Reduced hydrated (IW, 0.4 wt $\%$ water) Martian basalts would degas sulfur as efficiently as oxidized dry ones (FMQ-0.5, $0.1 \mathrm{wt} \%$ water). Maximum sulfur degassing is obtained for hydratedoxidized melts $(0.4$ wt $\%$ water, FMQ- 0.5$)$ which release into the atmosphere $75 \%$ of their initial Scontent. All this discussion is related to Figure 13 showing degassing at 0.1 to 0.01 bar.

\section{b. Defining $\mathrm{fO}_{2}$-water content of basaltic shergottites}

To date, there are insufficient data in hand to constrain the initial average water content of Martian basalts. Martian meteorites may have contained 140-260 ppm water (McCubbin et al., 2010) and there is evidence that their parental melts may have contained more water (McCubbin et al., 2012). One estimate (McSween et al. 2001) suggests a water content <1.8 wt\%, which is likely an upper limit, and which falls within the range of terrestrial magmas: arc-basalts, among the most hydrated magmas on Earth, have about 3 wt\% water (e.g., Wallace, 2005); MOR-Basalts (Mid Ocean Ridge), which constitute $75 \%$ of the Earth's volcanism, have $0.1 \mathrm{wt} \%$ water (e.g., Saal et al., 2002) and hotspot basalts have broadly 0.2-1 wt\% (e.g., Dixon et al., 1997).

Since the efficiency of sulfur degassing is being essentially controlled by pre-eruptive water content and $\mathrm{fO}_{2}$ conditions, it follows that constraints on the sulfur content of degassed Martian basalts can be used to infer the $\mathrm{fO}_{2}$ - water content prevailing during lava emplacement and degassing. To this end, Figure 13 shows the range of sulfur content analysed in shergottites (source data compiled Meyers 2008; see in addition Gibson et al., 1985; Zipfel et al., 2000; Lorand et al., 2005; and references in Righter et al., 2009). The figures yield a range from 1300 to 2700 ppm sulfur. A potential limitation of such an approach is that Martian meteorites may not represent the composition of a melt, but instead reflect the effect of cumulate processes. Righter et al. (2009) nevertheless considered that a basaltic shergottite with sulfur content at $1600 \mathrm{ppm}$, provides a reasonable estimate 
for degassed Martian basalts. If we assume that 1500-1800 ppm sulfur remains in the shergottite lava after degassing, the $\mathrm{fO}_{2}$-water content conditions needed to yield such $\mathrm{S}$-content after degassing at final pressure 0.1-0.01 bar are as follows: IW / 0.4wt $\% \mathrm{H}_{2} \mathrm{O}$; FMQ-1.5 / $0.2 \mathrm{wt} \% \mathrm{H}_{2} \mathrm{O}$; FMQ-0.5 / 0.1 wt $\% \mathrm{H}_{2} \mathrm{O}$. Given that the upper range of $\mathrm{fO}_{2}$ estimated for Martian meteorite (FMQ for nakhlites and chassignites; Herd et al., 2002; Herd et al., 2005) does not apply to shergottites, we can eliminate the uppermost $\mathrm{fO}_{2}$ conditions. We hence conclude that water content of at least $0.2 \mathrm{wt} \%$ is required by the sulfur left over in Shergottite magma after degassing. Water content of $0.2 \mathrm{wt} \%$ is a minimum because it matches the uppermost $\mathrm{fO}_{2}$ recorded for Shergottites. Mc Cubbin et al. (2012) also recently provided geochemical indications based on melt/apatite water partitioning that are consistent with water content for the parental melts of shergottites close to $0.2 \mathrm{wt} \%$. If IW is representative of the redox state of shergottite magmas, then Figure 13 indicates that $0.4 \mathrm{wt} \%$ water is needed: more water would be required if more reduced conditions prevailed, which cannot be excluded given that the lowermost $\mathrm{fO}_{2}$ for shergottite parental melts is IW-0.5 (Herd et al., 2002). Therefore, the range of oxygen fugacity recorded for shergottites, which spans over 4-log units, can be used along with Fig.13 to infer the corresponding variation in water contents of Martian primitive basalts, from 0.2 to $0.6 \mathrm{wt}$ $\%$, in the $\mathrm{fO}_{2}$ range FMQ-1.5 to IW-0.5, respectively.

\section{c. Changing $\mathrm{fO}_{2}$ during degassing of basaltic shergottites}

There is no consensus on the origin of oxygen fugacity variations for Martian shergottites. Assimilation of crustal material has been suggested (Wadhwa, 2001; Herd et al., 2002), but such oxidized crustal material remains to be identified. At the low oxygen fugacity of Martian basalts (relative to Earth's basalts), only a very small amount of ferric iron is present in the melt and the buffering capacity of such melts is low. Furthermore, varying oxygen fugacity from IW -0.5 to IW +3 as recorded in Shergottite rocks implies only moderate changes in ferric-ferrous ratio, with the implications that such $\mathrm{fO}_{2}$ changes do not require significant redox transfers (or mass transfer of oxygen). In Figure 14, the $\mathrm{fO}_{2}$ changes (see also Burgisser and Scaillet, 2007; Gaillard et al., 2011) 
resulting from the degassing of Martian basalts have been calculated for different initial water contents, and two representative initial $\mathrm{fO}_{2}$ (IW; FMQ-1.5). The initially oxidized melt does not change much in $\mathrm{fO}_{2}$ for degassing in the range 10-1000 bar, but for pressures lower than 10 bar, $\mathrm{SO}_{2}$ degassing from $\mathrm{S}^{2-}$ in basalts causes a strong $\mathrm{fO}_{2}$ decrease. The initially reduced melt exhibits a more complex pattern. A severe oxidation in the range 1-1000 bar is calculated and the magnitude of this oxidation correlates with pre-eruptive water content. This is due to the outgassing of water and $\mathrm{CO}_{2}$ which both decompose into the fluid as $\mathrm{H}_{2}$ and $\mathrm{CO}$ species respectively (which both have very low solubility in the melt, Gaillard et al., 2003b; Morizet et al., 2010). Degassing of $\mathrm{H}_{2} \mathrm{~S}$, which is dominant in the pressure range 1-1000 bar (see also Zolotov, 2003 for computation of the gas phase) produces no effect on $\mathrm{fO}_{2}$ (Gaillard et al., 2011). At pressures lower than $10^{-1}$ bar, sulfur degassing as $\mathrm{SO}_{2}\left(\mathrm{SO}_{2}\right.$ being the dominant $\mathrm{S}$-species in the gas, see also Zolotov, 2003) decreases $\mathrm{fO}_{2}$ as described above. It is noteworthy that reduction trends associated with degassing of sulfur may well explain mineralogical and geochemical observations in nakhlites too (Righter and Humayun, 2012; Chevrier et al., 2010). It thus appears that the simple process of volatile degassing upon magma ascent implies $\mathrm{fO}_{2}$ variations that reproduce the range recorded by shergottites and to a lesser extent in nakhlites. In essence, such results can be used to argue that all shergottites initially derived from parental melts at an $\mathrm{fO}_{2}$ close to IW and with water and sulfur contents of $0.4-0.6 \mathrm{wt} \%$ and $0.35 \mathrm{wt} \%$, respectively. McCubbin et al (2010) reported a range of water content, 0.4-0.8 wt\%, for Chassigny parental magma that are broadly compatible with such estimates. Nakhlites are slightly more oxidized than shergottites and might have experienced degassing with similar impacts on redox state (eg. $\mathrm{SO}_{2}$ degassing leading to reduction). It is, however, difficult to provide any estimates of redox state and water content of their source regions or parental melts. Our approach, which only assumes equilibrium degassing, is relatively robust and the resulting inverse approach can account for the available observations. Equilibrium degassing, like equilibrium crystal fractionation or equilibrium melting (Baratoux et al., 2011), provide us essential constraints as it pinpoints which chemical fractionation trend should have occurred under the sole assumption of thermodynamic equilibrium. It constitutes an essential 
approach since many of the relevant chemical parameters controlling Martian magmatic processes (e.g., water content, $\mathrm{fO}_{2}$, source vs. shallow status) are poorly known, largely because of the paucity of direct petrological observations, and also because Martian meteorites may not be straightforwardly reflective of the Martian magmatic processes (McSween et al., 2009).

\section{Sulfur emissions from volcanic vent to exosphere.}

\section{a. Sulfur degassing and speciation: Ancient vs. recent Mars}

The calculations described above indicate that a melt with $0.35 \mathrm{wt} \%$ sulfur (this study), $0.4 \mathrm{wt} \%$ water (this study), $200 \mathrm{ppm} \mathrm{CO}_{2}$ (Stanley et al., 2011) and $\mathrm{fO}_{2}$ close to IW (this study) may be representative of primary shergottitic basalts. During subaerial volcanism, such melts degas mixtures whose composition depends significantly on venting pressures (Zolotov, 2003; Gaillard and Scaillet, 2009). Ancient volcanism/magmatism on Mars, such as that associated with crust formation, was voluminous (Taylor and McLennan, 2009), intense and likely to have conveyed to the atmosphere an amount of gas sufficient to produce an atmospheric pressure close to 1 bar (Grott et al. 2011). On the other hand, present-day atmosphere on Mars has a low pressure and the shift from a dense to a tenuous atmosphere remains enigmatic (Barrabash et al, 2007).

Shergottites (and thus the various parameters inferred above) might not be representative of the Martian crust as a whole (McSween et al., 2009; Taylor and McLennan, 2009). Nevertheless, calculated gas compositions (Table 3 and figure 15 as a function of pressure), reveal several trends that are independent of the pre-eruptive melt chemical (volatile-free) features. For instance, degassing at a pressure slightly above but of similar magnitude to present day conditions $(0.01$ bar $)$ produces volcanic gases that are dominated by sulfur species, even if the absolute amount of $\mathrm{S}$ emitted per gram 
of lavas erupted remains small at low $\mathrm{fO}_{2}$ and low pre-eruptive amount of water (Table 3). Furthermore, sulfur emissions in a tenuous atmosphere $(0.01$ bar $)$ could have been greatly increased if either basalt water content or its oxidation state, or both, were higher. In detail, an increase in both fO $\mathrm{f}_{2}$ and water content also produces an increase of $\mathrm{SO}_{2}$ with respect to $\mathrm{H}_{2} \mathrm{~S}$ and $\mathrm{S}_{2}$ species.

If degassing occurred at 1 bar, the total sulfur species $\left(\mathrm{SO}_{2}+\mathrm{S}_{2}+\mathrm{H}_{2} \mathrm{~S}\right)$ amount to $\ll 1000 \mathrm{ppm}$ whatever the conditions of water content and $\mathrm{fO}_{2}$. In most cases, at 1 bar degassing conditions, sulfur is a minor component of the fluid phase and $\mathrm{H}_{2} \mathrm{~S}$ is the most abundant sulfur species on a molar basis (Fig. 15, Table 3). Such a high atmospheric pressure scenario applies to the earliest and intense phase of magmatism and degassing that triggered formation of the basaltic crust (Grott et al., 2011). It follows that sulfur emissions during this earliest and abundant volcanic phase on Mars were low with most sulfur being emitted as $\mathrm{H}_{2} \mathrm{~S}$ (Gaillard and Scaillet, 2009; see also Zolotov, 2003). We may also consider that a large part of this early magmatism was intrusive and therefore degassed at crustal pressures, even if this is difficult to demonstrate. As shown in Fig.15 and Table 3, intrusive magmatism is characterized by very low sulfur emissions, all sulfur being expelled as $\mathrm{H}_{2} \mathrm{~S}$, whereas the $\mathrm{CO}$ and $\mathrm{CO}_{2}$ emissions are, in contrast, similar irrespective of whether extrusive or intrusive magmatism occurs. Further complications for C-species may arise if magma cooling at depth triggers graphite saturation, but this should only moderately alter the above conclusion on extrusive vs. intrusive degassing of $\mathrm{CO}$ and $\mathrm{CO}_{2}$. It seems likely therefore that the earliest pre-Noachian Martian magmatism associated with the formation of the crust, while voluminous, was associated with only moderate sulfur yields to the atmosphere because conditions of degassing were unfavorable to the release of S-species, and the small amount of $\mathrm{S}$ released was emitted as $\mathrm{H}_{2} \mathrm{~S}$. In contrast, C-species and water-species, probably dominated early magmatic emissions.

The Tharsis region contains, by mass, a significant fraction of the volcanic material on Mars (Phillips et al., 2001), yet the outgassing of this structure is difficult to quantify because it is unknown what fraction of Tharsis' mass was emplaced as extrusive versus intrusive material (Phillips et al., 2001). Furthermore, while volcanoes in Tharsis may have remained active far beyond the intense 
early period of magmatism forming $>90 \%$ of the crust (Greeley and Schneid, 1991; McEwen et al., 1999; Phillips et al., 2001; Fasset and Head, 2011; Craddock and Greeley, 2009), it is not well known how much magmatism occurred in this province on early Mars. In fact, due to the low erosion rates that have occurred on Mars since the Hesperian (Golombek et al., 2006), much more is known about younger volcanism than is for the most ancient volcanic crust (Craddock and Greeley, 2009). If such subaerial volcanism occurred in an atmosphere similar to that of the present-day, then venting pressures in the range 0.1-0.005 bar are expected. Under such conditions, much more sulfur is introduced into the atmosphere by volcanic degassing than at high atmospheric pressure conditions ( $\geq 1$ bar). Table 3 indicates that on average $2000-2600$ ppm S would be injected by subaerial basaltic eruption at low venting pressure. Furthermore, $\mathrm{H}_{2} \mathrm{~S}$ constitutes only a minor part of sulfur species (typically $<5 \%$ of total $\mathrm{S}$ ) whereas $\mathrm{SO}_{2}$ becomes important (typically $30-50 \%$ of total $\mathrm{S}$ ), if not dominant, for hydrous and oxidized conditions (75\% of total $S$ ). Sulfur in the $S_{2}$ form is also a major emitted species.

So far we have considered here that the $\mathrm{fO}_{2}$ of Martian basalts did not significantly vary through time. The suggestion that oxygen fugacity during Martian mantle melting is buffered by graphite saturation (Stanley et al., 2011) calls for limited changes in $\mathrm{fO}_{2}$ in the mantle source of basalts. At first sight, this contrasts somewhat with the fact that the redox states of Martian meteorites span over 4 orders of magnitude, which suggests that secular changes in Martian mantle redox state cannot be excluded. Secular variations in oxygen fugacity (mantle oxidation state increasing with time) could indeed induce a change in sulfur outgassing and speciation released by volcanic activity. However, figure 14 shows that degassing can also account for most of these $\mathrm{fO}_{2}$ variations. Finally, Zolotov (2003) and Gaillard and Scaillet (2009) have shown that even for reduced basalts, $\mathrm{SO}_{2}$ is the dominant degassed sulfur species released at low pressure (0.01 bar).

To summarize (Figure 16), we can distinguish two eras with different amounts and types of volcanic sulfur injected into the atmosphere. (i) Ancient Mars (early to mid-Noachian), with higher fraction of intrusive magmatism and / or with extrusive emissions occurring in a relatively dense 
atmosphere and / or characterized by a more reduced mantle source, resulting in volcanic gases with low sulfur content, dominated by $\mathrm{H}_{2} \mathrm{~S}$; and (ii) recent Mars, Hesperian to Amazonian, dominated by extrusive magmatism and / or degassing within a low density atmosphere and / or more oxidized basaltic eruptions that produced gases dominated by sulfur $\left(\mathrm{SO}_{2}+\mathrm{S}_{2}+\mathrm{H}_{2} \mathrm{~S}\right)$ with $\mathrm{H}_{2} \mathrm{~S}$ constituting a negligible fraction. This change in the regime of $S$ delivered by volcanoes assumes the acceptance of several successive geochemical eras on Mars: The early clay period and the more recent sulfate period.

\section{b. Estimates of sulfur fluxes}

An important question is what is the total amount of sulfur that has been degassed over Martian geological history? Among other things, constraining this value constrains in turn the size of the sedimentary reservoir on Mars (McLennan, 2012). On Earth, a significant part of near-surface sulfur is recycled back into the mantle by plate tectonic processes leading to a complex S-cycle (Canfield, 2004). On Mars, the absence of plate tectonics imposes that degassed S remains at or near the surface, where it has progressively accumulated. Nevertheless, estimating the total S flux is a daunting task. As described above, $\mathrm{S}$ degassing speciation and efficiency is highly variable depending on atmospheric (venting) pressure, mantle oxygen fugacity and the overall composition of magmatic gases, all of which are uncertain and likely to have changed over geological time (e.g., Fig. 16). In addition, the S contents of the Martian mantle and mantle-derived magmas (e.g., representativeness of shergottite magmatism for all of Mars), magmatic production rates over geological time, and the relative roles of explosive versus effusive volcanism (Wilson and Head, 1994) are still all imperfectly understood.

A number of studies have recently estimated global Martian volcanic degassing rates, in each case constrained to be lower limits, and the wide range of derived values clearly illustrate some of the difficulties. Using various constraints on planetary degassing models (see original papers for details), Gaillard and Scaillet (2009) estimated that $5.4 \times 10^{21} \mathrm{~g}$ of $\mathrm{S}$ had been degassed by subaerial volcanism 
over geological times whereas Righter et al (2009) and Craddock and Greeley (2009) estimated S amounts are 1-2 orders of magnitude lower, from $4.5 \times 10^{19} \mathrm{~g}$ to $1.7 \times 10^{20} \mathrm{~g}$, respectively.

The estimates of Righter et al. (2009) and Craddock and Greeley (2009) rely on volcanic production rates determined by Greeley and Schneid (1991), which do not consider the early Noachian. McEwen et al. (1999) estimated Noachian volcanic rates and suggested that total Martian volcanism may have been more than a factor of 7 higher than that given by Greeley and Schneid (1991) due to much higher Noachian rates of volcanism. This in turn would lead to comparable increases to the S-degassing estimates of Righter et al. (2009) and Craddock and Greeley (2009). Accordingly, recent estimates, if recalculated to be consistent with the volcanic production rates of McEwen et al. (1999), agree to within about an order of magnitude, falling in the range $\sim 5 \times 10^{20} \mathrm{~g}$ to $\sim 5 \times 10^{21} \mathrm{~g}$. These values are still likely to be minimum estimates because volcanic production estimates of McEwen et al. (1999), corrected for a reasonable intrusive/extrusive ratio (<10), do not account for the entire Martian crust (Taylor and McLennan, 2009), the formation of which must have contributed some sulfur to the surface.

Attempting to constrain the size of the Martian sedimentary mass, McLennan (2012) used an entirely different approach by assuming that the proportion of $\mathrm{S}$ degassed from the Martian mantle during crust formation and evolution was comparable to the Earth, which Canfield (2004) estimated to be $\sim 11 \%$. The rationale for this approach is that during mantle melting, $\mathrm{S}$ is incompatible and Mars is more differentiated (i.e., larger proportion of planet's inventory of incompatible elements reside in the Martian crust compared to terrestrial crust) than Earth (Taylor and McLennan, 2009). The overall efficiency of $\mathrm{S}$ extraction from crust to exosphere, integrated over geological time was simply assumed to be comparable for the two planets. Correcting for differing masses and likely $\mathrm{S}$ concentrations of the terrestrial and Martian primitive mantles, McLennan (2012) arrived at a value of $2.2 \times 10^{22} \mathrm{~g}$ of degassed sulfur, about an order of magnitude greater than estimates based on magma degassing (Righter et al., 2009; Gaillard and Scaillet, 2009; Craddock and Greeley, 2009). 
In the discussion above, it was concluded that the "best estimate" for Martian S-degassing rates were $<1,000 \mathrm{ppm}$ for high venting pressures ( 1 bar), 2,000-2,600 ppm for low venting pressures $(<0.1$ bar) and, at most, a few ppm $\mathrm{S}$ for the intrusive components of the magmatism. From the perspective of estimating a global flux, it should be kept in mind that these values were derived in a similar manner to those of Gaillard and Scaillet (2009). The magnitude of S degassing that took place during early magma ocean processes (that led to the primary crust), which could represent as much as $80 \%$ of the total crust (Taylor and McLennan, 2009), is shown in Gaillard and Scaillet (2009) to be of minor importance in comparison to the more recent extrusive volcanism.

What do these values imply for total sulfur degassing? A simple model, again likely to be a lower limit, can be constructed in which younger volcanism (Hesperian and Amazonian; $1.97 \times 10^{23} \mathrm{~g}$ extrusive magma; Greeley and Schneid, 1991) is taken to occur at low atmospheric pressure and thus result in 2,000 ppm S degassing and early volcanism (Noachian; $1.45 \times 10^{24} \mathrm{~g}$ extrusive magma; Greeley and Schneid, 1991; McEwen et al., 1999) is taken to occur at high atmospheric pressure resulting in 200 ppm S degassing. Since reliable values are unavailable for combined intrusive- and (especially) magma ocean-related magmatism $\left(1.97 \times 10^{25} \mathrm{~g}\right.$ using crustal mass estimate of Taylor and McLennan, 2009) we adopt another order of magnitude lower value of 20 ppm sulfur (calculated after Gaillard and Scaillet, 2009). This leads to a lower limit total S degassing estimate of $1.1 \times 10^{21} \mathrm{~g}$, which is intermediate to the range for previous S-degassing calculations given above and about an order of magnitude less than the estimate of McLennan (2012).

\section{c. Global volcanic C/S ratio: Mars vs. Earth}

An important suggestion connecting the sedimentary records on Mars and its history of volcanic degassing is that ancient volcanic gases must have had high carbon/sulfur ratios possibly similar to those on Earth (see Symonds et al., 1994), whereas recent Martian volcanic gases had C/S ratios $\leq$ 0.1 , which is about 10 times lower than their terrestrial counterparts. This simple mass balance 
consideration is probably the most likely explanation for the growing body of evidence for Martian surface chemistry dominated by sulfur whereas the Earth's surface is more balanced between hydrogen-carbon-sulfur related chemical processes (Berner, 1995; 2005; Halevy et al., 2007; Gaillard and Scaillet, 2009). This in turn suggests that the sulfur driven surface chemistry of Mars is a somehow relatively recent evolution, i.e. it operated when the atmospheric pressure dropped below 0.1 bar. If, as often proposed (Melosh and Vickery, 1989; Jakosky and Phillips, 2001), ancient Mars had a denser atmosphere, then the $\mathrm{C} / \mathrm{S}$ ratios of magmatic gases were high and more similar to those of the modern Earth. The timing of interruption of the Martian core dynamo may have triggered the loss into space of the early dense atmosphere (Fassett and Head, 2011). The Martian dynamo ceased early, but no consensus has been established about the exact timing (Early Noachian to late Noachian, see discussion in Fassett and Head (2011) and also Milbury and Schubert (2010)). Impact erosion of the atmosphere has occurred throughout the Noachian (Melosh and Vickery, 1989) and it may therefore have also contributed to the decreases in atmospheric pressure demanded by numerous observations. Alternatively, carbonate formation in ancient sedimentary or hydrothermalised rocks (Ehlmann et al. 2008; Michalski and Niles 2010), whose importance is not yet clearly identified, might have contributed to a decrease in atmospheric $\mathrm{CO}_{2}$ pressure down to below 0.1 bar.

The low $\mathrm{H} / \mathrm{S}$, low $\mathrm{C} / \mathrm{S}$ ratios and high $\mathrm{SO}_{2}$ content of volcanic gases on Mars contrast with extrusive emissions on Earth. It is noteworthy that most extrusive rocks on Earth are emplaced in submarine conditions (average pressure 400 bar). Gases emitted by degassing at 400 bar are sulfurpoor and $\mathrm{CO}_{2}$ dominated. Only subaerial volcanism significantly contributes to sulfur emissions into the Earth's atmosphere. Gaillard et al. (2011) suggested an increasing amount of subaerial volcanism on Earth is the cause of a major change in composition of volcanic gases that became increasingly sulfur-rich and $\mathrm{SO}_{2}$-rich, with major impacts on surficial biogeochemistry. The Archean era on Earth has been clearly shown to display limited sulfur cycling whereas through time, sulfur increasingly invaded the exosphere (Lyons and Gill, 2010). As summarized in Figure 16, there are good reasons to believe that ancient Mars (early Noachian) had limited sulfur cycling and was wetter and warmer 
(Bibring et al., 2006). The large sulfate deposits now widely observed on the Martian surface, and the surface waters from which they were deposited, occurred during the late Noachian-Hesperian times (Figure 16). To some extent, it is possible that increasing contributions of sulfur to surficial chemical processes is a feature common to both Mars and Earth.

To summarize: (1) most extrusive volcanic degassing on Mars globally occurred at low pressure $(<0.1$ bar) in contrast to the Earth (where submarine volcanism dominates), (2) Martian basalts must contain more sulfur than terrestrial basalts, and (3) under the reduced conditions prevailing in the Martian mantle, enhanced graphite stability implies low $\mathrm{CO}_{2}$ content in basalts (Stanley et al., 2011), which is 3-10 times lower than the $\mathrm{CO}_{2}$ content of Earth's basalts. All this contributes to the low C/S of gases emitted on Mars, which can be lower by a factor of 10 compared to Earth.

The consequences for the chemistry of Martian surface waters are also significant. Low C/S, with sulfur mostly injected as $\mathrm{SO}_{2}$, would likely create aqueous systems dominated more by some form of a sulfur cycle (i.e., formation of strong S-based acids such as sulfurous and sulfuric acid) than the carbon cycle (weak C-based acids such as carbonic and organic acids). The acidic nature of Martian surface waters and the lack of carbonate minerals in late Noachian-Hesperian sediments in turn may be related to the composition of volcanic gases that for the reasons discussed above were different from those emitted on Earth. 


\section{Sulfur cycling: volcanoes, atmosphere, climate, and prospective.}

\section{a. Sulfur and climate models}

Farquhar et al. (2000) have shown that some sulfur found in certain SNC meteorites has massindependent isotopic fractionation, interpreted as evidence of an atmospheric source for sulfur. In detail, atmospheric $\mathrm{SO}_{2}$ that carries the isotopic mass independent fractionations must be involved in the sulfur transfer from atmosphere to the Martian regolith. Martian atmospheric $\mathrm{SO}_{2}$, deriving from volcanic activity, may have well influenced the climate on early Martian. Halevy et al (2007) and Bullock and Moore (2007), following the pioneering study of Wanke and Dreibus (1994), suggested that an $\mathrm{SO}_{2}$ greenhouse effect may have maintained warm conditions on early Mars that in turn could be reconciled with the clay deposits of the early-mid-Noachian and the formation of valley networks. This warm period goes along with wet conditions and may imply atmospheric pressures greater than about 0.5 bar. Atmospheric simulations performed in several studies corroborated the possibility of warming by $\mathrm{SO}_{2}$. Johnson et al. (2008) performed calculations showing that atmospheric temperature could increase above $+10^{\circ} \mathrm{C}$ if a concentration level of ca. $100 \mathrm{~s}$ ppmv $\mathrm{SO}_{2}$ is reached in a $\mathrm{CO}_{2}$ atmosphere of 0.5 bar. But, Johnson et al. (2008) did not consider that $\mathrm{SO}_{2}$ could react in the atmosphere and produce $\mathrm{H}_{2} \mathrm{SO}_{4}$ and $\mathrm{S}_{8}$ aerosols (Settle, 1979; Tian et al., 2010). These factors subsequently were considered by Johnson et al (2009) and imply that the $\mathrm{SO}_{2}$ lifetime in an ancient, reduced, denser, wetter Martian atmosphere is on the order of 100s years. This may allow transient warm periods to occur after volcanic eruptions, provided that volcanic eruptions supplied enough atmospheric $\mathrm{SO}_{2}$. The period of warming is however interrupted, and under certain circumstances, compensated by a period of cooling mainly due to $\mathrm{H}_{2} \mathrm{SO}_{4}$ and $\mathrm{S}_{8}$ aerosols being formed by photochemical processes from $\mathrm{SO}_{2}$ and successive reactions with $\mathrm{H}_{2} \mathrm{O}$ to form sulfuric acid (Tian et al., 2010). Like Johnson et al. (2009), Tian et al. (2010) used photochemical models but they found 
$\mathrm{SO}_{2}$ lifetimes much shorter than predicted by Johnson et al., (2009), typically on the order of several months. It is thus possible that intensive $\mathrm{SO}_{2}$ emission due to volcanic eruptions produced warm-wet conditions that lasted 1 to 100 years which were followed by cooling and glaciations due to formation of atmospheric S-aerosols. All this may well be consistent with various geomorphological features of Mars (Andrews-Hanna and Lewis, 2011).

The overall atmospheric processes are, however, complex and, accordingly, no consensus has yet emerged. The warming effect and the $\mathrm{SO}_{2}$ lifetime correlate with the amount of atmospheric $\mathrm{SO}_{2}$ and the total atmospheric pressure (i.e. $\mathrm{P}_{\mathrm{CO} 2}$ ). The redox state of the ancient Martian atmosphere as well as its humidity also influences $\mathrm{SO}_{2}$ lifetime and the extent of $\mathrm{H}_{2} \mathrm{SO}_{4}$ formation (Johnson et al., 2009; Tian et al. 2010). A possible way to resolve this complexity would be to construct an integrated Martian model in which the initial status of atmospheric models would be imposed by volcanic inputs similar to those calculated here (Table 2).

Johnson et al. (2008) attempted such an integrated approach but their estimates of volcanic sulfur emissions did not consider the high sulfur content in Martian basalts due to their high iron content (see Section 3.b.). In addition, their inference that $\mathrm{SO}_{2} / \mathrm{H}_{2} \mathrm{~S}$ ratio equals 1 , taken from Halevy et al. (2007), is not consistent with the arguments put forward in this review (see also Gaillard and Scaillet, 2009). Accordingly, Johnson et al. (2008) may have underestimated volcanic $\mathrm{SO}_{2}$ production by a factor 4-6.

Most atmospheric models neglect species other than $\mathrm{CO}_{2}-\mathrm{H}_{2} \mathrm{O}$. All volcanic gas compositions shown in Table 2 indicate that carbon monoxide is present at concentration levels as high as carbon dioxide and that the fraction of $\mathrm{H}_{2}$ is significant, whereas these species are generally not taken into account. In addition, all atmospheric simulations allow $\mathrm{SO}_{2}$ concentration and atmospheric pressure to vary independently whereas the above analysis clearly shows that high volcanic $\mathrm{SO}_{2}$ emissions would occur only if the atmospheric pressure is low ( 0.1 bar or less). Volcanic degassing in an atmosphere of 1 bar would produce gas dominated by $\mathrm{C}$ and $\mathrm{H}$-species with little sulfur (and all sulfur as $\mathrm{H}_{2} \mathrm{~S}$ ). Hence, if ancient warm and wet Mars existed with an atmosphere similar to 1 bar or higher, it follows 
that $\mathrm{SO}_{2}$ from volcanic sources is an unlikely candidate to trigger warm conditions. Furthermore, phyllosilicate deposits that dominated at this time (early-middle Noachian) do not require high activity of sulfur species in the exosphere. Instead, sulfate deposits that appeared later, during the late Noachian and the Hesperian, reveal high activities of oxidized S-species, which further generated acidic surface waters (see parts $1 \& 2$ and below). There is therefore incompatibility between the period of warm and wet Mars and the conditions conducive to high $\mathrm{SO}_{2}$ emissions by volcanic eruptions. The early wet-warm Mars must have had atmospheric pressures compatible with $\mathrm{CO}_{2}-\mathrm{H}_{2} \mathrm{O}$ $+/-\mathrm{H}_{2} \mathrm{~S}$ volcanic emissions, whereas the late Noachian, with sulfate deposits, was more likely in a low pressure atmosphere allowing volcanic emissions dominated by $\mathrm{SO}_{2}$ (Fig. 17). Accordingly, the analysis provided in this paper lends support to the conclusion of Tian et al. (2010) that early Mars must have been kept warm by mechanisms other than volcanic $\mathrm{SO}_{2}$ greenhouse warming.

It is, however, conceivable that the middle-late Noachian Mars had short episodes of warm periods due to high volcanic $\mathrm{SO}_{2}$ emissions and its relatively long residence time in a dry atmosphere. If we assume that flood basalts on Mars were comparable to those on Earth, $100 \mathrm{~km}^{3} / \mathrm{yr}$ of lava eruption rates is a reasonable estimate (Keszthelyi et al., 2006). Using gas compositions in Table 3, this implies $\mathrm{SO}_{2}$ degassing of about $10^{17} \mathrm{~g}$ per year and total sulfur $\left(\mathrm{SO}_{2}+\mathrm{S}_{2}+\mathrm{H}_{2} \mathrm{~S}\right)$ emissions of more than twice this value. Tian et al (2010) suggested that such a value is necessary to elevate the average surface temperature above the freezing point of water. Intermittent warming due to sporadic outbursts of volcanic $\mathrm{SO}_{2}$ may well be possible during the late Noachian-Hesperian epochs: however, $10^{17} \mathrm{~g}$ of $\mathrm{SO}_{2}$ in an atmosphere with 4 bar $\mathrm{CO}_{2}$ suggested by Tian et al. (2010) is incompatible with elevated volcanic $\mathrm{SO}_{2}$ emissions.

To conclude, atmospheric models involving S-species are a fascinating issue for future research on the ancient climate on Mars. The expected efforts will require volcanic emissions and atmospheric chemical physical processes to be related. 


\section{b. Sulfur cycling models}

The sulfur-rich character of sedimentary deposits on Mars (see Section 2), apparent dominance of sulfate minerals over carbonate minerals (see Section 1) and evidence at both Meridiani Planum and Gusev crater for extensive low $\mathrm{pH}$ environments in the form of widespread $\mathrm{Fe}^{3+}$ mobility under oxidizing conditions have led to suggestions that some form of a sulfur cycle dominated surficial processes over much of Martian geological history. Such a sulfur cycle would likely produce strong S-based acids (e.g., sulfuric acid) and thus surficial processes would be characterized by widespread, relatively low $\mathrm{pH}$ conditions $(\sim \mathrm{pH} 2-\mathrm{pH} 5)$. This is in contrast to terrestrial settings, where the carbon cycle, characterized by relatively weak C-based acids (e.g., carbonic acid, organic acids) and modest pH conditions ( pH5-8), dominates. McLennan (2012) recently reviewed the nature of such a potential Martian sulfur cycle and parts of that discussion are briefly summarized below.

Any Martian sulfur cycle would likely be divided into early and late phases with a transition occurring approximately at the time of loss of widespread aqueous conditions and reduction of magmatic rates, and thus sulfur degassing into the atmosphere, sometime $>3 \mathrm{Gyr}$. In addition to being a time of voluminous magmatism (McEwen et al., 1999), the early (>3Gyr) history of Mars was also characterized by widespread aqueous conditions, possibly facilitated by an early greenhouse effect (but see discussion above). Results from experiments, thermodynamic models, and direct measurements of Martian soils and rocks suggest that a variety of sulfur reservoirs and sulfur cycling processes may have been involved (Fig. 17a).

Acid alteration of basaltic rocks and minerals is now well established for the Martian surface, at least during parts of its early history (McLennan and Grotzinger, 2008). Among the major processes that have been documented are low temperature alteration (i.e., weathering) that produced the brines that in turn gave rise to evaporitic minerals such as those in the Burns formation, and higher temperature epithermal to hydrothermal fluids, such as those that have been identified in the Columbia Hills of Gusev crater. Extensive occurrences of sulfate and possible chloride minerals identified from orbit and by in situ techniques on rocks and soils also point to widespread formation 
of a variety of evaporite minerals across the Martian surface, dominated by $\mathrm{Ca}-\mathrm{Mg}$ - and Fe-sulfates of varying hydration states.

Correlations between occurrences of sulfate minerals and iron oxides on the Martian surface identified from orbit and also inferred for the Burns formation sulfate-rich outcrops (i.e., occurrence of hematitic concretions) further suggest a possible genetic link between iron and sulfur cycling (McLennan et al., 2005; Bibring et al., 2007; Tosca et al., 2008). Thus, Tosca et al. (2008) carried out experiments and modeling that evaluated diagenetic oxidation and ageing of iron sulfates to form iron oxides. These oxidation-ageing processes are almost certainly irreversible under Martian surficial conditions and also result in the liberation of sulfur that in turn may be recycled back through the sedimentary system.

As described above, Halevy et al. (2007) have proposed an even earlier version of the sulfur cycle to account for early widespread occurrence of clay minerals, but dearth of carbonates, in the earlier Noachian (e.g., Fig. 7). In this model, relatively reducing atmospheric conditions resulted in inhibition of oxidation of atmospheric $\mathrm{SO}_{2}$ and thus formation of sulfurous, rather than sulfuric, acids leading to low but more modest $\mathrm{pH}$ conditions ( $\mathrm{pH} 4.5-\mathrm{pH} 5.5)$. These conditions might allow for the formation of clay minerals while at the same time inhibit precipitation of carbonates. This model predicts formation of widespread sulfite minerals in the early Noachian for which there is no evidence but on the other hand, if formed, would be unlikely to survive later oxidizing conditions.

With the precipitous decline of aqueous activity and volcanic rates sometime before about 3 Gyr, the rate at which sulfur was degassed into the surficial environment likely also diminished. Nevertheless, there is evidence that surficial processes continued to be influenced by some form of a sulfur cycle after this time and through essentially to the present (Fig. 17b). Thus, the chemical compositions of relatively altered present-day rock surfaces and their relatively fresh interiors (exposed by the rock abrasion tool, RAT), analyzed by Spirit in Gusev crater, point to continued low water/rock ratio acid alteration, albeit likely at greatly reduced rates and scales (Hurowitz et al., 2006; Hurowitz and McLennan, 2007). The origin of acidity in younger environments is less clear. Although 
rates of magmatism are minimal during most of the Amazonian, volcanism is generally accepted to be continuing through to the present. As discussed above, under low atmospheric pressures, sulfur degassing is more efficient. Other possible sources include recycling of surface sulfate deposits by impact processes (McLennan et al., 2006; Zolotov and Mironenko, 2007) and continued slow recycling of sulfur related to ferrous iron sulfate oxidation processes (Fig. 17).

\section{Conclusion.}

\section{a. Secular changes in sulfur outgassing rates}

Numerous deposits of sulfate-bearing, ancient sedimentary rock, as well as the presence of a sulfurrich global regolith demonstrate that a large cache of $\mathrm{S}$ of likely volcanogenic origins is sequestered in the crust. The mineralogy of these deposits generally suggests they formed under water-limited, acidic aqueous conditions. In this review, we provide some constraints on how and when sulfur was delivered to the surface environment.

Our review makes it clear that volcanic sulfur may have been delivered by volcanoes on Mars but only as a consequence of subaerial volcanism that occurred in a low pressure atmosphere (ie. $<0.1$ bar). The apparent shift on Mars from an early phase, where clay minerals and carbonates formed more widely to a younger period seemingly dominated by sulfate-bearing sedimentary rocks might be linked to a decrease in atmospheric pressure, consistent with elevated sulfur emissions. We must recognize that interpretation of such secular changes on Mars may be non-unique and degassing simulations show that a change in Martian basalt redox state (increasingly oxidizing) or an increase in their water content could also result in enhanced volcanic sulfur outgassing. Changes in source processes might be expected with cooling of the mantle (Baratoux et al., 2011) but our current understanding of Martian igneous petrology is not sufficient to identify secular changes in water content or redox state with any confidence. Accordingly, we conclude that a decrease in average 
venting pressure due to a decrease in atmospheric pressure better explains the emission of significant volcanic sulfur in the atmosphere.

The parallel with the Earth is tempting. Like early Mars, early Earth also had limited surficial sulfur activities. Archean oceans on Earth are believed to be nearly sulfur free whereas the Proterozoic is marked by an increase in the sulfur content of surface waters. Sulfate is the second most abundant anion of modern terrestrial seawater (Lyons and Gill, 2009). Gaillard et al. (2011) suggested that such secular changes in sulfur delivery on Earth must have been related to modifications of the conditions of volcanic degassing rather than to a change in the volcanic source processes. We may adopt a similar model in the case of Mars. Enhanced volcanic sulfur emissions due to changes in atmospheric pressure (Gaillard and Scaillet, 2009) are then likely to have modified the composition of volcanic gases from carbon-dominated to sulfur-dominated. This in turn may have triggered major changes in the surface chemistry and in the nature of sedimentary processes.

\section{b. Sulfur on Mars, what's next?}

In spite of the overwhelming abundance of sulfate on Mars's surface, relatively few studies have addressed the fate of this element in the various Martian reservoirs (except for sedimentary deposits, see review and references in this paper and in McLennan, 2012). Igneous sulfur, volcanic sulfur, atmospheric sulfur and climatic sulfur have each been addressed in some studies, which contrasts with numerous investigations on the fate of $\mathrm{CO}_{2}$ or water and its relationships with ancient climate and surface chemistry (See Forget and Pierrehumbert, 1997; Phillips et al., 2001; Grott et al., 2011). The examination of our current understanding of sulfur cycling and its impact on climate indicates a need of studies that thoroughly integrate igneous fluxes and atmospheric processes; studies that to date are missing.

Fluids that deposited sedimentary sulfates on Mars also deposited chlorine-bearing minerals (Clark et al., 2005; Squyres and Knoll, 2005). The fate of chlorine, like that of sulfur, seems to be connected to acidic brines, abundant and common in the late Noachian. Both sulfur and chlorine most 
likely originate from volcanic emissions (Gaillard and Scaillet, 2009; Filiberto and Treiman, 2009). The volcanic degassing of chlorine is however poorly known. Future work will therefore need to address the systematics of multi-component $(\mathrm{C}-\mathrm{O}-\mathrm{H}-\mathrm{S}-\mathrm{Cl})$ volcanic degassing from Martian basalts.

The environmental conditions responsible for sulfate deposits on Mars have been addressed recently (King et al., 2004; Tosca et al., 2005; Berger et al., 2009; McLennan, 2011) but our review reveals that many of the driving processes remain to be determined. Combined experimentation and thermodynamic/kinetic modeling will allow for the most significant progress. But it remains uncertain the degree to which evaporation or acidic alteration or both are responsible for sedimentary sulfate deposits. The relationship between acidity and redox state of surface waters is also controversial. Finally, the possibility of sulfurous acids rather than sulfuric acids needs to be addressed in greater detail. The occurrence of acidic conditions in water expelled from mines, that are related to elevated discharge of sulfuric acidic (Nordstrom, 2011), may be interesting to further investigate as an analogue to Martian brines (Burns, 2003; King and McSween, 2005). The sulfuric acids in such water nevertheless derive from oxidation of pyrite. This is an important difference with the Martian context where most, if not all, of the sulfuric acid may derive from volcanic $\mathrm{SO}_{2}$ (Berger et al., 2009).

In spite of the many uncertainties, an emerging picture is that martian basalts are poor in $\mathrm{CO}_{2}$ and poor in water (McCubbin et al., 2010), whereas they are rich in S (Gaillard and Scaillet, 2009) and in $\mathrm{Cl}$ (Filiberto and Treiman, 2009), in comparison to Earth's basaltic rocks. This conclusion needs confirmation but it may indeed explain the S and Cl-rich nature of Mars's surface, which contrasts with the $\mathrm{H}_{2} \mathrm{O}$ and $\mathrm{CO}_{2}$ rich Earth's surface. The implications for the emergence of life and conditions favorable to that emergence need to be discussed in light of these fundamental geochemical differences, whose origin is intimately tied to planet formation and how volatiles (C-O$\mathrm{H}-\mathrm{S}-\mathrm{Cl}$ ) have been accreted to and/or lost during planetary accretion and evolution. 


\section{Acknowledgment.}

F. Gaillard is supported by the ERC grant \#279790. We acknowledge the editorial handling of Mike Toplis and the helpful reviews by K. Righter, M. Zolotov, and P. King.

\section{References}

A. Aiuppa, M. Burton, T. Caltabiano, G. Giudice, S. Guerrieri, M. Liuzzo, F. Mure, G. Salerno, Unusually large magmatic $\mathrm{CO}_{2}$ gas emissions prior to a basaltic paroxysm. Geophysical Research Letters 37, L17303 (2010) doi:10.1029/2010GL043837.

C. Allegre, G. Manhes, E. Lewin, Chemical composition of the Earth and the volatility control on planetary genetics. Earth and Planetary Science Letters 185, 49-69 (2001).

J. C. Andrews-Hanna, K.W. Lewis, Early Mars hydrology: 2. Hydrological evolution in the Noachian and Hesperian epochs. Journal of Geophysical Research-Planets, 116, (2011).

S. Barabash, A. Fedorov, R. Lundin, J.A. Sauvaud, Martian Atmospheric Erosion Rates. Science 315, 501-503 (2007).

D. Baratoux, M.J. Toplis, M. Monnereau, O. Gasnault, Thermal history of Mars inferred from orbital geochemistry of volcanic provinces. Nature 472, 338-341 (2011) doi: 10.1038/nature09903.

H. Behrens, F. Gaillard, Geochemical Aspects of Melts: Volatiles and Redox Behavior. Elements 2, 275-280 (2006).

G. Berger, M.J. Toplis, E. Treguier, C. d'Uston, P. Pinet, Evidence in favor of ephemeral and transient water during alteration at Meridiani Planum, Mars. Amer. Mineral. 94, 1279-1282 (2009).

R.A. Berner, Chemical weathering and its effects on atmospheric $\mathrm{CO} 2$ and climate. Reviews in Mineralogy, 31, 565-583 (1995). 
R.A. Berner, GEOCARBSULF: A combined model for Phanerozoic atmospheric $\mathrm{O}(2)$ and $\mathrm{CO}(2)$. Geochimica et Cosmochimica Acta 70, 5653-566 (2005).

J.P. Bibring, et al., Global mineralogical and aqueous mars history derived from OMEGA/Mars express data, Science, 312, 400-404 (2006).

J.P. Bibring, et al., Coupled ferric oxides and sulfates on the Martian surface, Science, 317(5842), 1206-1210 (2007).

J.L. Bishop, et al., Mineralogy of Juventae Chasma: Sulfates in the light-toned mounds, mafic minerals in the bedrock, and hydrated silica and hydroxylated ferric sulfate on the plateau, Journal of Geophysical Research-Planets, 114 (2009).

J. Brückner, G. Dreibus, R. Gellert, S.W. Squyres, H. Wänke, A. Yen, and J. Zipfel, Mars Exploration Rovers: Chemical compositions by the APXS. In: J. F. Bell III (ed.) The Martian Surface: Composition, Mineralogy, and Physical Properties. Cambridge University Press (Cambridge), pp. 58-101 (2008).

M.A. Bullock, J.M. Moore, Atmospheric conditions on early Mars and the missing layered carbonates, Geophysical Research Letters 34, L19201, (2007) doi:10.1029/2007GL030688.

A.S. Buono, D. Walker, The Fe-rich liquidus in the Fe-FeS system from 1 bar to $10 \mathrm{GPa}$. Geochimica et Cosmochimica Acta 75, 2072-2087 (2011).

A. Burgisser, B. Scaillet, Redox evolution of a degassing magma rising to the surface. Nature. 445, 194-197 (2007).

D.E. Canfield, The evolution of the Earth surface sulfur reservoir. American Journal of Science 304, 839-861, (2004).

J. Carter, F. Poulet, A. Ody, J. P. Bibring, and S. Murchie, Global Distribution, composition and setting of hydrous minerals on Mars: a reappraisal, in Lunar and Planetary Science Conference, edited, p. 2593 (2011).

N.L. Chabot, Sulfur contents of the parental metallic cores of magmatic iron meteorites. Geochimica et Cosmochimica Acta 68, 3607-3618 (2004). 
M.G. Chapman, K.L. Tanaka, Interior trough deposits on Mars: Subice volcanoes?, Journal of Geophysical Research-Planets 106(E5), 10087-10100 (2001).

V. Chevrier, J.-P. Lorand, V. Sautter, Sulfide petrology of four nakhlites: Northwest Africa 817, Northwest Africa 998, Nakhla, and Governador Valadares. Meteoritics and Planetary Science 46, 769-784 (2011) doi: 10.1111/j.1945-5100.2011.01189.x.

V. Chevrier, F. Poulet, J.-P. Bibring, Early geochemical environment of Mars as determined from thermodynamics of phyllosilicates. Nature 448, 60-63 (2007) doi:10.1038/nature05961.

P.R. Christensen, et al., Detection of crystalline hematite mineralization on Mars by the Thermal Emission Spectrometer: Evidence for near-surface water, Journal of Geophysical ResearchPlanets 105(E4), 9623-9642 (2000).

P.R. Christensen, R. V. Morris, M. D. Lane, J. L. Bandfield, M. C. Malin, Global mapping of Martian hematite mineral deposits: Remnants of water-driven processes on early Mars, Journal of Geophysical Research-Planets 106(E10), 23873-23885 (2001).

B.C. Clark, A. K. Baird, H. J. Rose jr., P. Toulmin III, R. P. Christian, W. C. Kelliher, A. J. Castro, C. D. Rowe, K. Keil, G. R. Huss, The Viking X Ray Fluorescence Experiment: Analytical Methods and Early Results. J. Geophys. Res., 82(28), 4577-4594 (1977) doi:10.1029/JS082i028p04577.

B.C. Clark, A.K. Baird, Is the martian lithosphere sulfur rich. Journal of Geophysical Research 84, 8395-8403 (1979).

B.C. Clark, Geochemical Components in Martian Soil, Geochimica et Cosmochimica Aacta 57, 45754581 (1993) doi: 10.1016/0016-7037(93)90183-W.

B.C. Clark, R.V. Morris et al., Chemistry and mineralogy of outcrops at Meridiani Planum, Earth and Planetary Science Letters 240(1), 73-94 (2005).

E.A. Cloutis, et al., Detection and discrimination of sulfate minerals using reflectance spectroscopy, Icarus 184(1), 121-157 (2006).

R.A. Craddock, R. Greeley, Minimum estimates of the amount and timing of gases released into the martian atmosphere from volcanic eruptions, Icarus 204, 512-526 (2009). 
V. Debaille, A. D.Brandon, C.O'Neill, Q.-Z.Yin, B. Jacobsen, Early martian mantle overturn inferred from isotopic composition of nakhlite meteorites. Nature Geoscience 2, 548-552 (2009) DOI: 10.1038/NGEO579.

E. Dehouck, V. Chevrier, A. Gaudin, N. Mangold, P.-E. Mathé, P. Rochette, Evaluating the role of sulfide-weathering in the formation of sulfates or carbonates on Mars. Geochimica et Cosmochimica Acta 90, 47-63 (2012).

J.E. Dixon, D.A. Clague, P. Wallace, R. Poreda, Volatiles in alkalic basalts from the North Arch volcanic field, Hawaii: Extensive degassing of deep submarine-erupted alkalic series lavas. Journal of Petrology 38, 911-939 (1997).

G. Dreibus, H. Palme, Cosmochemical constraints on the sulfur content in the Earth's core. Geochimica and Cosmochimica Acta 60, 1125-1130 (1996).

G. Dreibus, H. Wanke, Mars, a volatile-rich planet. Meteoritics 20, 367-381 (1985).

D.S. Ebel, Sulfur in Extraterrestrial Bodies and the Deep Earth. In Sulfur in Magmas and Melts: its importance for Natural and technical Processes. Reviews in Mineralogy \& Geochemistry 73, 315$336,(2010)$.

B.L. Ehlmann, J.F. Mustard, S.L. Murchie, F.F. Poulet, J.L. Bishop, A.J. Brown, W.M. Calvin, R. N. Clark, D. J. D. Marais, R.E. Milliken, L.H.Roach, T.L. Roush, G.A. Swayze, J.J. Wray, Orbital Identification of Carbonate-Bearing Rocks on Mars, Science 322, 1828-1832 (2008).

B.L. Ehlmann et al., Space Sci. Rev. (2012, this issue). doi:

L.T. Elkins-Tanton, P.C. Hess, E.M. Parmentier, Possible formation of ancient crust on Mars through magma ocean processes. Journal of Geophysical Research 110, E12S01, (2005) doi:10.1029/2005JE002480.

S. Fabre, G. Berger, A. Nédélec, Continental weathering under high- $\mathrm{CO}_{2}$ atmospheres during Precambrian times. G-cubed 12, (2011) doi:10.1029/2010GC003444

A.G. Fairen, D. Fernandez-Remolar, J.M. Dohm, V.R. Baker, R. Amils, Inhibition of carbonate synthesis in acidic oceans on early Mars. Nature 431, 423-426, (2004). 
J. Farquhar, J. Savrino, T.L. Jackson, M.H. Thiemnes, Evidence of atmospheric sulfur in the martian regolith from sulfur isotopes in meteorites, Nature 404, 50-52 (2000) doi:10.1038/35003517.

W.H. Farrand, T.D. Glotch, J.W. Rice, J.A. Hurowitz, G.A. Swayze, Discovery of jarosite within the Mawrth Vallis region of Mars: Implications for the geologic history of the region, Icarus 204(2), 478-488 (2009).

C.I. Fassett, J.W. Head, Sequence and timing of conditions on early Mars. Icarus 211, 1204-1214 (2011).

Y. Fei, C.M. Bertka, L.W. Finger, High pressure iron sulfur compound, $\mathrm{Fe}_{3} \mathrm{~S}_{2}$, and melting relations in the Fe-FeS system. Science 275, 1621-1623 (1997).

J. Filiberto, A.H. Treiman, Martian magmas contained abundant chlorine, but little water, Geology 37, p. 1087-1090 (2009) doi: 10.1130/G30488A.1

C.J.B. Fincham, F.D. Richardson, The behaviour of sulfur in silicate and aluminate melts. Proc. R. Soc. London 223A, 40-61 (1954).

K.E. Fishbaugh, F. Poulet, V. Chevrier, Y. Langevin, and J. P. Bibring, On the origin of gypsum in the Mars north polar region, Journal of Geophysical Research-Planets, 112(E7) (2007).

J. Flahaut, C. Quantin, P. Allemand, and P. Thomas, Morphology and geology of the ILD in Capri/Eos Chasma (Mars) from visible and infrared data, Icarus 207(1), 175-185 (2010a).

J. Flahaut, , C. Quantin, P. Allemand, P. Thomas, and L. Le Deit, Identification, distribution and possible origins of sulfates in Capri Chasma (Mars), inferred from CRISM data, Journal of Geophysical Research-Planets, 115 (2010b).

C.N. Foley, T.E. Economou, R.N. Clayton, J. Brückner, G. Dreibus, R. Rieder, H. Wänke, Martian surface chemistry: APXS results from the Pathfinder landing site. In: J. F. Bell III (ed.) The Martian Surface: Composition, Mineralogy, and Physical Properties. Cambridge University Press (Cambridge), pp. 35-57 (2008).

F. Forget, R.T. Pierrehumbert, Warming early Mars with carbon dioxide clouds that scatter infrared radiation. Science 278, 1273-1276 (1997). 
F. Fueten, J. Flahaut, L. Le Deit, R. Stesky, E. Hauber, and K. Gwinner, Interior layered deposits within a perched basin, southern Coprates Chasma, Mars: Evidence for their formation, alteration, and erosion, Journal of Geophysical Research-Planets 116 (2011).

F. Gaillard, B. Scaillet, The sulfur content of volcanic gases on Mars. Earth and Planetary Science Letters 279, 34-43 (2009).

F. Gaillard, B. Scaillet, N.T. Arndt, Atmospheric oxygenation caused by a change in volcanic degassing pressure, Nature 478, 229-232 (2011).

F. Gaillard, B.C. Schmidt, S. Mackwell, C. McCammon, Rate of hydrogen-iron redox exchange in silicate melts and glasses. Geochim. Cosmochim. Acta 67, 2427-2441 (2003b).

F. Gaillard, M. Pichavant, and B. Scaillet, Experimental determination of activities of $\mathrm{FeO}$ and $\mathrm{Fe}_{2} \mathrm{O}_{3}$ components in hydrous silicic melts under oxidizing conditions. Geochim. Cosmochim. Acta 67, 4389-4409 (2003a).

A. Gendrin, N. Mangold, J.P. Bibring, Y. Langevin, B. Gondet, F.Poulet, G. Bonello, C. Quantin, J. Mustard, R. Arvidson, S. LeMouélic, Sulfates in martian layered terrains: the OMEGA/Mars Express view. Science 307, 1587-1591 (2005).

E.K. Gibson, C.B. Moore, T.M. Primus, C.F. Lewis, Sulfur in achondritic meteorites. Meteoritics 20, 503-511 (1985).

T.D. Glotch, A.D. Rogers, Evidence for aqueous deposition of hematite- and sulfate-rich light-toned layered deposits in Aureum and Iani Chaos, Mars. Journal of Geophysical Research-Planets 112(E6) (2007).

T.D. Glotch, A.D. Rogers, Evidence for aqueous deposition of hematite- and sulfate-rich light-toned layered deposits in Aureum and Iani Chaos, Mars, Journal of Geophysical Research-Planets 112(E6) (2007).

T.D. Glotch, P. R. Christensen, Geologic and mineralogic mapping of Aram Chaos: Evidence for a water-rich history, Journal of Geophysical Research-Planets 110(E9) (2005). 
T.D. Glotch, J.L. Bandfield, P.R. Christensen, W.M. Calvin, S.M. McLennan, B.C. Clark, A.D. Rogers, S.W. Squyres, Mineralogy of the light-toned outcrop at Meridiani Planum as seen by the Miniature Thermal Emission Spectrometer and implications for its formation, Journal of Geophysical Research-Planets 111(E12), (2006a).

T.D. Glotch, P.R. Christensen, T. G. Sharp, Fresnel modeling of hematite crystal surfaces and application to martian hematite spherules, Icarus 181(2), 408-418 (2006b).

M. P. Golombek, et al., Erosion rates at the Mars Exploration Rover landing sites and long-term climate change on Mars, J. Geophys. Res., 111(E12), (2006) 1-14.

R. Greeley, B.D. Schneid, Magma generation on Mars: Amounts, rates, and comparisons with Earth, Moon, and Venus. Science 254, 996-998 (1991).

J.L. Griffes, R.E. Arvidson, F. Poulet, A. Gendrin, Geologic and spectral mapping of etched terrain deposits in northern Meridiani Planum, Journal of Geophysical Research-Planets 112(E8) (2007).

M. Grott, A. Morschhauser, D. Breuer, E. Hauber, Volcanic outgassing of CO2 and $\mathrm{H} 2 \mathrm{O}$ on Mars. Earth Planet. Sci. Lett. 308, 391-400 (2011).

J. Grotzinger, et al. (2006), Sedimentary textures formed by aqueous processes, Erebus crater, Meridiani Planum, Mars, Geology 34(12), 1085-1088.

J.P Grotzinger, R.E.Arvidson, J.F. Bell, W. Calvin, B.C. Clark, D.A. Fike, M. Golombek, R. Greeley, A. Haldemann, , K.E. Herkenhoff, B.L. Jolliff, A.H. Knoll, M. Malin, S.M. McLennan, T. Parker, L. Soderblom, J.N. Sohl-Dickstein, S.W. Squyres, N.J. Tosca, W.A. Watters, Stratigraphy, sedimentology and depositional environment of the Burns formation, Meridiani Planum, Mars. Earth Planet. Sci. Lett. 240, 11-72 (2005).

I. Halevy, M.T.Zuber, D.P. Schrag, A sulfur dioxide climate feedback on early mars. Science 318, 1903- (2007) doi: 10.1126/science.1147039.

C.D.K. Herd, L.E. Borg, J.H. Jones, J.J. Papike, Oxygen fugacity and geochemical variations in the martian basalts: Implications for martian basalt petrogenesis and the oxidation state of the upper mantle of Mars. Geochimica et Cosmochimica Acta 66, 11, 2025-2036 (2002). 
C.D.K. Herd, A.H. Treiman, G.A. McKay, C.K. Shearer, Light lithophile elements in martian basalts: Evaluating the evidence for magmatic water degassing. Geochimica et Cosmochimica Acta 69, 2431-2440 (2005).

K.E. Herkenhoff, M.P. Golombek, E.A. Guinness, J.B. Johnson, A. Kusack, L. Richter, R.J. Sullivan, S. Gorevan, In situ observations of the physical properties of the Martian surface. In: J. F. Bell III (ed.) The Martian Surface: Composition, Mineralogy, and Physical Properties. Cambridge Univ. Press (Cambridge), pp. 451-467 (2008).

A. Holzheid, T.L. Grove, Sulfur saturation limits in silicate melts and their implications for core formation scenarios for terrestrial planets. American Mineralogist 87, 227-237 (2002).

J.A. Hurowitz, S.M. McLennan, (2007) A 3.5 Ga record of water-limited, acidic conditions on Mars. Earth and Planetary Science Letters 260, 432-443.

J.A. Hurowitz, W.W. Fischer, N.J. Tosca, R.E. Milliken, Origin of acidic surface waters and the evolution of atmospheric chemistry on early Mars. Nature Geoscience 3, 323-326 (2010).

J.A. Hurowitz, S.M. McLennan, N.J. Tosca, R.E. Arvidson, J.R. Michalski, D.W. Ming, C. Schöder, and S.W. Squyres, In-situ and experimental evidence for acidic weathering on Mars. Journal of Geophysical Research 111, E02S19, (2006) doi:10.1029/2005JE002515.

B.M. Hynek, R.J. Phillips, The stratigraphy of Meridiani Planum, Mars, and implications for the layered deposits' origin. Earth and Planetary Science Letters 274(1-2), 214-220 (2008).

B.M. Hynek, R.E. Arvidson, R.J. Phillips, Geologic setting and origin of Terra Meridiani hematite deposit on Mars. J. Geophys. Res. 107, doi:10.1029/2002JE001891 (2002).

G. Iacono-Marziano, Y. Morizet, E. Le-Trong, F. Gaillard, New experimental data and semi-empirical parameterization of $\mathrm{H} 2 \mathrm{O}-\mathrm{CO} 2$ solubility in mafic melts. Geochimica Cosmochemica Acta (in press) doi: 10.1016/j.gca.2012.08.035.

B.M. Jakosky, R.J., Phillips, Mars' volatile and climate history, Nature 412, 237-244 (2001). 
S.S. Johnson, A.A. Pavlov, M.A. Mischna, Fate of $\mathrm{SO}_{2}$ in the ancient Martian atmosphere: Implications for transient greenhouse warming. Journal of Geophysical Research-Planets 114, E11011 (2009) doi: 10.1029/2008JE003313.

J.R. Johnson, J.F. Bell, E. Cloutis, M. Staid, W.H. Farrand, T. Mccoy, M. Rice, A. Wang, A. Yen, Mineralogic constraints on sulfur-rich soils from Pancam spectra at Gusev crater, Mars, Geophysical Research Letters 34(13), (2007).

S.S. Johnson, M.A. Mischna, T. L. Grove, M. T. Zuber, Sulfur-induced greenhouse warming on early Mars. J. Geophys. Res. 113, E08005 (2008) doi: 10.1029/2007JE002962.

L. Keszthelyi, S. Self, T. Thordarson, Flood lavas on earth, Io and Mars. Journal of the geological society 163, 253-264 (2006) doi: 10.1144/0016-764904-503.

M.R. Kilburn, B.J. Wood, Metal-silicate partitioning and the incompatibility of S and Si during core formation. Earth and Planetary Science Letters 152, 139-148 (1997).

P.L. King, H.Y. McSween, Effects of H2O, pH, and oxidation state on the stability of Fe minerals on Mars, J. Geophys. Res. 110, E12S10 (2005) doi: 10.1029/2005JE002482.

P.L. King, S.M. McLennan, Sulfur on Mars. Elements 6(2), 107-112 (2010).

P.L. King, D.T. Lescinsky, H.W.Nesbitt, The composition and evolution of primordial solutions on Mars, with application to other planetary bodies. Geochimica et Cosmochimica Acta 68, 49935008 (2004)

S.P. Kounaves, et al., Soluble sulfate in the martian soil at the Phoenix landing site, Geophysical Research Letters, 37 (2010).

M.D. Kraft, J. R. Michalski, T. G. Sharp, Effects of pure silica coatings on thermal emission spectra of basaltic rocks: Considerations for Martian surface mineralogy, Geophysical Research Letters 30(24), (2003).

M.D. Lane, P. R. Christensen, Thermal infrared emission spectroscopy of salt minerals predicted for Mars, Icarus 135(2), 528-536 (1998). 
M.D. Lane, J. L. Bishop, M. D. Dyar, P. L. King, M. Parente, B. C. Hyde, Mineralogy of the Paso Robles soils on Mars, American Mineralogist 93(5-6), 728-739 (2008).

Y. Langevin, F. Poulet, J. P. Bibring, and B. Gondet, Sulfates in the north polar region of Mars detected by OMEGA/Mars express, Science 307(5715), 1584-1586 (2005).

L. Le Deit, S. Le Mouelic, O. Bourgeois, J.P. Combe, D. Mege, C. Sotin, A. Gendrin, E. Hauber, N. Mangold, J-P. Bibring, Ferric oxides in East Candor Chasma, Valles Marineris (Mars) inferred from analysis of OMEGA/Mars Express data: Identification and geological interpretation: Journal of Geophysical Research-Planets 113, no. E7 (2008).

L. Le Deit, O. Bourgeois, D. Mege, E. Hauber, S. Le Mouelic, M. Masse, R. Jaumann, J-P. Bibring, Morphology, stratigraphy, and mineralogical composition of a layered formation covering the plateaus around Valles Marineris, Mars: Implications for its geological history, Icarus 208(2), 684-703 (2010).

J. Li, C.B. Agee, Geochemistry of mantle-core differentiation at high pressure. Nature 381, 686-689 (1996).

J. Li, C.B. Agee, Element partitioning constraints on the light element composition of the Earth's core. Geophysical Research Letters 28, 81-84 (2001) doi: 10.1029/2000GL012114

K.A. Lichtenberg, et al., Stratigraphy of hydrated sulfates in the sedimentary deposits of Aram Chaos, Mars, Journal of Geophysical Research-Planets, 115 (2010).

J.-P. Lorand, V. Chevrier, V. Sautter, Sulfide mineralogy and redox conditions in some Shergottites. Met. Planet. Sci. Lett. 40, 1257-1272 2005..

T.W. Lyons, B.C. Gill, Ancient Sulfur Cycling and Oxygenation of the Early Biosphere, Elements 6, 93-99 (2010).

N. Mangold, A. Gendrin, B. Gondet, S. LeMouelic, C. Quantin, V. Ansan, J. P. Bibring, Y. Langevin, P. Masson, G. Neukum, Spectral and geological study of the sulfate-rich region of West Candor Chasma, Mars. Icarus 194(2), 519-543 (2008). 
N. Mangold, L. Roach, R. Milliken, S. Le Mouelic, V. Ansan, J. P. Bibring, P. Masson, J. F. Mustard, S. Murchie, and G. Neukum, A Late Amazonian alteration layer related to local volcanism on Mars. Icarus 207(1), 265-276 (2010).

J.C. Marty, G. Balmino, J. Duron, P. Rosenblatt, S. Le Maistre, A. Rivoldini, V. Dehant, T. Van Hoolst, Martian gravity field model and its time variations from MGS and Odyssey data. Planetary and Space Science 57, 350-363 (2009).

M. Masse, S. Le Mouelic, O. Bourgeois, J-P. Combe, L. Le Deit, C. Sotin, J.-P. Bibring, B. Gondet, Y. Langevin, Mineralogical composition, structure, morphology, and geological history of Aram Chaos crater fill on Mars derived from OMEGA Mars Express data. Journal of Geophysical Research-Planets 113(E12) (2008)

M. Masse, O. Bourgeois, S. Le Mouelic, C. Verpoorter, L. Le Deit, J. P. Bibring, Martian polar and circum-polar sulfate-bearing deposits: Sublimation tills derived from the North Polar Cap, Icarus, 209(2), 434-451 (2010).

M. Masse, O. Bourgeois, S. Le Mouelic, C. Verpoorter, A. Spiga, L. Le Deit, Wide distribution and glacial origin of polar gypsum on Mars, Earth and Planetary Science Letters 317, 44-55 (2012).

J. Mavrogenes, H.S.C. O’Neill, The relative effects of pressure, temperature and oxygen fugacity on the solubility of sulfide in magmas. Geochimica Cosmochimica Acta 63, 1173-1180 (1999).

T. McCollom, B.M. Hynek, A volcanic environment for bedrock diagenesis at Meridiani Planum on Mars. Nature, 438 (2005).

F.M. McCubbin, A. Smirnov, H. Nekvasil, J. Wang, E. Hauri, D.H. Lindsley, Hydrous magmatism on Mars: A source of water for the surface and subsurface during the Amazonian. Earth and Planetary Science Letters 292, 132-138 (2010).

F.M. McCubbin, E.H. Hauri, S.M. Elardo, K.E. Vander Kaaden, J.H. Wang, C.K. Shearer, Hydrous melting of the martian mantle produced both depleted and enriched shergottites. Geology 40, 683686 (2012) doi: 10.1130/G33242.1. 
W.F. McDonough, S.S. Sun, The composition of the Earth. Chemical Geology. 120, 1125-1130 (1995).

A.S. McEwen, M. C.Malin, M. H. Carr, W. K. Hartmann, Voluminous volcanism on early Mars revealed in Valles Marineris. Nature 397, 584-586 (1999).

S.M. McLennan, J.P. Grotzinger, The sedimentary rock cycle of Mars. In: J. F. Bell III (ed.) The Martian Surface: Composition, Mineralogy, and Physical Properties. Cambridge Univ. Press (Cambridge), pp. 541-577 (2008).

S.M. McLennan, J.P. Grotzinger, J.A. Hurowitz, N. J. Tosca, Sulfate geochemistry and the sedimentary rock record of Mars. In: Workshop on Martian Sulfates as Records of Atmosphericfluid-Rock Interactions. p. 54. LPI Contribution No. 1331, The Lunar \& Planetary Institute, Houston (2006).

S.M. McLennan, Geochemistry of sedimentary processes on mars. In: J. P. Grotzinger and R. E. Milliken (eds.) Mars Sedimentology, SEPM Special Publication (2012).

S.M. McLennan, J.F. Bell, W.M. Calvin, P.R. Christensen, B.C. Clark, P.A. de Souza, J. Farmer, W.H. Farrand, D.A. Fike, R. Gellert, A. Ghosh, T.D. Glotch, J.P., Grotzinger, B., Hahn, K.E.Herkenhoff, , J.A., Hurowitz, J.R., Johnson, S.S., Johnson, B., Jolliff, G., Klingelhöfer, A.H., Knoll, Z., Learner, M.C., Malin, H.Y., McSween, J., Pocock, S.W., Ruff, L.A., Soderblom, S.W., Squyres, N.J., Tosca, W.A., Watters, M.B., Wyatt, A., Yen, Provenance and diagenesis of the evaporite-bearing Burns formation, Meridiani Planum, Mars. Earth Planet. Sci. Lett. 240, 95-121 (2005).

H.Y. McSween, G.J. Taylor, M. B. Wyatt, Elemental composition of the Martian crust. Science 324, 736-739 (2009).

H.Y. McSween, I.O. McGlynn, A.D. Rogers, Determining the modal mineralogy of Martian soils, Journal of Geophysical Research-Planets 115 (2010). 
H.Y. McSween, T.L. Grove, R.C. Lentz, J.C. Dann, A.H. Holzheid, L.R. Riciputi, J.G. Ryan, Geochemical evidence for magmatic water within Mars from pyroxenes in the Shergotty meteorite. Nature 409, 487-490 (2001).

H.J. Melosh, A.M. Vickery, Impact erosion of the primordial atmosphere of Mars, Nature 338,487489 (1989).

J.M. Metz, J.P. Grotzinger, D.M. Rubin, K.W. Lewis, S.W. Squyres, J.F. Bell, , Sulfate-rich eolian and wet interdune deposits, Erebus crater, Meridiani Planum, Mars. J. Sed. Research 79, 247-264 (2009).

C. Jr. Meyer, Website: http://curator.jsc.nasa.gov/antmet/mmc/index.cfm (2008).

J.R. Michalski, P.B. Niles, Deep crustal carbonate rocks exposed by meteor impact on Mars. Nature Geoscience 3, 751-755 (2010).

C. Milbury, G. Schubert, Search for the global signature of the Martian dynamo. J. Geophys. Res. 115, E10010 (2010).

R.E. Milliken, et al., Opaline silica in young deposits on Mars, Geology, 36(11), 847-850 (2008).

R.E. Milliken, J.P. Grotzinger, B.J. Thomson, Paleoclimate of Mars as captured by the stratigraphic record in Gale Crater, Geophysical Research Letters 37, (2010).

A.G. Monders, E. Médard, T.L. Grove, Phase equilibrium investigations of the Adirondack class basalts from the Gusev plains, Gusev crater, Mars. Meteoritics \& Planetary Science 42, 131-148 (2007).

G. Morard, D. Andrault, N. Guignot, C. Sanloup, M. Mezouar, S. Petitgirard, G. Fiquet, In situ determination of $\mathrm{Fe}-\mathrm{Fe}_{3} \mathrm{~S}$ phase diagram and liquid structural properties up to $65 \mathrm{GPa}$. Earth and Planetary Science Letters 272, 620-626 (2008).

Y. Morizet, M. Paris, F. Gaillard, B. Scaillet, C-O-H fluid solubility in haplobasalt under reducing conditions: An experimental study. Chem. Geol. 279, 1-16, (2010).

S.L. Murchie, J.F.Mustard, BL Ehlmann, RE Milliken, JL Bishop, NK McKeown, EZN Dobrea, FP Seelos, DL Buczkowski, SM Wiseman, RE Arvidson, JJ Wray, G Swayze, RN Clark, DJD 
Marais, AS McEwen, JP Bibring, A synthesis of Martian aqueous mineralogy after 1 Mars year of observations from the Mars Reconnaissance Orbiter, Journal of Geophysical Research-Planets 114, E00D06 (2009a) doi: 10.1029/2009JE003342.

S.L. Murchie, L Roach, F Seelos, R Milliken, J Mustard, R Arvidson, S Wisema, K Lichtenberg, J Andrews-Hanna, J Bishop, JP Bibring, M Parente, Morris, R., Evidence for the origin of layered deposits in Candor Chasma, Mars, from mineral composition and hydrologic modeling, Journal of Geophysical Research-Planets 114, E00D05 (2009b) doi: 10.1029/2009JE003343.

D.S. Musselwhite, H.A. Dalton, W.S. Kiefer, A.H. Treiman, Experimental petrology of the basaltic shergottite Yamato-980459: Implications for the thermal structure of the martian mantle. Meteoritics \& Planetary Science 41, 1271-1290 (2006).

P.B. Niles et al., Space Sci. Rev. (2012, this issue). doi:

P.B. Niles, J. Michalski, Meridiani Planum sediments on Mars formed through weathering in massive ice deposits, Nature Geoscience, 2(3), 215-220 (2009).

K. Nishida, H. Terasaki, E. Ohtani, A. Suzuki, The effect of sulfur content on density of the liquid FeS at high pressure. Physics and Chemistry of Minerals 35, 417-423 (2008).

D.K. Nordstrom (2011) Mine waters: Acidic to circumneutral. Elements 7, 393-398.

H.S.C. O’Neill, J. Mavrogenes, The sulfide saturation capacity and the sulfur content at sulfide saturation of silicate melts at $1400^{\circ} \mathrm{C}$ and 1 bar. Journal of Petrology 43, 1049- 1087 (2002).

E. Ohtani, H. Yurimoto, S. Seto Element partitioning between metallic liquid, silicate liquid, and lower-mantle minerals: Implications for core formation of the Earth. Physics of the Earth and Planetary interiors 100, 97-114 (1997).

C.H. Okubo, K.W. Lewis, A.S. McEwen, R.L. Kirk, Relative age of interior layered deposits in southwest Candor Chasma based on high-resolution structural mapping, Journal of Geophysical Research-Planets, 113(E12) (2008). 
R.J. Phillips, M.T. Zuber, S.C. Solomon, M.P. Golombek, B.M. Jakosky, W.B. Banerdt, D.E. Smith, R.M.E. Williams, B.M. Hynek, O. Aharonson, S.A. Hauck, Ancient geodynamics and global-scale hydrology on Mars. Science 291, 2587-2591 (2001).

F. Poulet, S. Erard, Nonlinear spectral mixing: Quantitative analysis of laboratory mineral mixtures, Journal of Geophysical Research-Planets, 109(E2), (2004).

F. Poulet, C. Gomez, J.P. Bibring, Y. Langevin, B. Gondet, P. Pinet, G. Belluci, J. Mustard, Martian surface mineralogy from Observatoire pour la Mineralogie, l'Eau, les Glaces et l'Activite on board the Mars Express spacecraft (OMEGA/MEx): Global mineral maps, Journal of Geophysical Research-Planets, 112(E8) (2007).

F. Poulet, J. P. Bibring, Y. Langevin, J. F. Mustard, N. Mangold, M. Vincendon, B. Gondet, P. Pinet, J. M. Bardintzeff, and B. Platevoet, Quantitative compositional analysis of martian mafic regions using the MEx/OMEGA reflectance data, Icarus 201(1), 69-83 (2009).

F. Poulet, R. E. Arvidson, C. Gomez, R. V. Morris, J. P. Bibring, Y. Langevin, B. Gondet, and J. Griffes, Mineralogy of Terra Meridiani and western Arabia Terra from OMEGA/MEx and implications for their formation, Icarus 195(1), 106-130 (2008).

C. Quantin, P. Allemand, N. Mangold, and C. Delacourt, Ages of Valles Marineris (Mars) landslides and implications for canyon history. Icarus 172(2), 555-572 (2004).

K. Righter, K. Pando, L.R. Danielson, Experimental evidence for sulfur-rich martian magmas: Implications for volcanism and surficial sulfur sources. Earth and Planetary Science Letters 288, 235-243 (2009).

K. Righter, M.J. Drake, Core formation in Earth's Moon, Mars, and Vesta. Icarus 124, 513-529 (1996).

K. Righter, M.J. Drake, E. Scott, Compositional relationships between meteorites and terrestrial planets, in: Lauretta, D., Leshin, L. \& McSween, H.Y. (Eds.), In Meteorites and the Early Solar System II, D. S. Lauretta and H. Y. McSween, Jr., eds, pp. 803-828. Univ. Arizona Press (2006). 
K. Righter, N.L. Chabot, Moderately and slightly siderophile element constraints on the depth and extent of melting in early Mars. Meteoritics and Planetary Science 46, 157-176 (2011) doi: 10.1111/j.1945-5100.2010.01140.x

K. Righter, M. Humayun, Volatile Siderophile Elements in Shergottites: Constraints on Core Formation and Magmatic Degassing. 43 ${ }^{\text {rd }}$ LPSC Program, abstract number 2465.

A. Rivoldini, T. Van Hoolst, O. Verhoeven, A. Mocquet, V. Dehant, Geodesy constraints on the interior structure and composition of Mars. Icarus 213(2), 451-472 (2011).

L.H. Roach, , J. F. Mustard, G. Swayze, R. E. Milliken, J. L. Bishop, S. L. Murchie, K. Lichtenberg, Hydrated mineral stratigraphy of Ius Chasma, Valles Marineris. Icarus 206(1), 253-268 (2010b).

L.H. Roach, J. F. Mustard, M. D. Lane, J. L. Bishop, S. L. Murchie, Diagenetic haematite and sulfate assemblages in Valles Marineris. Icarus 207(2), 659-674 (2010a).

L. Rose-Weston, J.M. Brenan, Y. Fei, R.A. Secco, D.J. Frost, Effect of pressure, temperature, and oxygen fugacity on the metal-silicate partitioning of Te, Se, and S: Implications for earth differentiation Source. Geochimica Cosmochimica acta 73, 4598-4615 (2009).

A.E. Saal , E.H. Hauri , C.H. Langmuir, M.R. Perfit, Vapour undersaturation in primitive mid-oceanridge basalt and the volatile content of Earth's upper mantle. Nature 419, 451-455 (2002).

P. Schiffman, R. Zierenberg, N. Marks, J.L. Bishop, M.D. Dyar, Acid-fog deposition at Kilauea volcano: A possible mechanism for the formation of siliceous-sulfate rock coatings on Mars. Geology 34, 921-92 (2006).

E. Sefton-Nash, D.C. Catling, Hematitic concretions at Meridiani Planum, Mars: Their growth timescale and possible relationship with iron sulfates. Earth and Planetary Science Letters 269, 365-375 (2008).

M. Settle, Formation and deposition of volcanic sulfate aerosols on Mars. Journal of Geophysical Research 84, 8343-8354 (1979).

P.F. Shi, S.K. Saxena, Thermodynamic modelling of the C-H-O-S fluid system. American Mineralogist 77, 1038-1049 (1992). 
S.W. Squyres, A. H. Knoll, Sedimentary rocks at Meridiani Planum: Origin, diagenesis, and implications for life on Mars, Earth and Planetary Science Letters 240(1) 1-10 (2005).

S.W. Squyres, et al., The Spirit Rover's Athena science investigation at Gusev crater, Mars, Science 305, 794-799 (2004).

S.W. Squyres, R.E. Arvidson, J.F. Bell, F. Calef, B.C. Clark, B.A. Cohen, L.A. Crumpler, P.A. de Souza, W. H. Farrand, R. Gellert, J. Grant, K.E. Herkenhoff, J.A. Hurowitz, J.R. Johnson, B.L. Jolliff, A.H. Knoll, R. Li, S.M. McLennan, D.W. Ming, D.W. Mittlefehldt, T.J. Parker, G. Paulsen, M.S. Rice, S.W. Ruff, C. Schröder, A.S. Yen, K. Zacny, Ancient impact and aqueous processes at Endeavour crater, Mars. Science 336, 570-576 (2012).

B.D. Stanley, M.M. Hirschmann, A.C. Withers, CO2 solubility in Martian basalts and Martian atmospheric evolution. Geochimica Cosmochimica acta 75, 5987-6003 (2011).

A.J. Stewart, M.W. Schmidt, W. Van-Westrenen, C. Liebske, Mars: A New Core-Crystallization Regime. Science 316, 1323-1325 (2007).

R.B. Symonds, T.M. Gerlach, M.H. Reed, Magmatic gas scrubbing: implications for volcano monitoring. Journal of Volcanology and Geothermal Research 108, 303-341 (2001).

R.B. Symonds, W.I. Rose, G.J.S. Bluth, T.M. Gerlach, Volcanic-gas studies: methods, results, and applications, in: Carroll, M.R., and Holloway, J.R. (Eds), Volatiles in magmas, Reviews in Mineralogy, v. 30, p.p. 1-66, (1994).

K.L. Tanaka, J.A. Skinner, T.M. Hare, T. Joyal, A. Wenker, Resurfacing history of the northern plains of Mars based on geologic mapping of Mars Global Surveyor data: Journal of Geophysical Research-Planets, 108, no. E4 (2003).

S.R. Taylor, S.M. McLennan, Planetary Crusts: Their Composition, Origin and Evolution. Cambridge University Press (Cambridge) 378pp, (2009). 
E. Tertre, S. Castet, G. Berger, M. Loubet, E. Giffaut, Surface chemistry of kaolinite and Namontmorillonite at 25 and $60^{\circ} \mathrm{C}$ : Experimental study and modelling. Geochim. Cosmochim. Acta 70, 4579-4599 (2006).

B. J. Thomson, N.T. Bridges, R. Milliken, A. Baldridge, S.J. Hook, J.K. Crowley, G.M. Marion, C.R. de Souza, A.J. Brown, C.M. Weitz, Constraints on the origin and evolution of the layered mound in Gale Crater, Mars using Mars Reconnaissance Orbiter data. Icarus 214, 413-432 (2011).

F. Tian, M.W. Claire, J.D. Haqq-Misra, M. Smith, D.C. Crisp, D. Catling, K. Zahnle, J.F. Kasting, Photochemical and climate consequences of sulfur outgassing on early Mars, Earth and Planetary Science Letters 295, 412-418, (2009) doi: 10.1016/j.epsl.2010.04.016.

J.N. Tosca, S.M.,McLennan, B.C. Clark, J.P. Grotzinger, J.A. Hurowitz, A.H. Knoll, C. Schröder, S.W. Squyres, Geochemical modeling of evaporation processes on Mars: insight from the sedimentary record at Meridiani Planum. Earth Planet. Sci. Lett. 240, 122-148 (2005).

N.J. Tosca, S.M. McLennan, M.D. Dyar, E.C. Sklute, F.M. Michel, Fe oxidation processes at Meridiani Planum and implications for secondary Fe mineralogy on Mars. J. Geophys. Res. 113, E05005, (2008) doi:10.1029/2007JE003019.

E. Tréguier, et al., Overview of Mars surface geochemical diversity through APXS data multidimensional analysis: first attempt at modelling rock alteration. J. Geophys. Res. 113, E12S34, (2008) doi:10.1029/2007JE003010

M. Wadhwa, Redox states of Mars' upper mantle and crust from Eu anomalies in shergottite pyroxenes. Science, 291, 1527 - 1530, (2001) doi:10.1126/science.1057594.

P.J. Wallace, Volatiles in subduction zone magmas: concentrations and fluxes based on melt inclusion and volcanic gas data. Journal of Volcanology and Geothermal Research 140, 217-240 (2005).

A. Wang, et al., Sulfate deposition in subsurface regolith in Gusev crater, Mars, Journal of Geophysical Research-Planets, 111(E2), (2006).

C. Wang, J. Hirama, T. Nagasaka, S. Ban-Ya, Phase equilibria of liquid Fe-S-C ternary. ISIJ International. 11, 1292-1299 (1991). 
H. Wänke, G. Dreibus, Chemistry and accretion history of Mars. Phil. Trans. Royal Soc. London A 359, 285-293 (1994).

C.M. Weitz, J.L. Bishop, P. Thollot, N. Mangold, L.H. Roach, Diverse mineralogies in two troughs of Noctis Labyrinthus, Mars. Geology 39, 899-902 (2011).

C.M. Weitz, R.E. Milliken, J.A. Grant, A.S. McEwen, R.M.E. Williams, J.L. Bishop, B.J. Thomson, Mars Reconnaissance Orbiter observations of light-toned layered deposits and associated fluvial landforms on the plateaus adjacent to Valles Marineris. Icarus 205(1), 73-102 (2010).

L. Wendt, C. Gross, T. Kneiss1, M. Sowe, J.P. Combe, L. LeDeit, P.C. McGuire, G. Neukum, Sulfates and iron oxides in Ophir Chasma, Mars, based on OMEGA and CRISM observations. Icarus 213(1), 86-103 (2011).

L. Wilson, J.W. Head, Mars: review and analysis of volcanic eruption theory and relationships to observed landforms. Rev. Geophys. 32, 221-264 (1994).

S.M. Wiseman, R.E. Arvidson, R.V. Morris, F. Poulet, J.C. Andrews-Hanna, J.L. Bishop, S.L. Murchie, F.P. Seelos, D. Des Marais, J.L. Griffes, Spectral and stratigraphic mapping of hydrated sulfate and phyllosilicate-bearing deposits in northern Sinus Meridiani, Mars. Journal of Geophysical Research-Planets 115 (2010).

S.M. Wiseman, et al., Phyllosilicate and sulfate-hematite deposits within Miyamoto crater in southern Sinus Meridiani, Mars, Geophysical Research Letters 35 (2008).

J.J. Wray, E.Z.N. Dobrea, R.E. Arvidson, S.M. Wiseman, S.W. Squyres, A.S. McEwen, J.F. Mustard, S.L. Murchie, Phyllosilicates and sulfates at Endeavour Crater, Meridiani Planum, Mars. Geophysical Research Letters 36 (2009).

J.J. Wray, R.E. Milliken, C.M. Dundas, G.A. Swayze, J.C. Andrews-Hanna, A.M. Baldridge, M. Chojnacki, J.L. Bishop, B.L. Ehlmann, S.L. Murchie, R.N. Clark, F.P. Seelos, L.L. Tornabene, S.W. Squyres, Columbus crater and other possible groundwater-fed paleolakes of Terra Sirenum, Mars. Journal of Geophysical Research-Planets, v. 116 (2011). 
J.J. Wray, S.W. Squyres, L.H. Roach, J.L. Bishop, J.F. Mustard, E.Z.N. Dobrea, Identification of the Ca-sulfate bassanite in Mawrth Vallis, Mars. Icarus 209(2), 416-421 (2010).

R.G. Yen, and 34 co-authors, An integrated view of the chemistry and mineralogy of martian soils. Nature 436, 49-54 (2005).

K. J. Zahnle, The Earth earliest Atmosphere. Elements 2, 217-222 (2006).

J. Zipfel, P. Scherer, B. Spettel, G. Dreibus, L. Schultz, Petrology and chemistry of the new shergottite Dar al Gani 476. Meteoritics \& Planetray Science 35, 95-106 (2000).

M.Y. Zolotov, Origin of acid fluids on Mars: Impacts vs. volcanism. Lunar and Planetary Science, v. XXXVIII, Abstract \#1343, The Lunar and Planetary Institute, Houston (CD-ROM) (2007).

M.Y. Zolotov, M.V. Mironenko, Timing of acid weathering on Mars: A kinetic-thermodynamic assessment. J. Geophys. Res. 112. (2007) doi: 10.1029/2006JE002882.

M.Y. Zolotov, Martian Volcanic Gases: Are they Terrestrial-like? Lunar and Planetary Science XXXIV, abstract number 1795 (2003). 


\section{Table.}

Table 1: Detections of sulfate minerals on Mars from orbital data.

\begin{tabular}{|c|c|c|c|c|c|}
\hline Description & Lat & Long & Elev & Minerals & References \\
\hline Noctis Labrynthis & -11 & 261,7 & 3500 & PHS, MHS, S, P & Weitz et al. 2011 \\
\hline Gale Crater mound & -5 & 137,5 & -4000 & PHS, MHS, P & Thomson et al., 2011; Milliken et al., 2010 \\
\hline \multirow[t]{4}{*}{ Ophir Chasma } & $-4,2$ & 286 & -2000 & PHS, MHS, FeOx & Wendt et al. 2011 \\
\hline & $-4,5$ & 287 & -600 & PHS, MHS, FeOx & Wendt et al. 2011 \\
\hline & $-3,5$ & 287,1 & -2500 & PHS, MHS, FeOx & Wendt et al. 2011 \\
\hline & $-4,4$ & 288,4 & -4500 & PHS, MHS, FeOx & Wendt et al. 2011 \\
\hline Coprates Chasma & -13 & 295,1 & 80 & PHS, MHS & Fueten et al. 2011 \\
\hline Columbus Crater & $-29,4$ & 194 & 900 & PHS, MHS & Wray et al., 2011 \\
\hline Cross Crater & $-30,1$ & 202,4 & 700 & PHS, MHS & Wray et al., 2011 \\
\hline Capris Chasma & $-13,3$ & 312,6 & -1500 & PHS, MHS & Flahaut et al., 2010b; Gendrin et al. 2005 \\
\hline polar till & 82 & 115 & -4500 & PHS & Masse et al. 2010 \\
\hline polar dunes & 82 & 200 & -4200 & PHS & Langevin et al., 2005; Fishbaugh et al., 2007 \\
\hline Mawrth Vallis & 24,2 & 341,6 & -3000 & PHS, MHS & Wray et al., 2010 \\
\hline Mawrth Vallis & 22,9 & 341,5 & -3200 & PHS, MHS & Wray et al., 2010 \\
\hline Mawrth Vallis & 25,4 & 339,7 & -3350 & $\mathrm{~J}$ & Farrand et al., 2009 \\
\hline Mawrth Vallis & 25,5 & 340,7 & -3585 & $\mathrm{~J}$ & Michalski et al., 2011 \\
\hline layered plains deposits & $-8,16$ & 307,3 & 1824 & FeSO4 & Le Deit et al. 2010 \\
\hline Opportunity landing site & $-1,95$ & 354,5 & -1383 & J, PHS & Glotch et al., 2006a \\
\hline \multirow[t]{3}{*}{ Meridiani Plaunum } & 1 & 4 & -1300 & PHS, MHS & Wiseman et al., 2010; Poulet et al., 2008; Wray et al., 2009 \\
\hline & 1 & 1 & -1200 & PHS, MHS & Wiseman et al., 2010; Poulet et al., 2008 \\
\hline & 2 & 358,5 & -1380 & PHS, MHS & Wiseman et al., 2010; Poulet et al., 2009 \\
\hline Aram Chaos & 3 & 339,2 & -2700 & PHS, MHS & Lichtenberg et al. 2010; Glotch and Christensen, 2005; Masse et al., 2008 \\
\hline Phoenix landing site & 68,2 & 234,25 & -4115 & $\mathrm{MgSO} 4, \mathrm{CaSO} 4$ & Kounaves et al. 2010 \\
\hline Noctis Labrynthis & $-7,3$ & 263,9 & 2000 & MHS/PHS/? & Mangold et al. 2010 \\
\hline Ius Chasma & $-8,5$ & 280,6 & -3950 & PHS, MHS, S & Roach et al., $2010 \mathrm{~b}$ \\
\hline layered plains deposits & $-8,3$ & 274,8 & 4280 & $\mathrm{~S}, \mathrm{FeSO} 4$ & Weitz et al. 2010; Le Deit et al., 2010; Milliken et al., 2008 \\
\hline layered plains deposits & $-9,6$ & 280,8 & 3880 & $\mathrm{~S}, \mathrm{FeSO} 4$ & Weitz et al. 2010; Le Deit et al., 2010; Milliken et al., 2008 \\
\hline layered plains deposits & $-6,8$ & 283,5 & 4448 & $\mathrm{~S}, \mathrm{FeSO} 4$ & Weitz et al. 2010; Le Deit et al., 2010; Milliken et al., 2008 \\
\hline layered plains deposits & -4 & 296,5 & 2320 & $\mathrm{~S}, \mathrm{FeSO} 4$ & Weitz et al. 2010; Le Deit et al., 2008 \\
\hline \multirow[t]{2}{*}{ Juventae Chasma } & $-4,4$ & 297,6 & -857 & PHS, MHS & Bishop et al., 2009 \\
\hline & $-4,6$ & 296,9 & -1357 & PHS, MHS & Bishop et al., 2009 \\
\hline \multirow[t]{2}{*}{ S. Highlands } & $-49,2$ & 14,5 & 500 & S-Z & Wray et al., 2009 \\
\hline & $-63,2$ & 18,2 & 2247 & PHS, MHS & Wray et al., 2009 \\
\hline \multirow[t]{3}{*}{ Candor Chasma } & -5 & 283,5 & 550 & PHS, MHS & Murchie et al., 2009b; Mangold et al., 2008; Bibring et al., 2007 \\
\hline & -6 & 283,8 & 3000 & PHS, MHS & Murchie et al., 2009b; Mangold et al., 2008; Bibring et al., 2007 \\
\hline & -6 & 286 & 910 & PHS, MHS & Murchie et al., 2009b; Mangold et al., 2008; Bibring et al., 2007 \\
\hline Miyamoto Crater & $-3,2$ & 352,5 & -1954 & PHS, MHS & Wiseman et al., 2008 \\
\hline Gusev Crater & $-14,57$ & 175,5 & -1920 & $\mathrm{FeSO} 4$ & Lane et al., 2008; Johnson et al., 2007 \\
\hline \multirow[t]{2}{*}{ Melas } & $-10,5$ & 285,2 & -100 & PHS, MHS & Gendrin et al., 2005 \\
\hline & $-12,5$ & 290,3 & -2500 & PHS, MHS & Gendrin et al., 2005 \\
\hline Ophir Chasma & $-4,3$ & 288,3 & -4500 & PHS, MHS & Gendrin et al., 2005 \\
\hline Candor Chasma & $-6,4$ & 288,8 & -2300 & PHS, MHS & Gendrin et al., 2005 \\
\hline Hebes Chasma & $-1,2$ & 284,8 & -3052 & MHS & Gendrin et al., 2005 \\
\hline Capris Chasma & $-13,9$ & 310 & -3690 & PHS, MHS & Gendrin et al., 2005 \\
\hline Iani Chaos & $-1,3$ & 342,3 & -2000 & PHS, MHS & Gendrin et al., 2005; Glotch and Rogers, 2007 \\
\hline Aureum Chaos & $-3,5$ & 332,5 & -3780 & PHS, MHS & Gendrin et al., 2005; Glotch and Rogers, 2007 \\
\hline Arisinoes Chaos & $-7,3$ & 331,6 & -3090 & PHS, MHS & Gendrin et al., 2005; Glotch and Rogers, 2007 \\
\hline
\end{tabular}


Table 2: Sulfur content in the Martian core, mantle and basalts as deduced from partitioning modelling and comparison with Earth. For Mars, estimations are from this study for the Earth, see text for references.

\begin{tabular}{lcc}
\hline Reservoirs & Mars & Earth \\
\hline Basalt / basaltic crust & $3000-5000 \mathrm{ppm}$ & $1000-1500 \mathrm{ppm}$ \\
Mantle & $700-2000 \mathrm{ppm}$ & $100-250 \mathrm{ppm}$ \\
Core & $2-16 \mathrm{wt} \%$ & $0-5 \mathrm{wt} \%$ \\
\hline
\end{tabular}


Table 3: Calculated compositions of volcanic gases in ppm wt of Martian magmas. $\mathrm{T}=1300^{\circ} \mathrm{C}$. Gas compositions are computed following Gaillard et al., (2011), using solubility laws of Iacono-Marziano et al. (2012) for $\mathrm{H}_{2} \mathrm{O}-\mathrm{CO}_{2}$, the work of Gaillard et al (2003b) for $\mathrm{H}_{2}$ and the sulfur capacity formulation from O’Neill and Mavrogenes (2002). Speciation in the C-O-H-S gas phase is computed following Shi and Saxena (1991).

\begin{tabular}{|c|c|c|c|c|}
\hline Pressure of degassing (bar) & 500 & 1 & 0.10 & 0.01 \\
\hline Conditions of magma emplacement & Intrusive magmas & Subaerial ancient Mars & Subaerial recent Mars & Subaerial present-day Mars \\
\hline \multicolumn{5}{|c|}{$I W, 0.01$ wt\% water, 0.02 wt\% carbon dioxide } \\
\hline $\mathrm{H}_{2} \mathrm{O}$ ppm wt & 0 & 3 & 15 & 24 \\
\hline $\mathrm{H}_{2}$ & 0 & 0 & 1 & 3 \\
\hline $\mathrm{H}_{2} \mathrm{~S}$ & 0 & 1 & 3 & 4 \\
\hline $\mathrm{SO}_{2}$ & 0 & 0 & 3 & 20 \\
\hline $\mathrm{S}_{2}$ & 0 & 2 & 21 & 165 \\
\hline $\mathrm{CO}$ & 141 & 168 & 167 & 177 \\
\hline $\mathrm{CO}_{2}$ & 75 & 96 & 98 & 82 \\
\hline \multicolumn{5}{|c|}{$I W, 0.1$ wt $\%$ water, 0.02 wt $\%$ carbon dioxide } \\
\hline $\mathrm{H}_{2} \mathrm{O}$ & 0 & 274 & 427 & 363 \\
\hline $\mathrm{H}_{2}$ & 0 & 14 & 23 & 33 \\
\hline $\mathrm{H}_{2} \mathrm{~S}$ & 0 & 49 & 70 & 50 \\
\hline $\mathrm{SO}_{2}$ & 0 & 6 & 74 & 156 \\
\hline $\mathrm{S}_{2}$ & 0 & 23 & 262 & 770 \\
\hline $\mathrm{CO}$ & 141 & 134 & 138 & 164 \\
\hline $\mathrm{CO}_{2}$ & 74 & 147 & 142 & 100 \\
\hline \multicolumn{5}{|c|}{$I W, 0.4$ wt $\%$ water, 0.02 wt $\%$ carbon dioxide } \\
\hline $\mathrm{H}_{2} \mathrm{O}$ & 7 & 2323 & 2302 & 1952 \\
\hline $\mathrm{H}_{2}$ & 1 & 58 & 86 & 115 \\
\hline $\mathrm{H}_{2} \mathrm{~S}$ & 1 & 334 & 244 & 131 \\
\hline $\mathrm{SO}_{2}$ & 0 & 238 & 616 & 1027 \\
\hline $\mathrm{S}_{2}$ & 0 & 339 & 957 & 1595 \\
\hline $\mathrm{CO}$ & 142 & 93 & 114 & 140 \\
\hline $\mathrm{CO}_{2}$ & 73 & 206 & 172 & 133 \\
\hline \multicolumn{5}{|c|}{ FMQ-1.4, 0.01 wt\% water, 0.08 wt\% carbon dioxide } \\
\hline $\mathrm{H}_{2} \mathrm{O}$ & 0 & 9 & 34 & 39 \\
\hline $\mathrm{H}_{2}$ & 0 & 0 & 1 & 2 \\
\hline $\mathrm{H}_{2} \mathrm{~S}$ & 0 & 2 & 5 & 4 \\
\hline $\mathrm{SO}_{2}$ & 1 & 166 & 332 & 404 \\
\hline $\mathrm{S}_{2}$ & 1 & 176 & 548 & 1078 \\
\hline $\mathrm{CO}$ & 112 & 181 & 262 & 365 \\
\hline $\mathrm{CO}_{2}$ & 559 & 640 & 513 & 352 \\
\hline \multicolumn{5}{|c|}{ FMQ-1.4, 0.1 wt\% water, 0.08 wt\% carbon dioxide } \\
\hline $\mathrm{H}_{2} \mathrm{O}$ & 1 & 389 & 536 & 462 \\
\hline $\mathrm{H}_{2}$ & 0 & 7 & 16 & 26 \\
\hline $\mathrm{H}_{2} \mathrm{~S}$ & 0 & 63 & 69 & 44 \\
\hline $\mathrm{SO}_{2}$ & 0 & 233 & 480 & 625 \\
\hline $\mathrm{S}_{2}$ & 0 & 251 & 744 & 1338 \\
\hline $\mathrm{CO}$ & 78 & 132 & 188 & 252 \\
\hline $\mathrm{CO}_{2}$ & 361 & 435 & 346 & 247 \\
\hline \multicolumn{5}{|c|}{ FMQ-1.4, 0.2 wt\% water, 0.08 wt\% carbon dioxide } \\
\hline $\mathrm{H}_{2} \mathrm{O}$ & 4 & 1076 & 1173 & 999 \\
\hline
\end{tabular}




\begin{tabular}{|c|c|c|c|c|}
\hline $\mathrm{H}_{2}$ & 0 & 18 & 35 & 52 \\
\hline $\mathrm{H}_{2} \mathrm{~S}$ & 1 & 154 & 126 & 72 \\
\hline $\mathrm{SO}_{2}$ & 1 & 431 & 771 & 1053 \\
\hline $\mathrm{S}_{2}$ & 0 & 417 & 966 & 1544 \\
\hline $\mathrm{CO}$ & 98 & 169 & 237 & 309 \\
\hline $\mathrm{CO}_{2}$ & 479 & 553 & 446 & 334 \\
\hline \multicolumn{5}{|c|}{ FMQ-1.4, 0.4 wt\% water, 0.08 wt\% carbon dioxide } \\
\hline $\mathrm{H}_{2} \mathrm{O}$ & 16 & 2533 & 2512 & 2178 \\
\hline $\mathrm{H}_{2}$ & 0 & 42 & 69 & 96 \\
\hline $\mathrm{H}_{2} \mathrm{~S}$ & 3 & 298 & 200 & 102 \\
\hline $\mathrm{SO}_{2}$ & 1 & 781 & 1324 & 1910 \\
\hline $\mathrm{S}_{2}$ & 1 & 601 & 1140 & 1562 \\
\hline $\mathrm{CO}$ & 113 & 184 & 251 & 320 \\
\hline $\mathrm{CO}_{2}$ & 552 & 619 & 513 & 405 \\
\hline \multicolumn{5}{|c|}{ FMQ-O.5, 0.1 wt\% water, 0.08 wt\% carbon dioxide } \\
\hline $\mathrm{H}_{2} \mathrm{O}$ & 1 & 469 & 605 & 538 \\
\hline $\mathrm{H}_{2}$ & 0 & 6 & 14 & 23 \\
\hline $\mathrm{H}_{2} \mathrm{~S}$ & 0 & 63 & 60 & 36 \\
\hline $\mathrm{SO}_{2}$ & 14 & 783 & 1095 & 1319 \\
\hline $\mathrm{S}_{2}$ & 4 & 503 & 1004 & 1521 \\
\hline $\mathrm{CO}$ & 50 & 160 & 250 & 345 \\
\hline $\mathrm{CO}_{2}$ & 692 & 739 & 599 & 448 \\
\hline \multicolumn{5}{|c|}{ FMQ-O.5, 0.2 wt\% water, 0.08 wt\% carbon dioxide } \\
\hline $\mathrm{H}_{2} \mathrm{O}$ & 6 & 1164 & 1271 & 1112 \\
\hline $\mathrm{H}_{2}$ & 0 & 15 & 30 & 46 \\
\hline $\mathrm{H}_{2} \mathrm{~S}$ & 1 & 140 & 108 & 60 \\
\hline $\mathrm{SO}_{2}$ & 276 & 975 & 1387 & 1766 \\
\hline $\mathrm{S}_{2}$ & 31 & 599 & 1095 & 1542 \\
\hline $\mathrm{CO}$ & 22 & 168 & 251 & 338 \\
\hline $\mathrm{CO}_{2}$ & 749 & 725 & 595 & 459 \\
\hline \multicolumn{5}{|c|}{ FMQ-O.5, 0.4 wt $\%$ water, $0.08 w t \%$ carbon dioxide } \\
\hline $\mathrm{H}_{2} \mathrm{O}$ & 17 & 2669 & 2668 & 2350 \\
\hline $\mathrm{H}_{2}$ & 0 & 36 & 61 & 87 \\
\hline $\mathrm{H}_{2} \mathrm{~S}$ & 3 & 264 & 171 & 85 \\
\hline $\mathrm{SO}_{2}$ & 15 & 1357 & 1981 & 2667 \\
\hline $\mathrm{S}_{2}$ & 4 & 704 & 1137 & 1404 \\
\hline $\mathrm{CO}$ & 50 & 170 & 243 & 318 \\
\hline $\mathrm{CO}_{2}$ & 692 & 713 & 598 & 480 \\
\hline
\end{tabular}




\section{Figure Captions:}

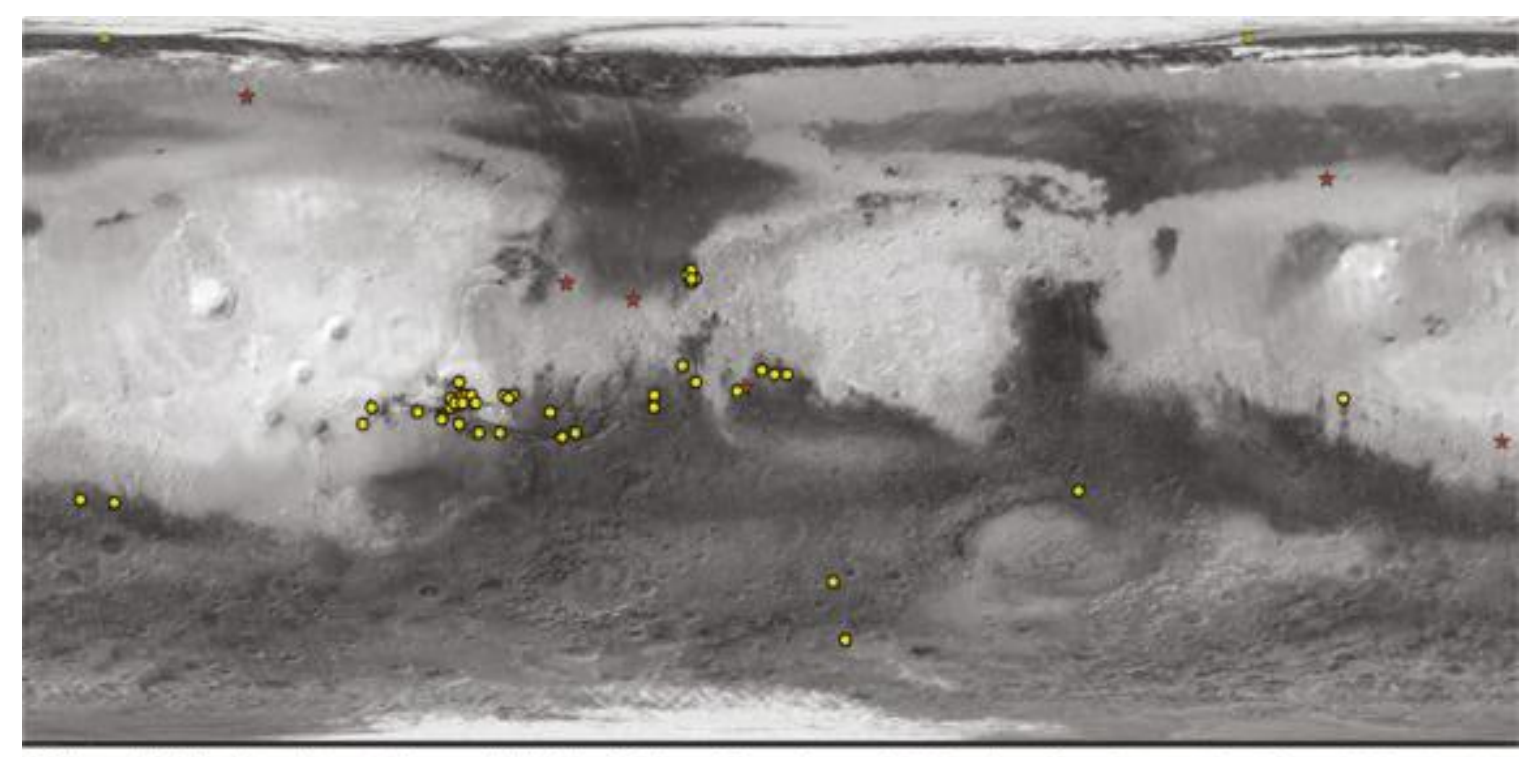

O layered $\mathrm{N}$-H sulfates detected from orbit by IR

- Polar sulfates detected by IR

sulfates detected or inferred at landing sites

Figure 1. A survey of sulfate detections to date is shown over a global map of surface albedo measured by TES. The detections are grouped into 3 categories shown symbolically, corresponding to layered Hesperian-Noachian sulfates (Yellow circles), polar sulfates (green circles), and sulfates measured or inferred within soils at landing sites (Red crosses). 

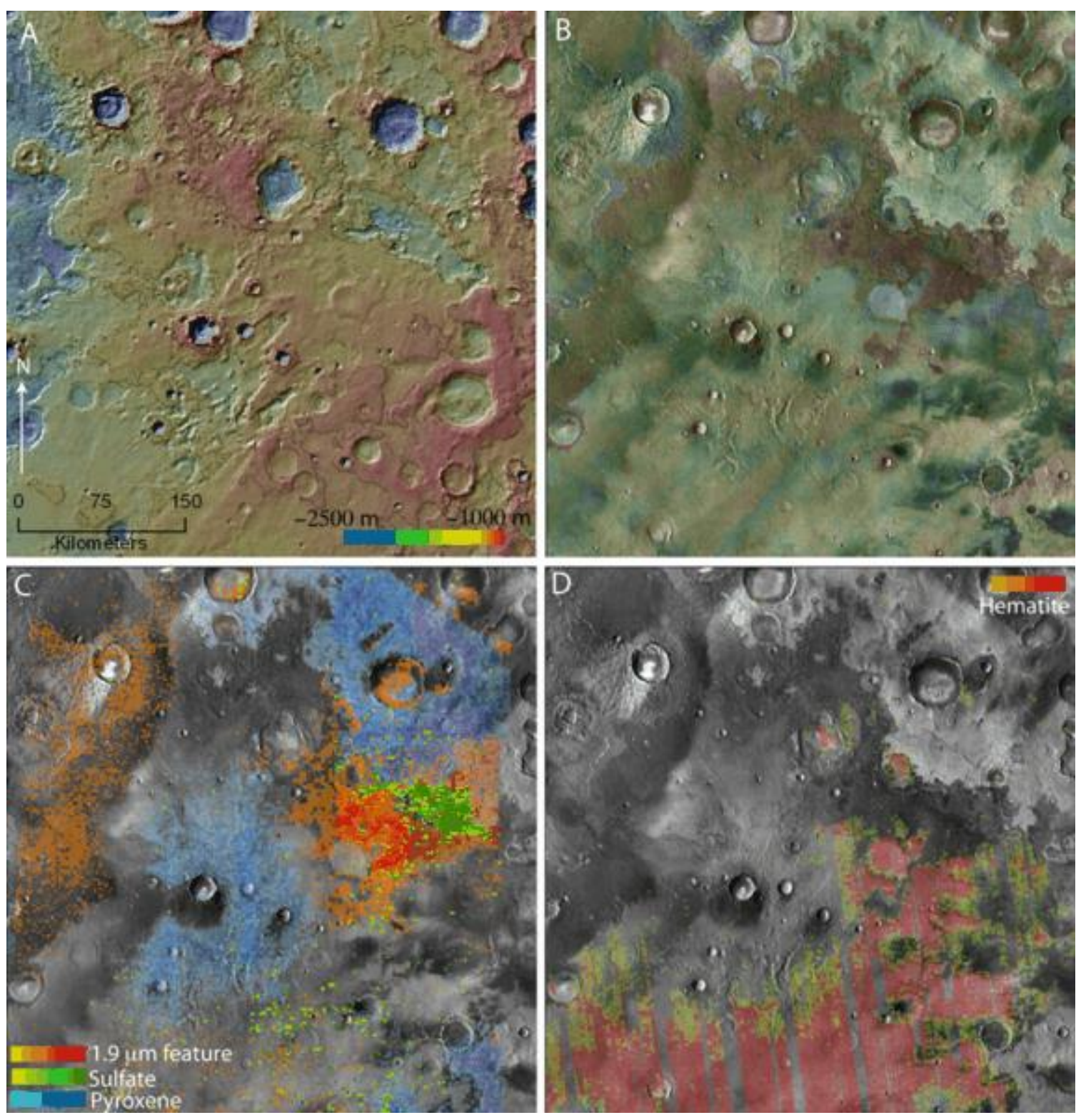

Figure 2. MOLA topographic data are shown in for the Meridiani Planum area in "A." THEMIS nighttime thermal infrared data are draped over daytime infrared data in "B." Warm colors correspond to surfaces containing coarser grained or more well indurated materials. In "C," OMEGA spectral index maps are shown. Orange colors correspond to the 1.9-micron index that maps bound water; blue colors correspond to pyroxene minerals (after Poulet et al., 2009); and the green colors correspond to 2.4-micron index values that correlate with sulfates. In "D," TES hematite index data are shown draped onto THEMIS daytime infrared. The scale is from $10 \%$ to $18 \%$ hematite (after Christensen et al., 2001). 

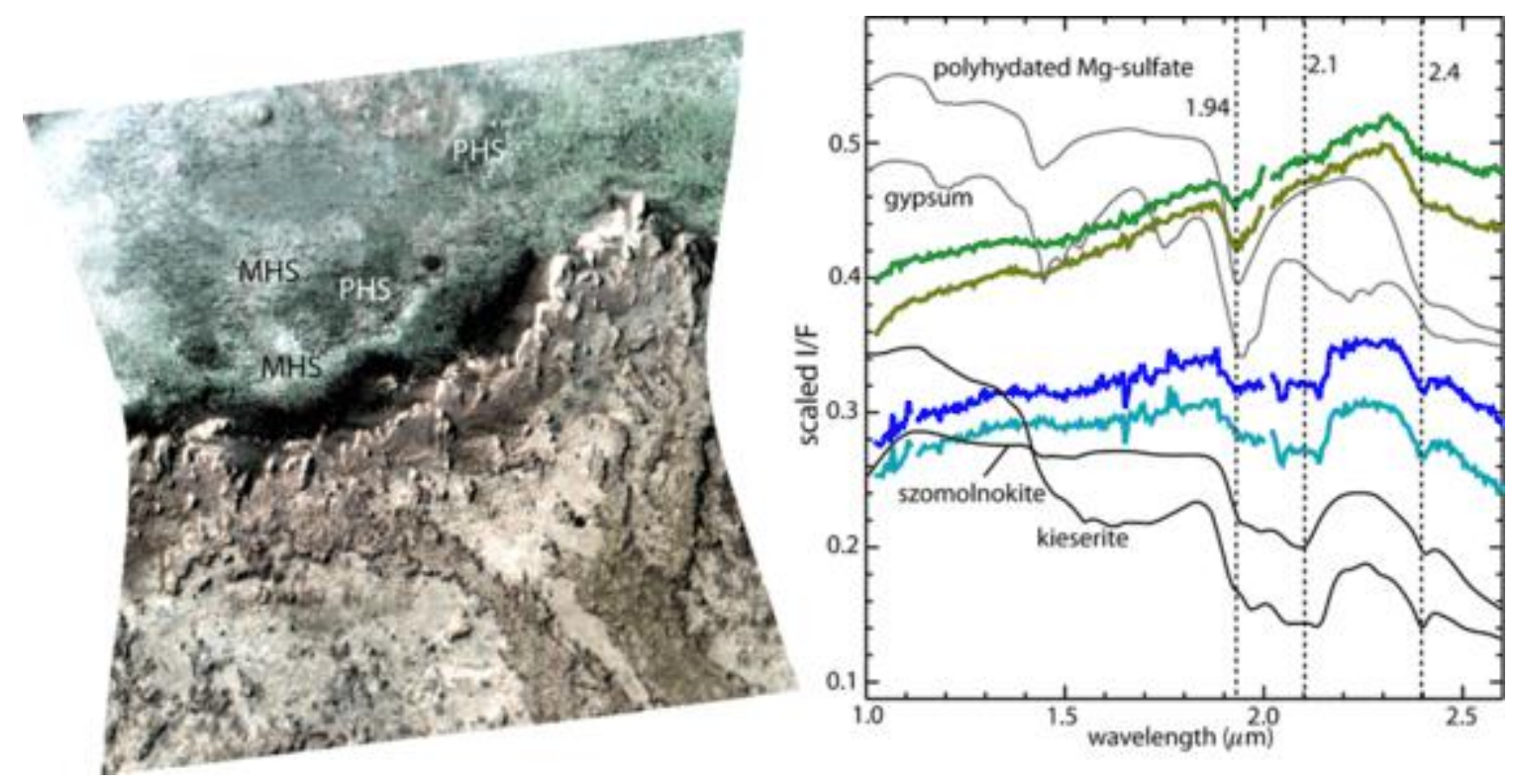

Figure 3. CRISM cube frt00016f45_07_if1651_trr3 shows sulfates in the Meridiani Planum area. The annotations "PHS" and "MHS" indicate the locates where spectra were extracted to show examples of polyhydrated and monohydrated sulfates, respectively. The spectra were ratioed against a spectrally unremarkable terrain. 

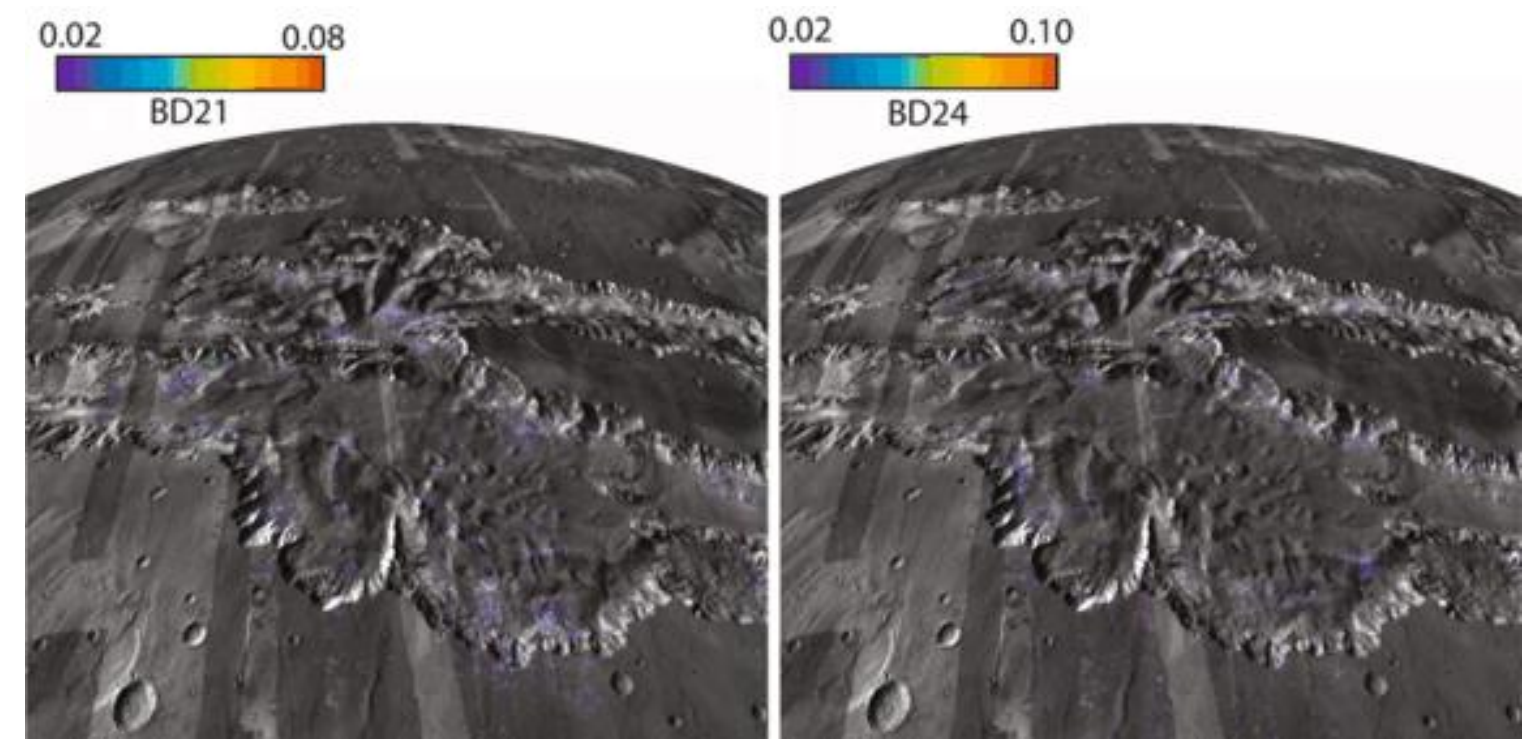

Figure 4. OMEGA spectral index maps of the central Valles Marineris area are shown. The 2.1 micron index (BD21) corresponds to detections of monohydrated sulfates and the BD24 map corresponds to polyhydrated sulfates.
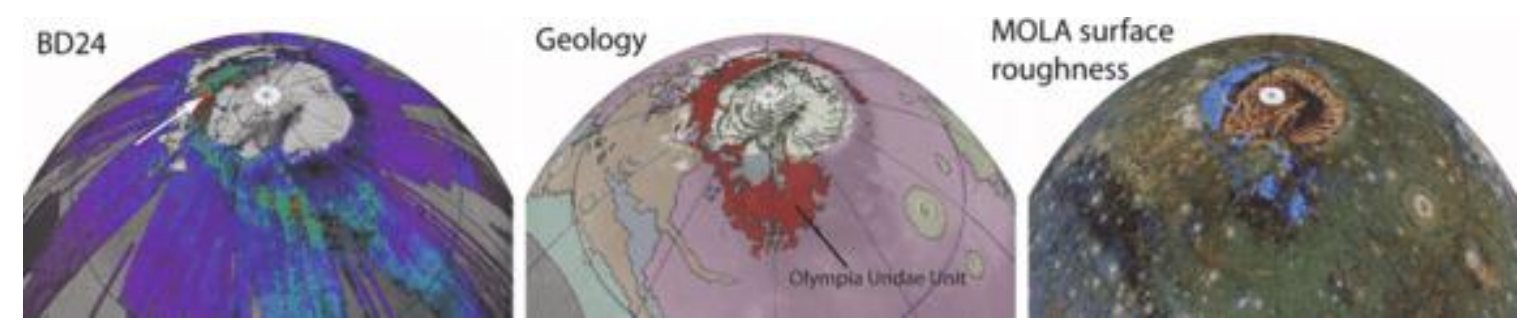

Figure 5. An OMEGA 2.4 micron spectral index map shows the location of sulfates in the northern polar region of Mars. The locations of the sulfates correspond roughly to locates mapped as the Olymbia Undae unit (Tanaka et al. 2003), and to unique regions in MOLA surface roughness maps. 


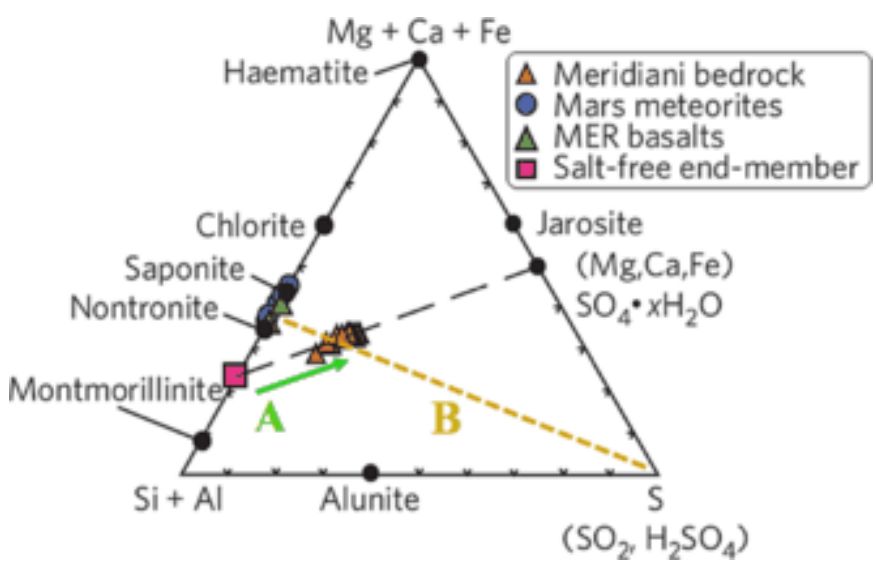

Figure 6. Evaporite model (MER team, A) against by McCollom \& Hynek, 2005 (B) analysis of the Burns formation composition. The evaporite model focuses on the "Meridiani trend" assuming a mixture between an altered basalt (pink square) and a sulfate salt. The McCollom and Hynek model assumes a mixture between a pristine basalt and a pure sulfur component. 


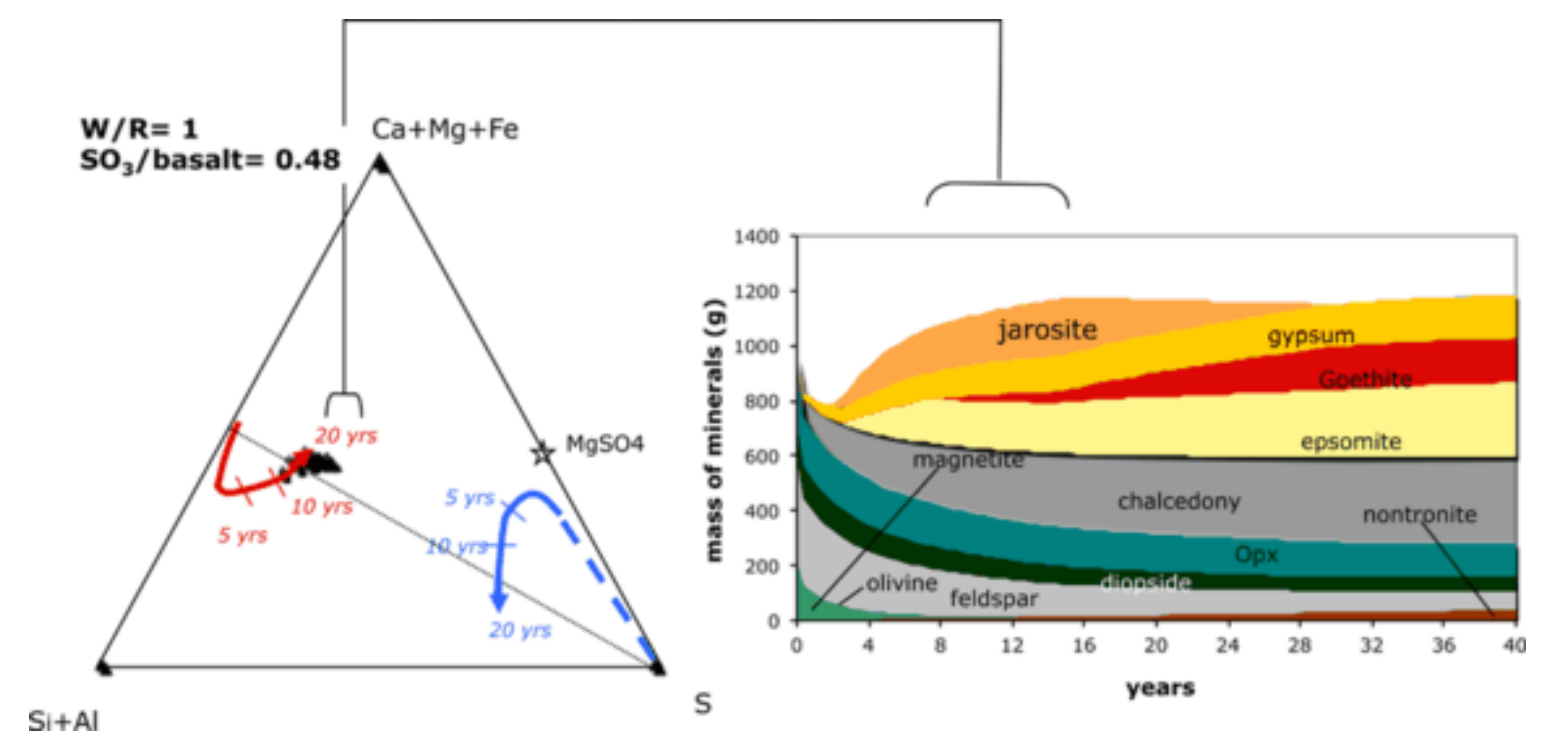

Figure 7. $\mathrm{SO}_{3}$-basalt-water kinetic model (Berger et al. 2009) accounting for the "Meridiani trend".

Small amount, ephemeral, but strongly acid brine reproduces the chemical and mineralogical features of the Burn Cliff Formation. The variation of mineral composition with time is reported in the right graph. The chemical composition of the solid fraction (red) and brine (blue) is also showed with time in the left ternary diagram, and compared to the Meridiani compositions (black triangles). The best fit is obtained when assuming a concentrated sulfuric acid reacting with the rock for a short time, without in-situ evaporation of the resulting brine. 


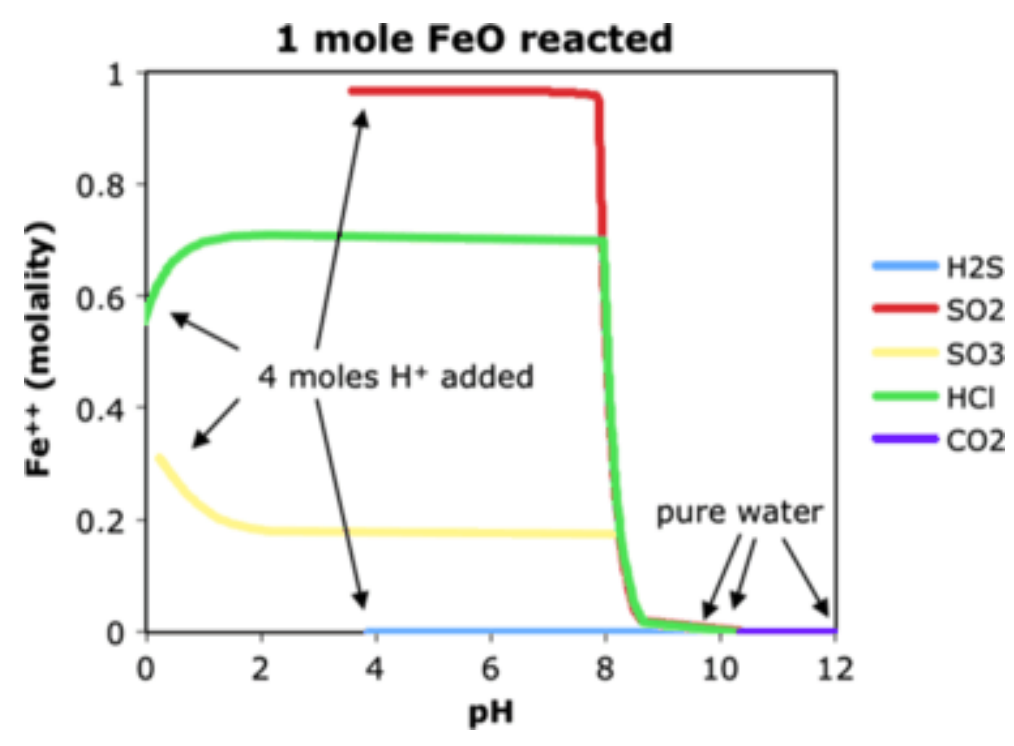

Figure 8. Aqueous concentration of free $\mathrm{Fe}^{++}$species during dissolution of 1 mole of $\mathrm{FeO}$ (the ferrous component in mineral) by fluids of various acidity. The $\mathrm{pH}$ of the resulting solution depends on the concentration and also the nature of the acidic reactant. The conjugate anions strongly influence the amount of the aqueous ferric specie following a general equation: $\mathrm{FeO}+\mathrm{H}_{2} \mathrm{O}+\mathrm{HX} \Leftrightarrow \mathrm{aFe}^{++}{ }_{\text {aq }}+$ $\mathrm{bFeX}_{\mathrm{aq}}^{-}+\mathrm{cFeX}_{2 \mathrm{aq}}+\mathrm{dFeX}_{2 \text { solid }}$ 


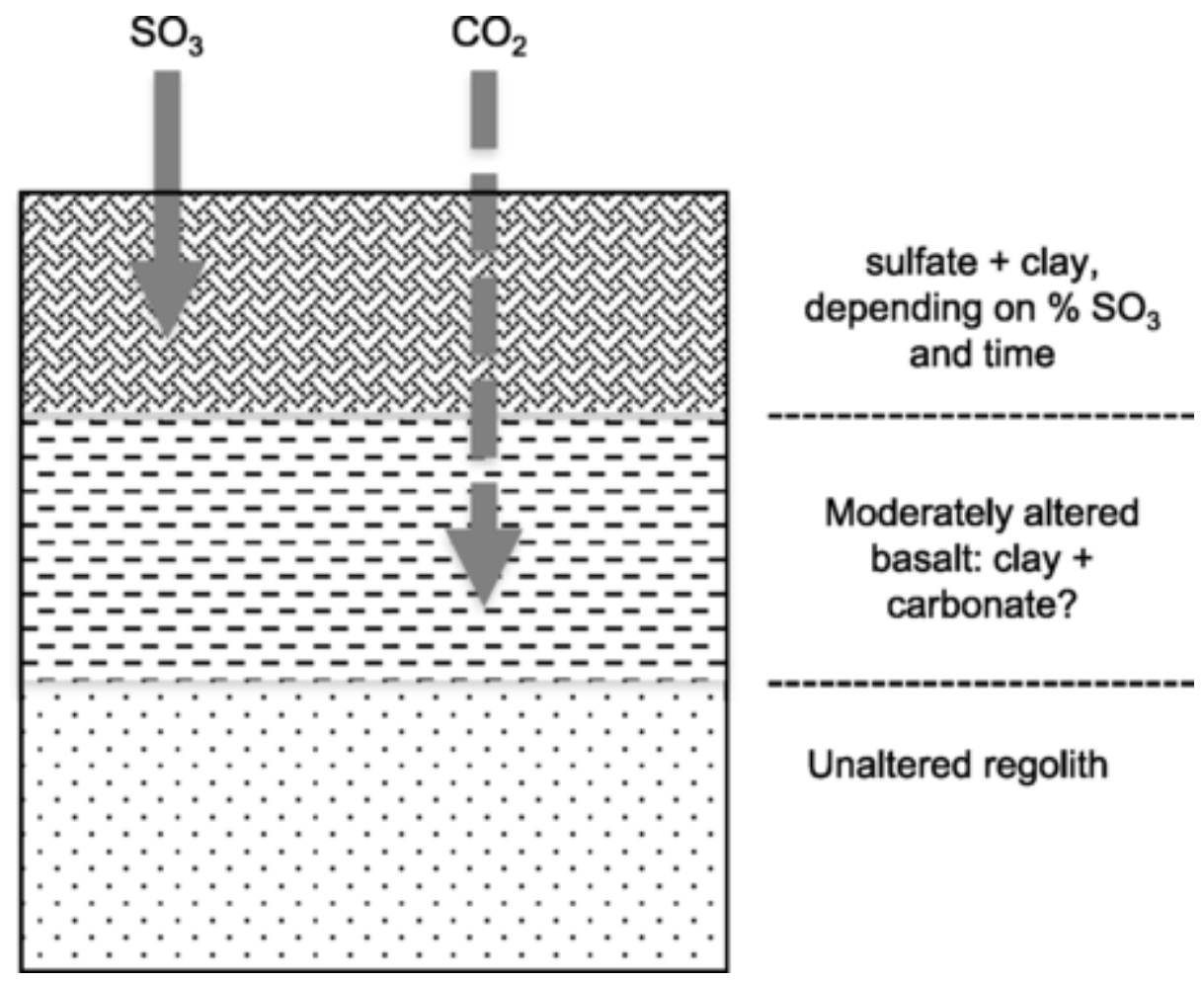

Figure 9. A possible differential consumption of $\mathrm{SO}_{3}$ and $\mathrm{CO}_{2}$ with depth. $\mathrm{SO}_{3}$ first reacts with the surface of the basaltic regolith, excluding the $\mathrm{CO}_{2}$ mineralization. $\mathrm{CO}_{2}$ reacts deeper, below the zone altered by $\mathrm{SO}_{3}$. 

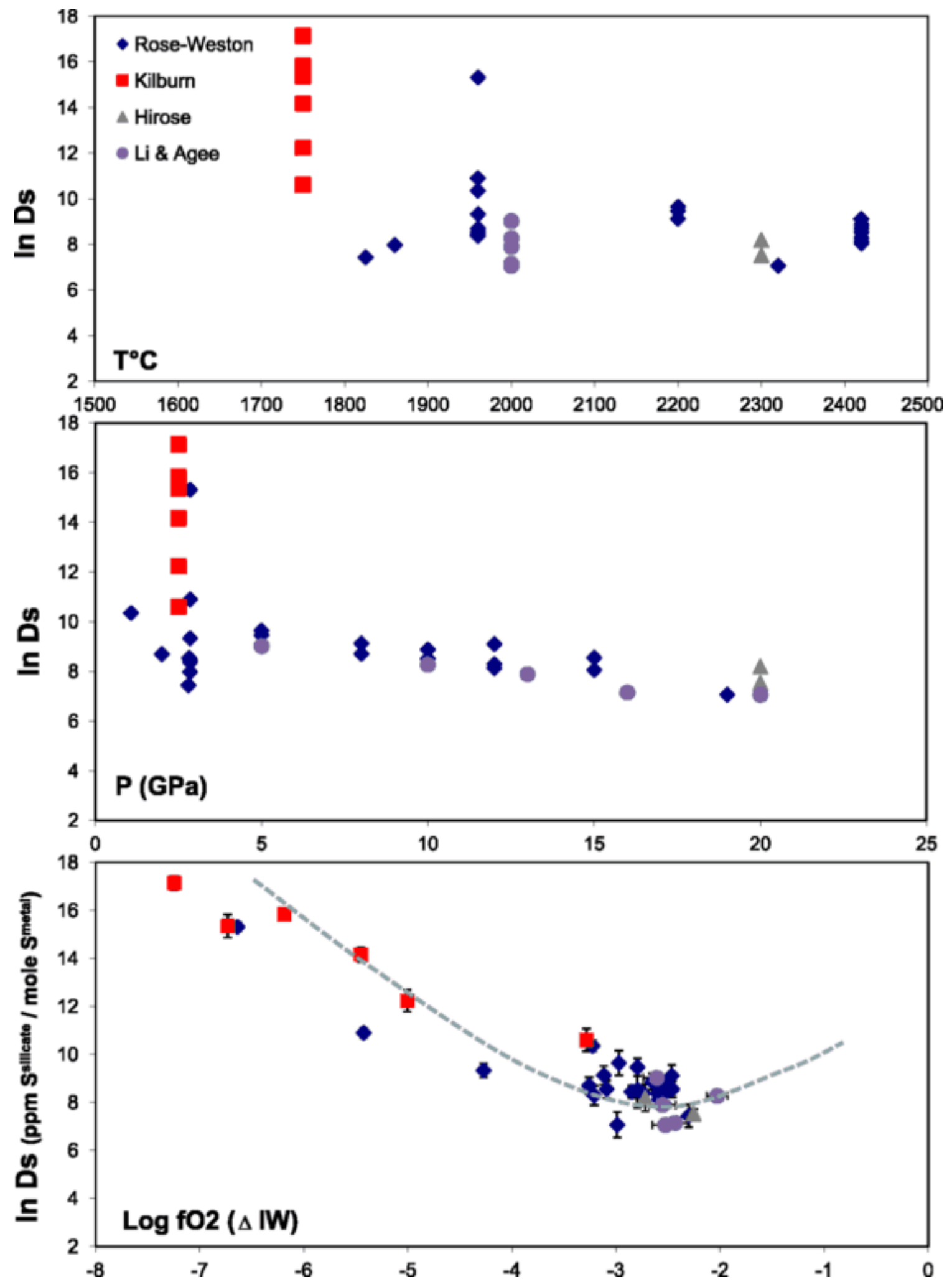

Figure 10. Sulfur partitioning between molten silicate and molten Fe-metal (D silicate / metal). The fraction of sulfur in the silicate melt is in ppm-wt $\mathrm{S}$ and the fraction of sulfur in the metal is in molar fraction (see eq. 4). Top panel shows sulfur partitioning as a function of temperature and indicates that sulfur becomes slightly more siderophile as temperature increases. Middle panel shows sulfur 
partitioning as a function of pressure and indicates that sulfur become slightly more siderophile as pressure increases. Bottom panel shows sulfur partitioning as a function of oxygen fugacity _expressed in log-units relative to oxygen fugacity buffered by the iron-wustite, IW, assemblage_and indicates that sulfur becomes increasingly lithophile as conditions are increasingly reducing. The combination of the three panels clearly indicates that oxygen fugacity $\left(\mathrm{fO}_{2}\right)$ is the prime parameter controlling sulfur partitioning between molten metal and molten silicate. Changes in $\mathrm{fO}_{2}$ explains the large scatter that partitioning data otherwise shows when plotted as a function of pressure or temperature. In the bottom panel, the dashed line indicates sulfur partitioning calculated using equation (4). In agreement with existing experimental data, it predicts that $S$ is increasingly siderophile as fO2 increases but it also predicts an inversion of the trend as fO2 is higher than IW -2 . Above this $\mathrm{fO}_{2}$ value, increasing $\mathrm{FeO}$ content in the silicate (with increasing $\mathrm{fO}_{2}$ at metal saturation) implies that sulfur becomes increasingly lithophile with increasing $\mathrm{fO}_{2}$. There is however, no experimental data existing in this range of redox conditions, which however corresponds to that expected for Mars core-mantle equilibration. Experimental data from Ohtani et al. (1997), Kilburn et al. (1997) and Rose-Weston et al. (2009); Calculation after Gaillard and Scaillet (2009). 


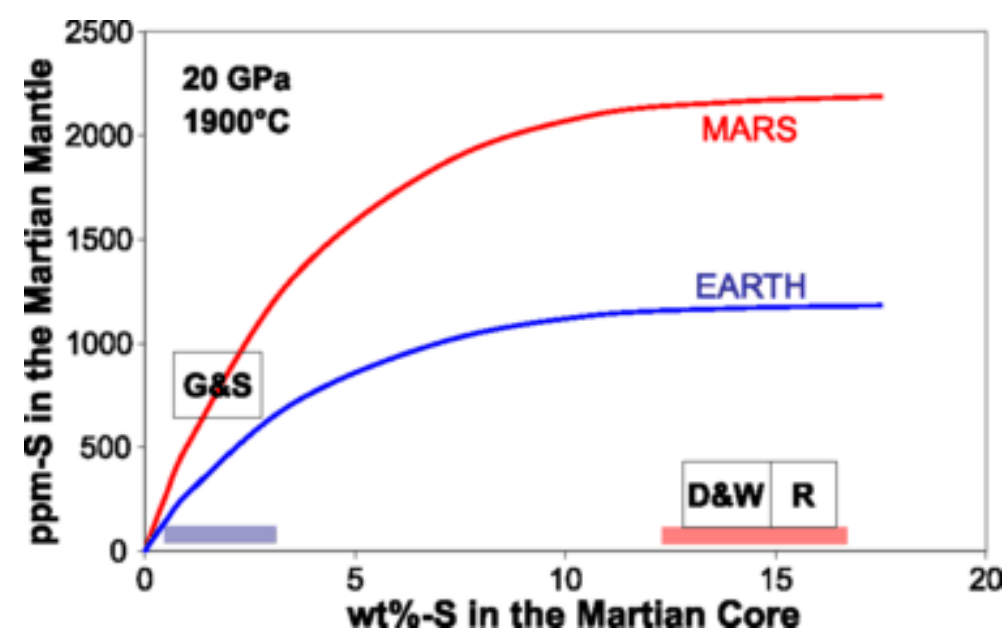

Figure 11. Likely ranges of sulfur content in the core and mantle of Mars. The red and blue curves show sulfur content calculated from the metal - silicate partitioning (eq.4) at $1900^{\circ} \mathrm{C}, 20 \mathrm{GPa}$ and considering variable bulk sulfur content in the core-mantle system. The red curve shows calculation for a Martian core-mantle case (mantle $\mathrm{FeO}=18 \mathrm{wt} \%$ ) and the blue curve illustrate an Earth-like core-mantle case $(\mathrm{FeO}=8 \mathrm{wt} \%)$. The boxes indicate $\mathrm{S}$-content suggested by previous studies: G\&S refers to the estimation of Gaillard and Scaillet (2009) on S content in the mantle and core of Mars; a sulfur content in the Martian core in the range of 14-18 wt\% has been suggested by cosmochemical constraints (D\&W, Dreibus and Wanke, 1985; Wanke and Dreibus, 1994: averaging 14.2\%) or inferred from recent inversions of geodetic data ( $\mathrm{R}$, Rivoldini et al., 2011; estimated at 16 $\pm 2 \%$ ). Variations by a factor of 8 on estimations of sulfur content in the core between G\&S and R only translate into a factor of 3 in mantle $S$ content because of the strongly non-ideal activity-composition of sulfur in molten Fe-metal. 


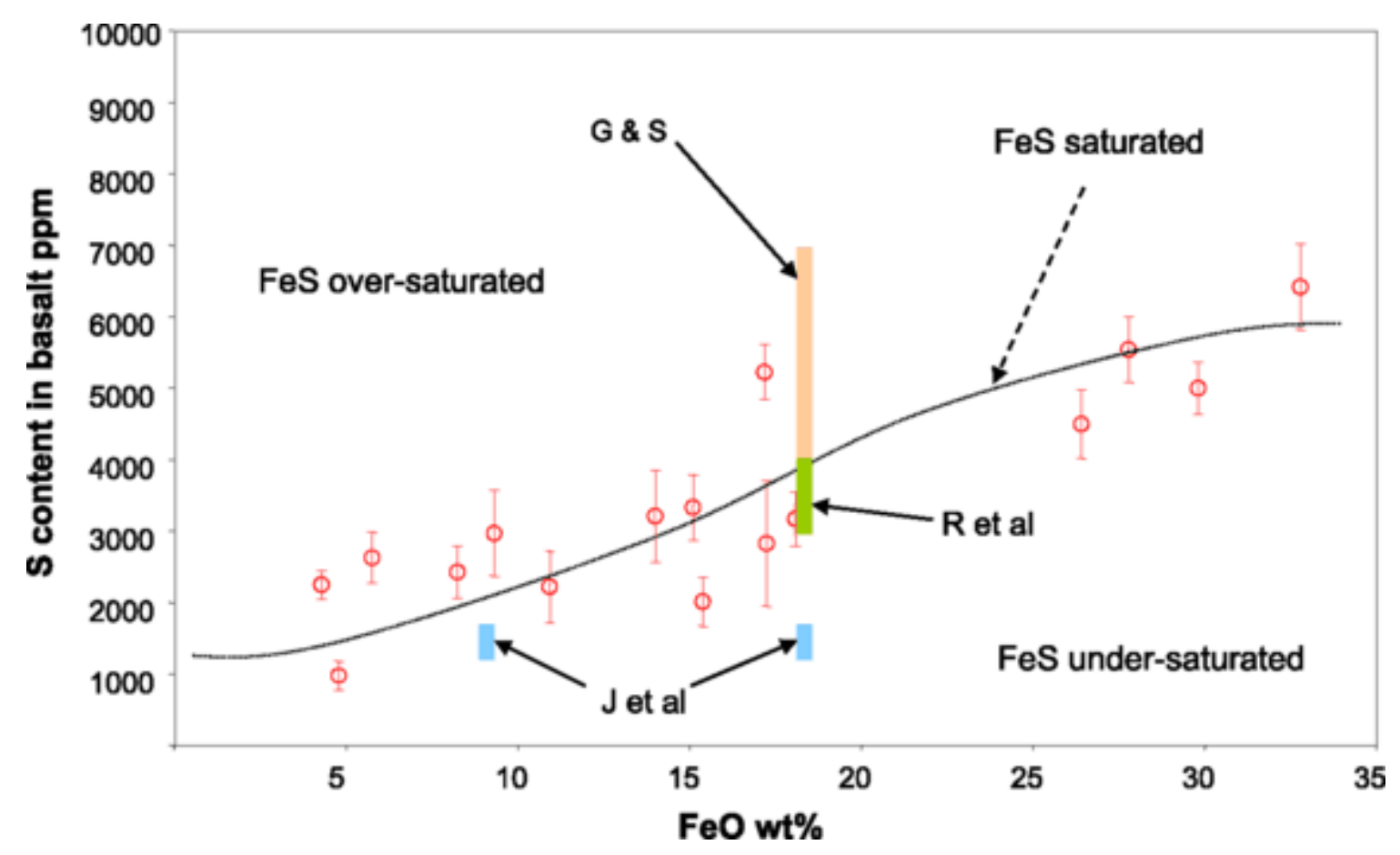

Figure 12. Sulfur content in basalts saturated in $\mathrm{FeS}$ as a function of $\mathrm{FeO}$ content in basalts. The red dots are experimental data taken from Righter et al. (2009) _ $0.1 \mathrm{MPa}$ to $800 \mathrm{MPa}, 1200-1600^{\circ} \mathrm{C}$. The dashed line is a line drawn for visual guidance. Coloured boxes represent estimations of sulfur content in Martian basalts by Gaillard and Scaillet (G\&S), Righter et al. (R), and Johnson et al. (J et al). The likely range of Martian sulfur content defined by the saturation in FeS upon mantle melting is 3500 ppm (this study). 

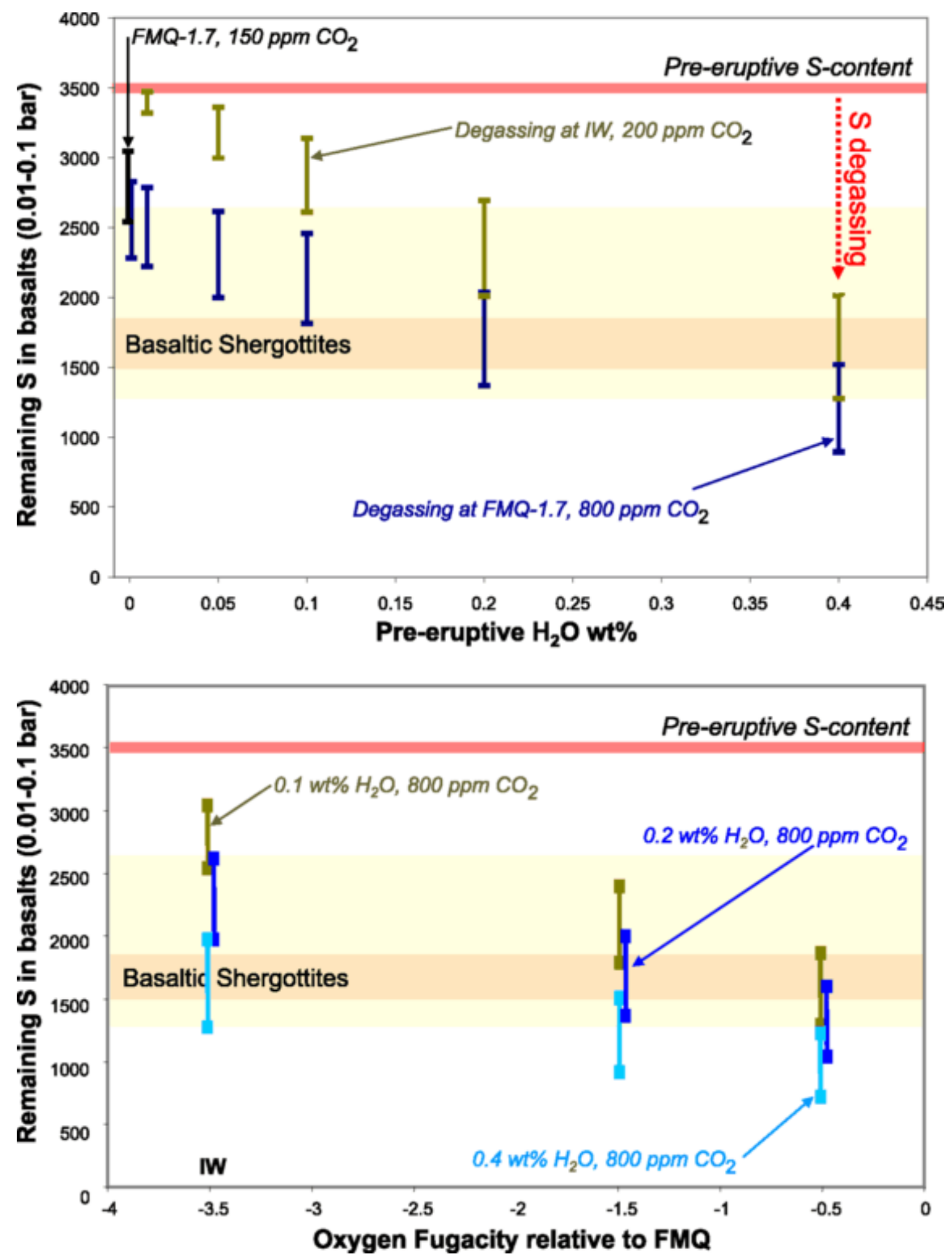

Figure 13. The efficiency of sulfur degassing from basalts as a function pre-eruptive water content and oxygen fugacity. Pre-eruptive sulfur content in basalts is shown by the horizontal pink line at $3500 \mathrm{ppm}$ S. Undegassed sulfur contents in basalts are represented by horizontal bars whose top and bottom values respectively correspond to 0.1 and 0.01 bar of degassing conditions. Values are taken from Table 2. Top panel shows undegassed sulfur in basalts as a function of pre-eruptive water 
contents for two pre-eruptive oxygen fugacities (IW; FMQ-1.7). Bottom panel shows undegassed sulfur content in basalts as a function of pre-eruptive oxygen fugacity for three pre-eruptive water contents $(0.1 ; 0.2 ; 0.3 \mathrm{wt} \% \mathrm{H} 2 \mathrm{O})$. Pre-eruptive $\mathrm{CO}_{2}$ content in basalts varies with oxygen fugacity in agreement with experimental constraints on $\mathrm{CO}_{2}$ content in basalts at graphite saturation (Stanley et al., 2011). Horizontal boxes show the range of sulfur contents reported in SNC meteorites (see Meyer (2008) _ 1300-2600 ppm_and the sulfur content in basaltic shergottites as evaluated in Righter et al. (2009)_1600 ppm_. These sulfur concentration ranges must be considered with cautions as many of the SNC rocks are cumulates and their sulfur content is poorly representative of that of the parental basaltic melts (Lorand et al., 2005). Nevertheless, degassed basalts with sulfur content at 1600 ppm are obtained if degassing from melts with pre-eruptive water content of $0.4 \mathrm{wt} \%$ and pre-eruptive $\mathrm{fO}_{2}$ at IW and/or if degassing from melts with pre-eruptive water content of $0.2 \mathrm{wt} \%$ and pre-eruptive $\mathrm{fO}_{2}$ at FMQ-1.7. Because FMQ-1.7 represents the upper most $\mathrm{fO}_{2}$ ranges for shergottites, it implies a minimum water content of $0.2 \mathrm{wt} \%$ for their parental melts if we admit that $1600 \mathrm{ppm} \mathrm{S}$ is a reasonable estimates for degassed mafic basalts on Mars's surface. 


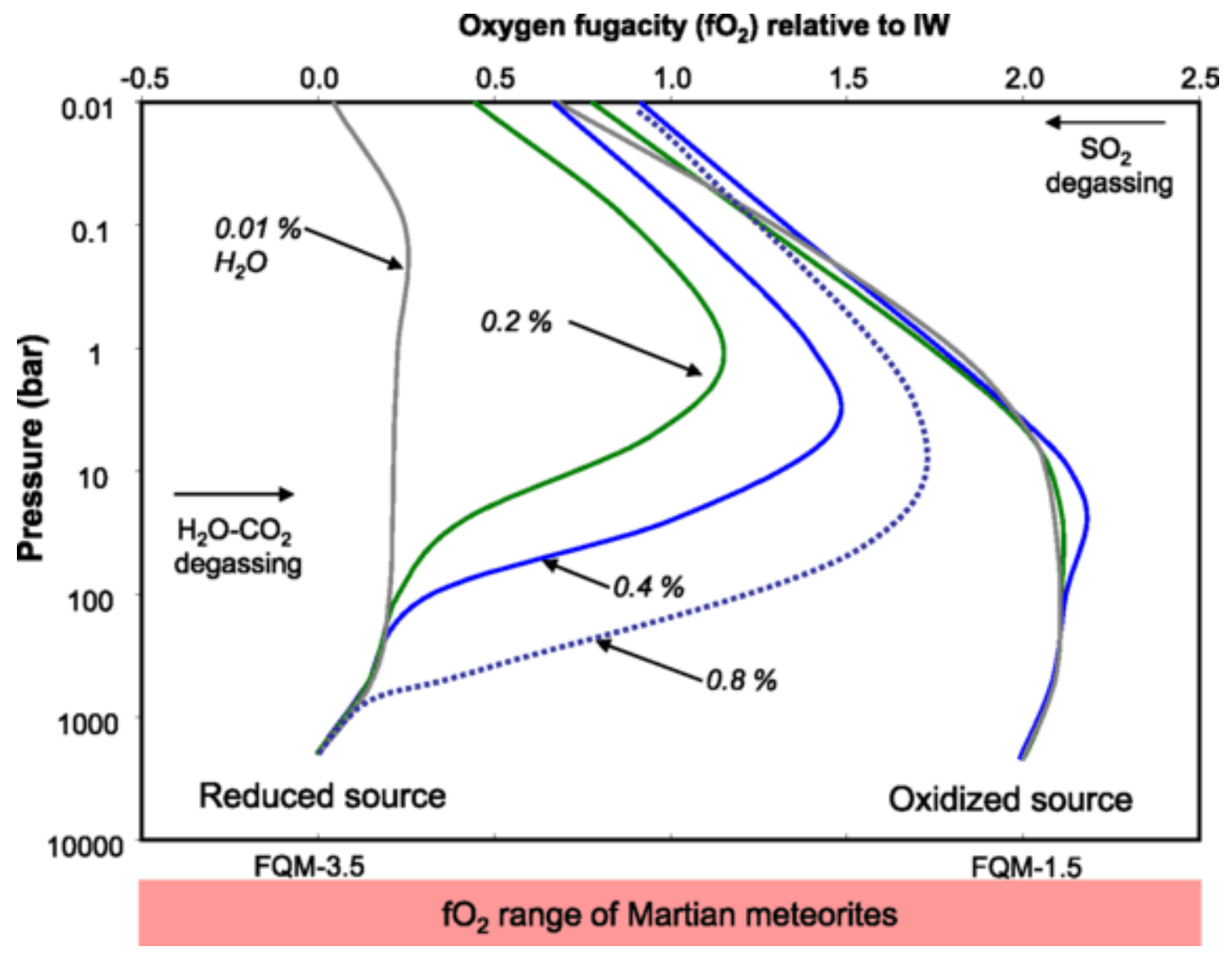

Figure 14. Changes in oxygen fugacity during degassing of Martian basalts. As degassing occurs in response to decompression, the oxygen fugacity changes are shown as a function of pressure. Two conditions of pre-eruptive oxygen fugacity are considered: IW, the lower range, and FMQ-1.7, the upper range of $\mathrm{fO}_{2}$ (for Shergottites). From these two initial $\mathrm{fO}_{2}$ conditions, we also computed several possible pre-eruptive water contents $(0.01$ to $0.8 \mathrm{wt} \%)$. Pre-eruptive $\mathrm{CO}_{2}$ contents are taken following Stanley et al. (2011). Degassing from oxidized sources produces almost no effect on $\mathrm{fO}_{2}$ as melts rise through the crust, but near venting conditions, ie. 2-5 bars, $\mathrm{fO}_{2}$ strongly decreases as sulfur degases as $\mathrm{SO}_{2}$. Degassing from reduced sources produces a strong $\mathrm{fO}_{2}$ increase at crustal depth, which correlates with the pre-eruptive water contents. At venting conditions, SO2 degassing decreases fO2. See Burgisser and Scaillet (2007), Gaillard and Scaillet (2009) and Gaillard et al. (2011) for methods. 


\section{Mole fraction in the gas}

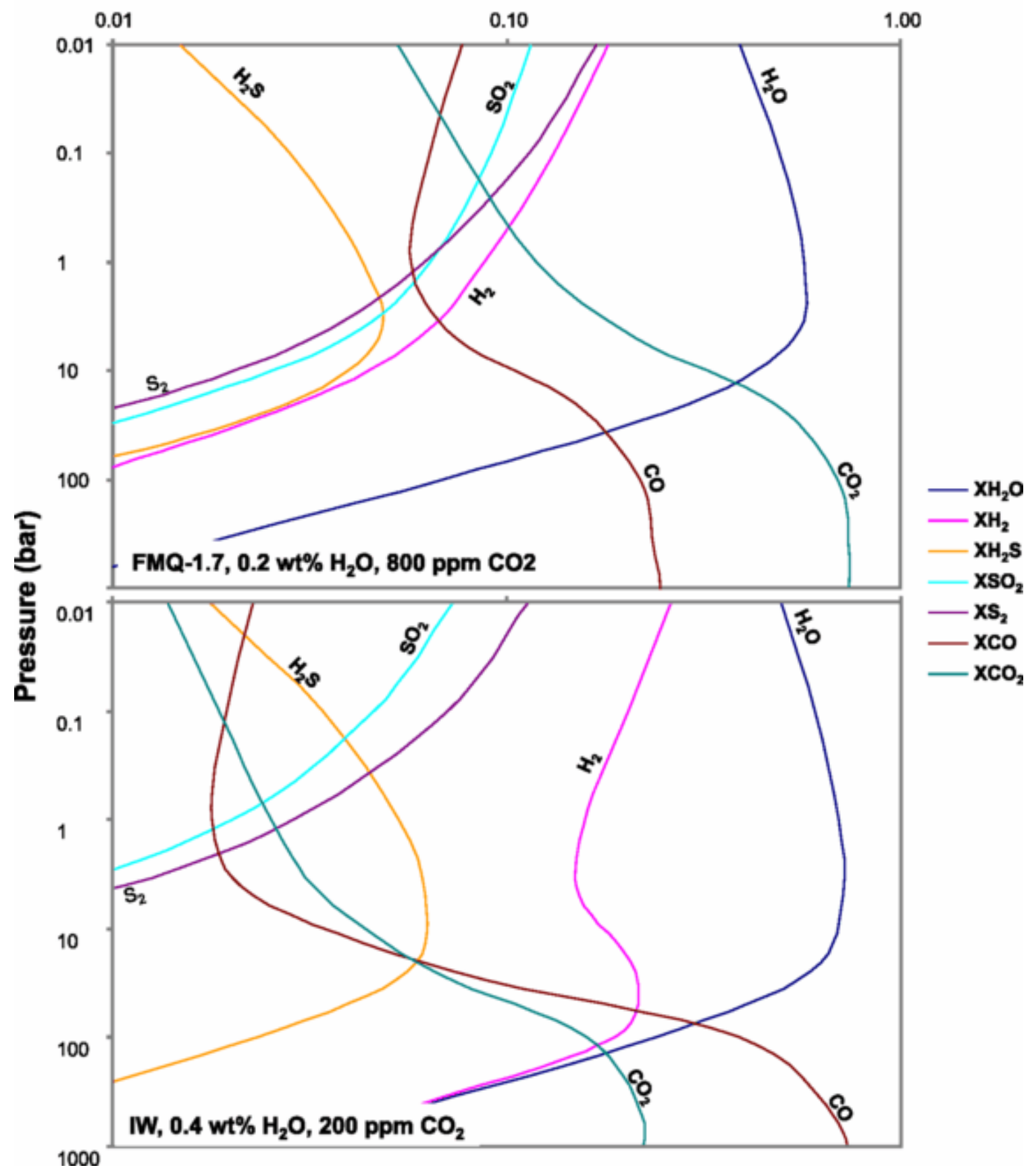

Figure 15. The composition of Martian volcanic gases as a function of pressure. Two simulations of basalt degassing in the COHS system are shown, representing two pre-eruptive conditions (Top panel: FMQ-1.7, 0.2 wt $\% \mathrm{H}_{2} \mathrm{O}, 800$ ppm $\mathrm{CO}_{2}$; Bottom panel: IW, 0.4 wt $\% \mathrm{H}_{2} \mathrm{O}, 200$ ppm $\mathrm{CO}_{2}$ ). These choices are based on observations in figure 4 that such pre-eruptive conditions conduct to degassed basalts with 1600 ppm S. Globally, C-species $\left(\mathrm{CO}_{2}\right.$ and $\left.\mathrm{CO}\right)$ dominate at pressure higher than a few tens bar. At lower pressure, water-species $\left(\mathrm{H}_{2} \mathrm{O}\right.$ and $\left.\mathrm{H}_{2}\right)$ dominate. Both simulations show that total sulfur species $\left(\mathrm{SO}_{2}+\mathrm{S}_{2}+\mathrm{H}_{2} \mathrm{~S}\right)$ concentration in the gas increases as pressure decreases. In detail, 
however, there is a fundamental change in sulfur speciation at pressure of $0.2-3$ bar depending on pre-eruptive conditions. At higher pressure, nearly all sulfur is present as $\mathrm{H}_{2} \mathrm{~S}$ and at lower pressure, all sulfur is in $\mathrm{SO}_{2}$ and $\mathrm{S}_{2}$ forms. This shift in $\mathrm{S}$-speciation is well-known from thermodynamic studies on basalt degassing (see Gaillard et al., 2011 and references therein).

\begin{tabular}{|c|c|c|c|}
\hline & Noachian & Hesperian & Amazonian \\
\hline \multicolumn{4}{|l|}{$\begin{array}{l}\text { Dynamo } \\
\text { Impact ejection } \\
\text { of atmosphere }\end{array}$} \\
\hline \multicolumn{4}{|l|}{$\begin{array}{l}\text { Atmospheric } \\
\text { pressure }\end{array}$} \\
\hline \multicolumn{4}{|l|}{$\begin{array}{l}\text { Extrusive } \\
\text { volcanism }\end{array}$} \\
\hline \multicolumn{4}{|l|}{ Volcanic C/S } \\
\hline \multicolumn{4}{|l|}{$\begin{array}{l}\text { Volcanic } \\
\mathrm{SO}_{2} / \mathrm{H}_{2} \mathrm{~S}\end{array}$} \\
\hline \multicolumn{4}{|l|}{$\begin{array}{l}\text { pH of surface } \\
\text { waters }\end{array}$} \\
\hline $\begin{array}{l}\text { Alteration } \\
\text { mineralogy }\end{array}$ & sillicates & /Evaporites & \\
\hline
\end{tabular}

Figure 16. Schematic flowchart summarizing the timing of volcanic degassing in a general Martian time-framework. Interruption of the core dynamo and impact ejection of the atmosphere are the causes of a pressure decrease of the initial (primordial) atmosphere. Extrusive volcanism is not believed to have significantly decreased from the early Noachian to the late Hesperian. But in response to a decrease of degassing pressure (atmospheric pressure from ca 1 to ca 0.05 bar), the $\mathrm{C} / \mathrm{S}$ ratio of volcanic gases severely decreased and their $\mathrm{SO}_{2}$ fraction became dominant over $\mathrm{H}_{2} \mathrm{~S}$. By the processes described in part 6 and 7, this led to extensive acidification of surface waters, and may have 
influenced climate in a complex way. The phyllosilicate - sulfate shift may constitute the sedimentary record of such a change in gas compositions.

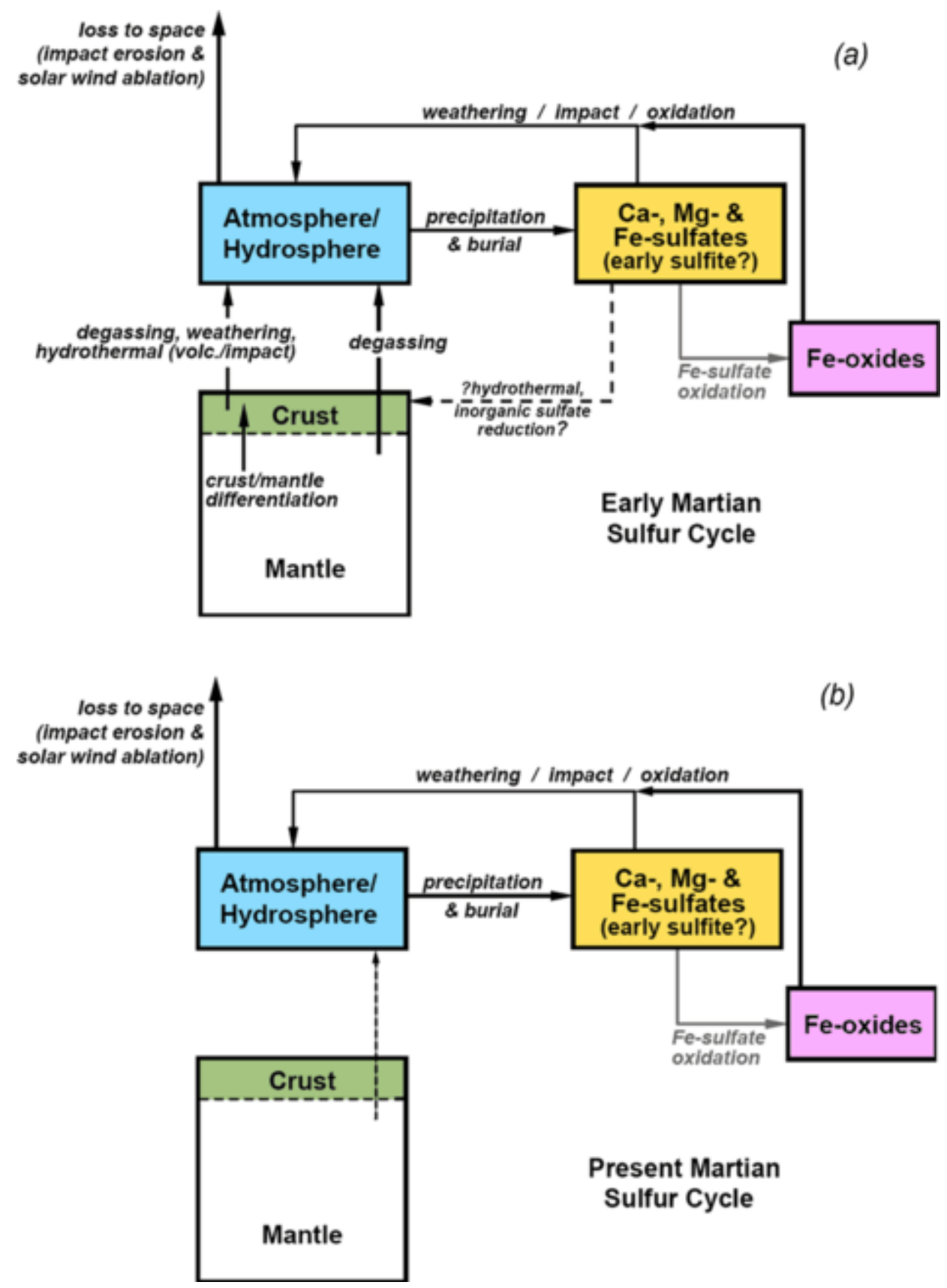

Figure 17. Simplified model for a possible Martian sulfur cycle. (a) Early Mars when abundant sulfur was delivered to the surface through magmatic and related processes. (b) Recent Mars after reduction of rated in magmatism and sulfur degassing. During this, sulfur species taking part in surficial processes were likely dominated by sulfur recycling processes with only minor contributions related 
to magmatic degassing. The possible link between the sulfur and iron cycles at the Martian surface through oxidation of iron sulfates to iron oxides is shown by the grey arrow. After McLennan (2012). 